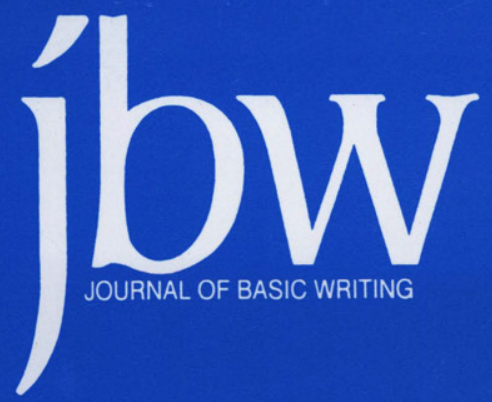

\title{
FALL 1997
}

VOLUME 16 NUMBER 2

When Working Class Students "Do" the Academy: How We Negotiate With Alternative Literacies

Martha Marinara

Some Effects of Culture-Referenced Topics on the Writing Performance of African American Students Nathaniel Norment, Jr.

A Story About Grammar and Power Lynn Briggs and Ann Watts Pailliotet

Towards a Consciousness of Language: A Language Pedagogy for Multicultural Classrooms Mary Soliday

Connections Between Reading and Successful Revision Mary Hurley Moran

Karen L. Greenberg Responds to Ira Shor

Terence G. Collins Responds to Ira Shor 


\section{LANGUAGE ACQUISITION A Journal of Developmental Linguistics}

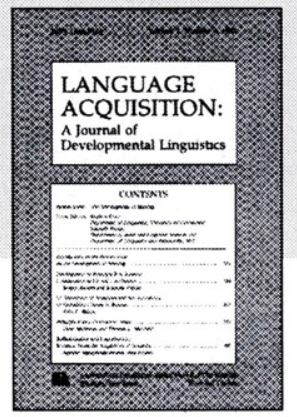

Robert Berwick

Massachusetts Institute of Technology

Thomas Roeper

University of Massachusetts, Amherst

Kenneth Wexler

Massachusetts Institute of Technology

editorial scope:

Contributions to this journal offer explanatory insights into, and advance our knowledge of, how language is acquired. Focusing primarily on experimental, linguistic, and computational approaches, the journal discusses the syntax, semantics, pragmatics, and phonology of language acquisition - merging the data of developmental psycholinguistics with recent discoveries in linguistic theory to yield a more adequate understanding of the growth of language. Coverage includes in-principle solutions to problems of how children select among possible grammars, discussions of relevant acquisition data, integrations of theoretical representations of languages to be acquired, and perspectives derived from second language acquisition, language impaired speakers, and other domains of cognition. Language Acquisition also discusses such topics as the relationship between disorders and acquisition, and studies of theoretical linguistics.

audience:

Researchers and professionals in linguistics, psycholinguistics, and developmentalists.

Volume 7, 1998, Quarterly

Individual: $\quad \$ 39.50$ US/Canada

$\$ 69.50$ All Other Countries

Institution: $\quad \$ 200.00$ US/Canada

$\$ 230.00$ All Other Countries

ISSN: $1048-9223$

abstracted or indexed in:

Linguistic Abstracts; MLA International Bibliography; PsycINFO/Psychological Abstracts; Current Index to Journals in Education/Educational Resources Information Center; Linguistics and Language Behavior Abstracts

Free Sample Issues Available.

Lawrence Erlbaum Associates, Inc.

10 Industrial Avenue, Mahwah, NJ 07430 201/236-9500 FAX 201/236-0072

Call toll-free to order: 1-800-9-BOOKS-9...9am to 5pm EST only.

e-mail to: orders @ erlbaum.com

visit LEA's web site at http://www.erlbaum.com 


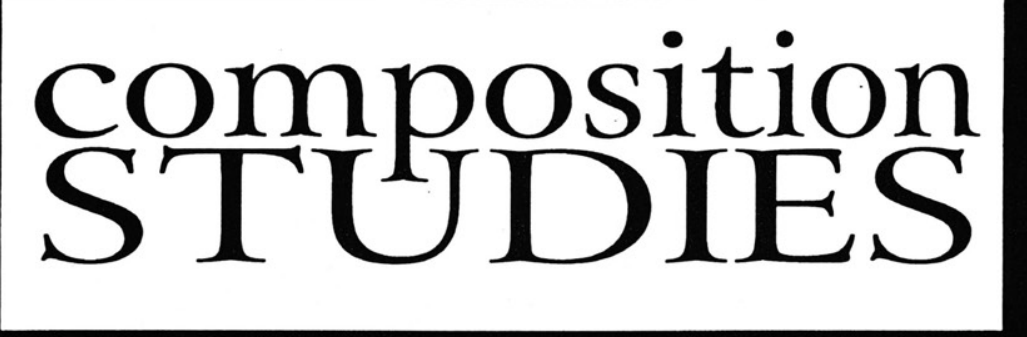

\section{Freshman English News}

\section{Volume 25, Number 1 Now Available}

Featuring essays by

John Clifford and Janet Ellerby, Lauren Sewell, and Teresa M. Redd

\section{Call for Papers}

Composition Studies requests submissions for its new feature on course design. This feature, which will appear regularly in future issues, allows writing/rhetoric teachers at all post-secondary levels a unique opportunity to publish full descriptions of curricular development. Visit our web site for the complete project statement and submission guidelines.

Quality essay submissions on issues of general interest to rhetoric and composition teachers and scholars are also strongly encouraged. Three titled, letter-quality copies conforming to current MLA guidelines for format and documentation, free of authors' names and other identifying references, should be accompanied by a cover letter.

\section{SUBSCRIPTIONS}

Individuals $\$ 12$ - Institutions $\$ 25$ • Graduate Students $\$ 9$

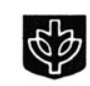

DePaul University

Department of English • 802 W. Belden Avenue • Chicago, IL 60614-3214 


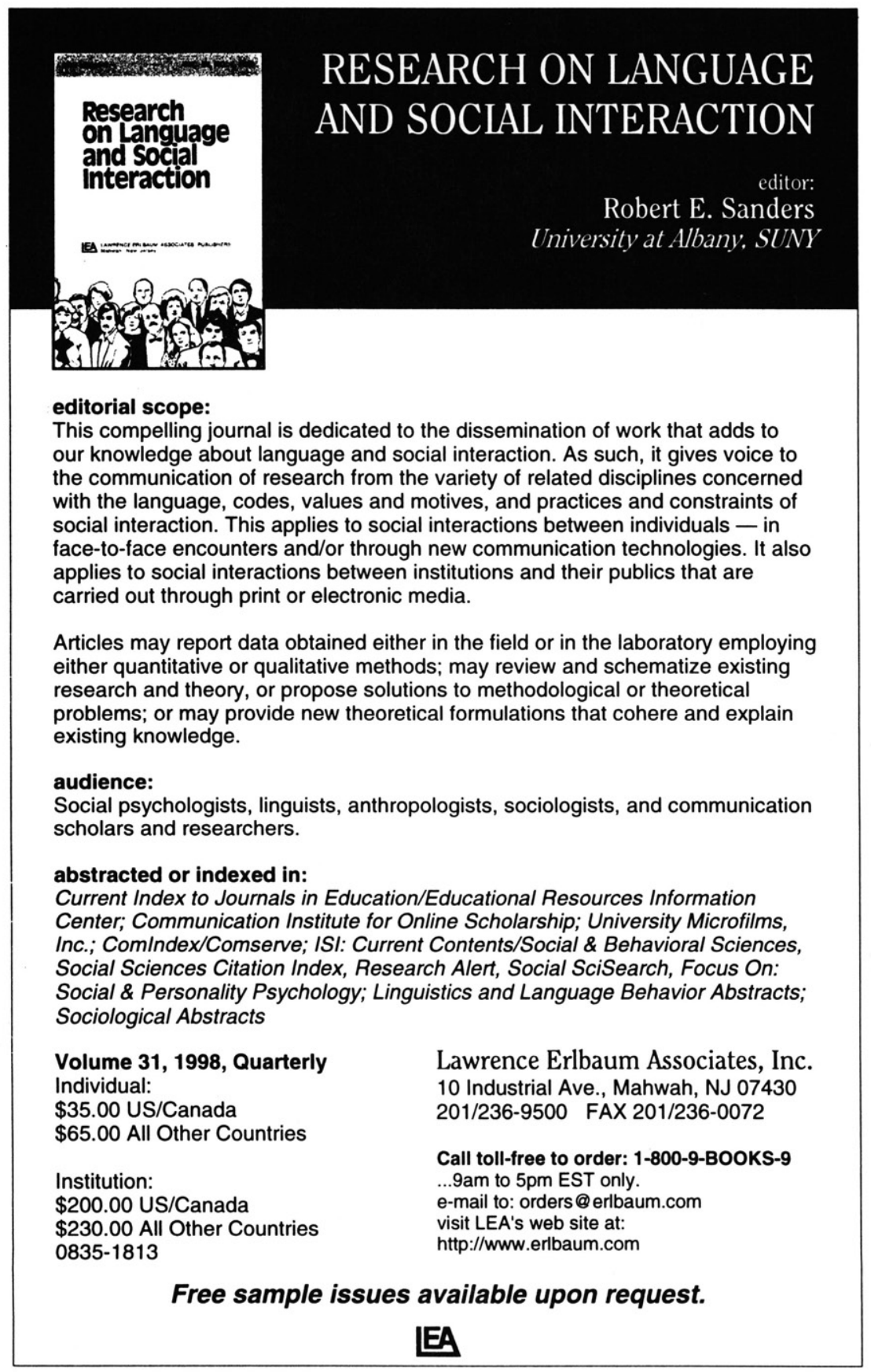




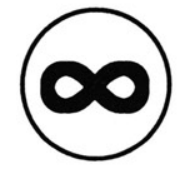

The paper used in this publication meets the minimum requirements of the American National Standard for Information Science Permanence of Paper for Printed Library Materials, ANSI Z39.48-1984.

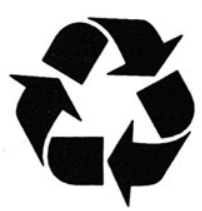

The text stock is also recycled.

\section{This publication is available in microform from UMI.}

Please send me information about the titles I've listed below:

Name

Title

Company/Institution

Address

City/State/Zip

Phone

\section{$\mathrm{U} \cdot \mathrm{M} \cdot \mathrm{I}$}

A Bel I \& Howell Company

300 North Zeeb Road, Ann Arbor, M 48106 USA 800-521-0600 toll-free 313-761-4700 collect from Alaska and Michigan 800-343-5299 toll-free from Canada 



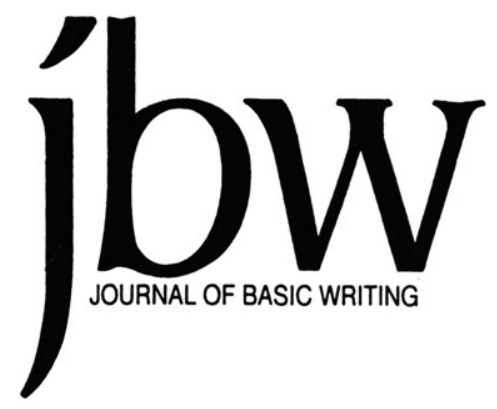

VOLUME 16 NUMBER 2

FALL 1997

The Journal of Basic Writing publishes articles of theory, research, and teaching practices related to basic writing. Articles are refereed by members of the Editorial Board (see overleaf) and the Editors.

\title{
Trudy Smoke and George Otte
}

Editors

\section{Linda Camarasana and Carl Whithaus Editorial Assistants}

\section{Mary E. Carney, Subscriptions}

The Journal of Basic Writing is published twice a year, in the spring and fall. We welcome unsolicited manuscripts and ask authors to consult the detailed "Call for Articles" in this issue. Subscriptions for individuals are $\$ 10.00$ for one year and $\$ 19.00$ for two years; subscriptions for institutions are $\$ 15.00$ for one year and $\$ 29.00$ for two years. Foreign postage is $\$ 5.00$ extra per year. ADDRESS:

\author{
Journal of Basic Writing \\ Instructional Resource Center \\ The City University of New York \\ 535 East 80th Street \\ New York, NY 10021
}




\section{JOURNAL OF BASIC WRITING}

\section{EDITORIAL BOARD}

Peter Dow Adams

Essex Community College, Baltimore

Akua Duku Anokye

University of Toledo

Chris M. Anson

University of Minnesota

David Bartholomae

University of Pittsburgh

Sarah Benesch

College of Staten Island, CUNY

Bill Bernhardt

College of Staten Island, CUNY

\section{Patricia Bizzell}

College of the Holy Cross

Lynn Z. Bloom

University of Connecticut, Storrs

Nancy Carriuolo

University of New Haven

Richard Courage

Westchester Community College,

SUNY

Donald Daiker

Miami University

Suellynn Duffey

Ohio University

Sarah Warshauer Freedman

University of California, Berkeley

Karen L. Greenberg

Hunter College, CUNY

Brenda M. Greene

Medgar Evers College, CUNY

Muriel Harris

Purdue University

Irvin Hashimoto

Whitman College

Warren Herendeen

Mercy College

Myra Kogen

Brooklyn College, CUNY
Patricia Ondek Laurence

City College, CUNY

Elaine O. Lees

Carlow Hill College

Andrea A. Lunsford

Ohio State University

Jane Maher

Nassau Community College

Peter Miller

College of Staten Island, CUNY

Susan Miller

University of Utah

Nathaniel Norment, Jr.

Temple University

Jerrold Nudelman

Queensborough Community

College, CUNY

Jane Peterson

Richland College, Dallas County

Community College Distnct

Nell Ann Pickett

Hinds Community College

Charles I. Schuster

University of Wisconsin, Milwaukee

Tony Silva

Purdue University

Lynn Quitman Troyka

Oueensborough Community

College, CUNY, ret.

Karen S. Uehling

Boise State University

Billie J. Wahlstrom

University of Minnesota

Evelyn E. Webb

Mississippi State Board for

Community and Junior Colleges

Harvey S. Wiener

Adelphi University 


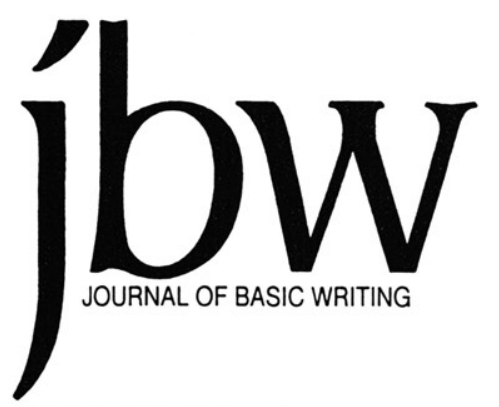

VOLUME 16

NUMBER 2

FALL 1997

Editors' Column

When Working Class Students "Do" the Academy:

How We Negotiate With Alternative Literacies

Martha Marinara

Some Effects of Culture-Referenced Topics on the Writing Performance of African American Students

Nathaniel Norment, Jr.

A Story About Grammar and Power

Lynn Briggs and Ann Watts Pailliotet

Towards a Consciousness of Language:

A Pedagogy for Multi-cultural Classrooms

Mary Soliday

The Connection between Reading Aloud and Stylistic Improvement for Basic Writing Students

Mary Hurley Moran

Karen L. Greenberg Responds to Ira Shor

Terence G. Collins Responds to Ira Shor

News and Announcements 


\section{CALL FOR ARTICLES}

We welcome manuscripts of $10-20$ pages on topics related to basic writing, broadly interpreted.

Manuscripts will be refereed anonymously. We require five copies of a manuscript and an abstract of about 100 words. To assure impartial review, give author information and a short biographical note for publication on the cover page only. Papers which are accepted will eventually have to supply camera-ready copy for all ancillary material (tables, charts, etc.). One copy of each manuscript not accepted for publication will be returned to the author, if we receive sufficient stamps (no meter strips) clipped to a self-addressed envelope. We require the MLA style (MLA Handbook for Writers of Research Papers, 4rd ed., 1995). For further guidance, send a stamped letter-size, self-addressed envelope for our style sheet and for camera-ready specifications.

All manuscripts must focus clearly on basic writing and must add substantively to the existing literature. We seek manuscripts that are original, stimulating, well-grounded in theory, and clearly related to practice. Work that reiterates what is known or work previously published will not be considered.

We invite authors to write about such matters as classroom practices in relation to basic writing theory; cognitive and rhetorical theories and their relation to basic writing, social, psychological, and cultural implications of literacy; discourse theory, grammar, spelling, and error analysis; linguistics; computers and new technologies in basic writing; English as a second language; assessment and evaluation; writing center practices; teaching logs and the development of new methodologies; and cross-disciplinary studies combining basic writing with psychology, anthropology, journalism, and art. We publish observational studies as well as theoretical discussions on relationships between basic writing and reading, or the study of literature, or speech, or listening. The term "basic writer" is used with wide diversity today, sometimes referring to a student from a highly oral tradition with little experience in writing academic discourse, and sometimes referring to a student whose academic writing is fluent but otherwise deficient. To help readers therefore, authors should describe clearly the student population which they are discussing.

We particularly encourage a variety of manuscripts: speculative discussions which venture fresh interpretations; essays which draw heavily on student writing as supportive evidence for new observations; research reports, written in nontechnical language, which offer observations previously unknown or unsubstantiated; and collaborative writings which provocatively debate more than one side of a central controversy.

A "Mina P. Shaughnessy Writing Award" is given to the author of the best JBW article every two years (four issues). The prize is $\$ 500$, now courtesy of Lynn Quitman Troyka. The winner, to be selected by a jury of three scholars/teachers not on our editorial board, is announced in our pages and elsewhere. 


\section{EDITORS' COLUMN}

As many of you told us during last year's national review of JBW, we are a journal providing a much-needed forum for a field that is itself a perennial site of conflict. In this issue we are again made intensely aware of the complex issues our field faces in enabling "border" students to enter the academy, assessing these students, helping them to respect their own "ways with words," and finding ways to ensure the future of our programs and students in higher education. Reviewing the essays in this issue, we were struck by how class, race, and gender emerge as prevailing concerns, as they were in our special spring issue. But here these themes are consistently presented from the viewpoint of teacher as researcher. Our authors have made this an issue in which theory and practice come together to bear fruitful insights to inform curricula and program decisions.

In her essay, "When Working Class Students 'Do' The Academy: How We Negotiate with Alternative Literacies" Martha Marinara problematizes what she sees as a one-sided negotiation in which working class students are expected to alter their perspectives to enter an unchanging academy. Marinara's aim in developing her course is to foster two-sided interaction in which both the student and the university change, allowing the student to retain a sense of identity and worth.

The power of culture and identity play a major role in "Some Effects of Culture-Referenced Topics on the Writing Performance of African American Students" by Nathaniel Norment, Jr. Norment describes a long-term, large-scale collaborative project involving Temple University and four Philadelphia high schools, studying the effects of essay prompts that incorporate values, attitudes, and information relevant to African American culture. The project entailed testing 711 eleventh and twelfth graders using both standard and culture-referenced prompts and analytical as well as holistic assessment.

In "A Story about Grammar and Power," Lynn Briggs and Ann Watts Pailliotet look at what occurs when a Writing Center Director is told to create a grammar exam for gauging pre-service teachers' awareness of grammar patterns. Briggs and Paillotet worked together to develop a test that would enable mostly female future teachers not only to assess but also to write about grammar and conventionality. Reviewing test responses they thought would give the two of them insights into problems with the process/product dichotomy, they came to see their - and our - own culpability in using grammar to maintain power relations, especially in uncertain, devalued academic situations.

If Briggs and Pailliotet examine how grammar may be used to maintain power relations and disempower student writers, Mary 
Soliday's "Towards a Consciousness of Language: A Language Pedagogy for Multicultural Classrooms" offers its antithesis, how language study can be used to empower students and encourage respect for the "languages" of their communities. Soliday describes the Language Research Project at CCNY in which students examine local language use and learn to write a literacy narrative. In guiding students through the steps of doing on-site research, students develop awareness of text, of subtext, of context-above all, of language's complexity.

Mary (Molly) Hurley Moran of the University of Georgia presents a detailed description of her research process as well as her results in "Connections between Reading and Successful Revision." What began with the observation of one student in a writing center led Moran to study whether reading strategies enable students to become better revisers of their writing. As descriptions of the teacher/ research paradigm, both Moran's and Briggs and Pailliotet's articles enable us to trace the trajectory from initial assignment or question and the development of a research project to the findings of the project and the intricacy of interpreting the findings, just as Soliday's article shows us how far students can go in doing these very things themselves.

Because we believe that articles are not ends in themselves, that they are to be valued for the light they shed and especially the thoughts they provoke, we are pleased to present the last two essays in this issue, responses from two major scholars in our field to Ira Shor's "Our Apartheid: Writing Instruction and Inequality," which appeared in the Spring 1997 issue of JBW. Karen L. Greenberg is professor of English at Hunter College, former co-editor of $J B W$, and former director of the Developmental English Program at Hunter College. Greenberg, editor of Writing Assessment: Issues and Strategies (Longman,1986), is a frequent writer and presenter on assessment issues. The second respondent is Terence G. Collins, Director of Academic Affairs and Curriculum at the General College and also the Morse-Alumni Distinguished Teaching Professor of Writing and Literature at the University of Minnesota. Collins often presents and writes on issues bearing on basic writing in higher education.

We said at the outset that our field is a perennial site of conflict. Greenberg and Collins remind us - as Shor did in provoking these responses - that it is a field whose future, whose very existence, is in question. Sobering as such reminders are, we are grateful for them, as we are for the ways the other authors in this issue convince us that the field is vital, critically aware of its challenges, determined to press knowledge forward for the sakes of the students it serves. 


\section{WHEN WORKING CLASS STUDENTS "DO" THE ACADEMY: HOW WE NEGOTIATE WITH ALTERNATIVE LITERACIES}

ABSTRACT: Narratives concerning working ciass students are constructed to highlight the difficulties of negotiating academic codes and the necessity for writing teacleers to strive to provide the space for working class students to "speak differently." Although the narratives of working class students open up sites of conflict and allow students to negotiate the borders between work and classroom, this negotiation carries the expectation for the student to learn the codes of the institution and the values of the academy. The knowledge and work that is valued by the university doesn't change; instead, the narratives of the zorking class are subtly shaped to fit a set of representations of cultural knowledge that serve to reproduce the academy intact. Howvever, the negotiation must flow in two directions: the academy cannot take over a text without being uncomfortably altered by it.

In 1981 I began to work for a man named Mike Cirincioni. My job was to bring him supplies when he needed them. You see, we did tile work. We were working at the Ledbetter's house at the Landings. The job cost these people over thirty thousand dollars. Most of the house was set in white and green marble. When you set marble in place you must take great care in lining up the joints and making sure the pieces are all level. To get the pieces just perfect takes great patience.

Chris Brist

Work is the means by which people construct and change their material and imaginative worlds.

Maggie Humm

If you don't show up on a Saturday or Sunday,

You've already been fired when it's Monday.

Chris Llewellyn

Martha Marinara teacles composition and directs the Writing Center at Armstrong Atlantic State University in Savannah, Georgia. 
In the last several years, more than a few compelling personal narratives have been presented by both graduate students and teachers that concern the position of working class students within the academy. Most of these narratives were constructed to highlight the difficulties of negotiating academic codes (on the part of the student) and the necessity for writing teachers to strive to provide the space for working class students to "speak differently" (Giroux BC 32). In many of the narratives Mary Louise Pratt's notion of a "contact zone" becomes the metaphor for this negotiation as the classroom often becomes the territory where the colonizing academy and the colonized student clash (34). The classroom as a site of contest and control "needs to create new forms of knowledge through its emphasis on ... new spheres in which knowledge can be produced" (Giroux BC 72). The definition of the writing classroom as a political space constructs the mission of critical pedagogies as self-consciously political, focusing composition courses on a study of the social workings of language.

This politicized classroom space should provide the disorienting effects that allow the imposed boundaries to be questioned and academic authority (knowledge) to be challenged. Although the personal narratives of working class students open up the site of conflict and allow the students to negotiate the borders between home, work, and classroom, this negotiation most often carries the expectation for the students to learn the codes of the institution and the language and way of thinking of particular disciplines: "The student has to learn to speak our language, to speak as we do, to try on the peculiar ways of knowing, selecting, evaluating, reporting, concluding, and arguing that define the discourse of our community" (Bartholomae 134). The basic writing class effectively becomes an introduction to academic discourse, an introduction to what a scholarly conversation is about and looks/ sounds like. The university doesn't change; the knowledge and work that is most valued by the university doesn't change because there is no equally valued place for working class experience within the public domain of the academy. Instead, the narratives of the working class, rather than acting as a transgressive collective, are subtly shaped to fit representations of cultural knowledge that serve to reproduce the academy intact. The academy effectively shields itself from the transformation it would realize if it recognized that when students learn, they create meaning from past experiences, making connections with rather than merely assimilating new knowledge.

Adult learners bring a wealth of life learning and knowledge to academic encounters, but their knowledge and experience is not only largely undervalued by the academy, but hasn't been named and claimed by the learners themselves. When students are also labeled "basic writers" or "remedial" students, writing instructors are forced 
to wonder just what "basic" means, in whose eyes do they need remediation and for what purpose? The academic labeling of inadequacies is so pervasive that adult students labeled as "basic writers" are often unaware of the richness of their lives in domains that the academy hasn't labeled. When asked to look at literacies learned outside of the university as social constructs that can be compared to the construct of a literate self that is valued by the university, adult students can reintegrate themselves as learners and knowers, building upon what they know and do best in order to critique the learning conditions in the university. Integrating outside literacies with academic literacy means the shape of academic knowledge changes; rather than indoctrinating students into academic ways of knowing and defining those ways of knowing as having the highest value, the academy must then work within a larger nexus of literacy and knowledge.

I am not claiming that the academy hasn't changed structurally, bureaucratically, logistically. Since the early 70 s, more access to a university education has been given to those who have been previously excluded. Besides the changes in admissions standards, colleges have restructured degree programs, added degree programs, provided evening and weekend classes and services such as child care in order to accommodate the growing numbers of adult, working class students who make up their populations. Although these structural changes have certainly made the educational process easier for working class students, they have not necessarily created a parallel ideological change in the public activity of academic knowledge and writing. The university's role as a change agent is incomplete and unspectacular. Rather than reconstructing the culture of the academy so that it is more enriched, academic literacy as a gatekeeper to education only gives access to standard rhetorical conventions and thought which may empower students while minimizing negotiation between the academy and other facets of their lives. Change is not enacted on notions of academic excellence or epistemologies, but on those students labeled "remedial" or "basic." As Bruce Horner notes in "Discoursing Basic Writing,"

Paradoxically, defining the "practice" of Basic Writing in "academic" - that is, nonmaterial and nonpolitical terms, is eminently impractical, leaving undeterred the ways in which material constraints, rather than academic theories, come to determine the how and what as well as the why of teaching. (219)

Although the academy's movement toward cultural democracy, the advent of open admissions, and the introduction of basic writing programs has been admirable, I believe the goal of democratized educa- 
tion, what John Trimbur sees as the rejection of "the traditional academy, calling instead for a 'community of scholars'" (89) and Bruce Herzberg as a "move from demystification to critical consciousness, to a more general awareness for students that knowledge is made by groups for their own purposes" (115) is still largely unrealized. While bureaucratic or system changes may be prompted by the changes in educational philosophy which radicalized university campuses in the late 60 s and early 70 s, these logistical changes do not necessarily change the ways of thinking that the academy sees as culturally valuable.

During Augusto Boal's keynote address at the Pedagogy of the Oppressed Conference in Omaha, Nebraska in February 1995, he defined one of the challenges of liberatory pedagogy as getting students "talking about things they already know in other forms." These "other forms" or alternative ways of seeing put into question the concept of literacy as a mere transference of skills and knowledge. However, no one-neither students nor teachers-questions the assumption that a college education as defined by the academy encompasses the knowledge that is most valued by society. The knowledge of the working class the knowledge working class students bring to the academy - really isn't given much credence in this academic movement toward cultural democracy.

My sister Irene is attending a graduate program in nursing at a large research university in the Northeast. She calls me regularly to discuss her classes and ideas for her thesis. Recently she was told that the topic she wanted to explore for her thesis-relationships of power within the hierarchical structures of long term care facilities - wasn't academic enough. For the past five years, my sister has been a nursing supervisor at a long term care facility. One of the problems she encounters at work concerns the attitudes of RNs toward health aides (who have considerably less formal education and make considerably less money), which in turn has been causing increased tension between the staff and the clients they serve. Irene had initiated a series of workshops aimed at increasing the health aides' knowledge of caregiving and thereby enhancing their sense of professionalism. She hoped that she could raise the health aides self-respect and help them achieve the respect of the RNs. At the same time she was initiating these workshops, Irene's political consciousness was on fire from reading Foucault and Friere for her graduate class. For her thesis, she proposed to study these power inequities in depth and propose a solution. Irene has been guided toward another topic, but at this point she feels that all she has learned in graduate school is that what she does every day for a living isn't intellectually valuable. Unfortunately, my sister's story isn't unique.

Rather than teachers placing value on and working with the 
knowledge of "lived relations" that students bring to the classroom, they often ask students to remove themselves from their more practical experiences and theorize about work, to recognize that a particular kind of "knowledge" exists within a structure that benefits some and oppresses others, that the ways in which students acquire knowledge operate within an ideological structure that indelibly imprints what they learn. Althusser describes this structure as a "system of ideas and representations which dominate the mind ... of a social group" (158). It is this system of ideas and representations under which students learn to reproduce the divisions and the rules of a rigid class system, rules hidden behind the absorption by "good manners" and "moral" codes. These divisions in the class structure reinforce their identities as workers and students by controlling the material conditions of their relationships to institutions. For Irene, the codes of the academy reproduced the worker/knowledge giver dichotomy that she had been aware of all her working life.

This already constructed identity includes the socially acceptable modes of behavior connected to particular social classes. These class structures are reflected in and reinforced by the knowledge making processes within the university. Althusser writes in "Ideology and Ideological State Apparatuses" that, besides "techniques and knowledges," school children learn "the attitude that should be observed by every agent in the division of labor .... which actually means rules of respect for the socio-technical division of labor and ultimately the rules of order established by class domination" (132). Some of these rules so carefully establish the lines between workers and the owners who need their services that the laborers are rendered virtually invisible. The products of their work, paid for and owned by someone else, cause the workers themselves to fade into the background. One of my students is a carpenter, an exceptionally skilled and artistic craftsperson. Mike enjoys talking about his work, and late one afternoon, he told me about the job he had just finished: shingling a house at the Landings, a golf course community on Skidaway Island. Caught up in Mike's enthusiasm, I suggested that the class take a drive out to this house so that we could look at the wood shingles he had cut and shaped by hand, carefully molded to fit the architect's specifications and the owners' taste. The concept of going to look at the house presented a real dilemma for Mike: on the one hand he wanted to show off his work, but on the other hand, he had firmly bought into a particular mode of thinking about ownership and work. The work was his; the house, however, was not. And, his invisibility was an inevitable part of this construction process because, according to Mike, "once the job is done, the owners don't want us coming around anymore." Once he had been paid for the job, he lost the privilege of visiting the work site.

In parallel fashion, working class students don't see knowledge 
as something they own or can own, but rather view a college education as a particular point on the continuum of apprenticeship. Paradoxically, working class students are not unskilled; however, their entrance into the college classroom effectively de-skills them. Indeed, the very notion of working class becomes problematic when one attempts to enclose these students within an academic definition. The usual identifiers only make class identity more complex; "blue collar workers" - auto mechanics, health professionals, dental hygienists, radiologists - often have two to four years of specialized training, knowledge of computers and other technology, and command fairly high salaries. For the university, this politically crucial term posits the working class students' knowledge as different from academic knowledge. Within the educational system sanctioned by the university, this binary difference governs the codes of academic excellence, as those students who cannot write in academic English or discuss university sanctioned knowledge are labeled "basic" or "remedial" regardless of the skills or knowledge they hold in the work force. Buying into the myth of social and economic ascendancy that their difference from the academy perpetuates, working class students go to college to get better jobs, to become professionals; the work of education must have a practical end. The stories they tell often reify existing class structures:

My grandfather didn't go to a fancy university but he owns his own charter business. I just don't want to spend my life working outside.

And, from another student,

Thinking about the idea that I had the knowledge and ability to put up drywall made me very proud. But I knew I would never want to do it for a living. This type of work wears your body down too fast for my liking.

Unlike narratives of race and gender; class status works against difference; the lower classes can not afford not to be mainstreamed. Because their educational goals include a move upward in status, working class students are not comfortable questioning the system that creates those spaces they are working so hard to occupy. As Monique wrote in her final reflection, "When I entered the job market, I knew little about how our system worked or the shortcuts that one could take, such as college."

But since the students' stories are so often the site of conflict, personal narratives give us the unique opportunity to help students negotiate the borders between work and school, past and present, self and other. Talking and writing about class status, however, is difficult and 
messy as is recognizing how the stories in/of our lives inform our definitions of work. In The Violence of Literacy Elspeth Stuckey writes that it is how we desire to define ourselves as Americans, our belief that "citizens get what they achieve" that makes it difficult, if not impossible, for the working class to perceive their marginality (3). When students are encouraged to narrate their own educational and work histories and then deconstruct their own stories, this not only broadens the parameters of the lives of working class students, but at the same time raises questions about academic knowledge.

In an effort to recognize the impossibility of maintaining the opposition between the academic and the personal, give credence to the knowledge of workers and the knowledge of work, and question the relationship of knowledge written about and legitimized by the academy and the texts of students' lives, I decided to make work and working lives the focus of a basic writing course which met two evenings a week. My purpose for this course was to move students' knowledge and ways of knowing and academic knowledge and ways of knowing into the same space so that questions of their contradictory epistemologies could be raised. During the ten-week quarter, we read, discussed, and wrote about how literature, essays, and films shape our thinking about work and our identity as workers. We read selections from Working Classics and Havel's The Memorandum, viewed Michael Moore's Roger and $\mathrm{Me}$, and with the then immediate and extremely emotional closing of Union Camp-Savannah's Paper Bag Plant (389 workers were laid off), watched and discussed videos of the news coverage, read newspaper accounts and related personal experiences of lay-offs.

Most of the students in this particular class were non-traditional, working class students (with full-time jobs) and their own experiences became a part of the classroom experience. One student's first journal responses to Roger and $\mathrm{Me}$ begin with a note of disapproval towards the laid-off workers in the film: "I don't understand. If they get laidoff so often couldn't they see the handwriting on the wall? Why didn't they move, or look for other jobs? That's not the company's responsibility." The class discussed the inequalities in the film, who was powerless and who was not (i.e., Roger Smith has enough power to avoid Moore's camera and questions). Tom Kay, GM's lobbyist, claims in the film that "Roger Smith has as much social conscience as anyone." We discussed Tom Kay's statement along with his later statement that "GM has no obligation to Flint." Are corporations responsible to/for workers? Must stockholders' profits always come before community obligations? Later in the quarter, after the student who felt that laidoff workers are responsible for themselves experienced her husband's lay-off off from Union Camp, she began comparing the actions of the Union Camp management with the corporate face of General Motors: “We don't want to move so my husband is getting tuition money from 
UC to go back to school. This is very different from the problems in Flint. Did GM offer the workers any educational or relocation help I wonder?"

My experiences with encouraging students to write personal narratives as a method of opening texts to different and socially useful interpretations doesn't ask for a privileged and particular understanding of texts or an acceptance of how students "relate" to texts and tell parallel stories, but rather asks for an expansion of the parameters of historical memoir as critical discourse. Stories are not only a set of representations that impart knowledge. Widening their definition to include a revision of the writer's argument and circumstances allows personal narratives to be culturally productive. And, to be culturally productive, students' critical writing must unsettle our definitions of work in all its forms. Accepting the experience of work as the basis for critical discourse means one must first recognize that students' responses to texts do not reflect meaning; they constitute meaning. Working with students' personal narratives involves an ongoing definition of what constitutes a "public working self" - the self that one student wrote of as having "no certainty .... because of social class ladders which by the way still exist" and another student defined the self as one who "either takes orders and executes decisions or makes the decisions himself." Students can be encouraged to see through their class descriptions that serve the status quo by depicting students as free and sovereign individuals. As Todd wrote, "When I work hard at something, I only need to see an end product I can be proud of. I don't care what others think." Most of the students when pressed admitted that they did care how others view the quality of their work, especially as this evaluation impacts on the material conditions of their lives. Recognizing the power in locating their place in the class hierarchy allows students to restructure their roles in such a way that they can then question the system that perpetuates that hierarchy.

As an integral part of the system, the classroom experience, education as work and its place in the social hierarchy, and the students' particular and immediate relations on the college campus should become part of the questioning process. Ira Shor writes, "by identifying, abstracting and problematizing the most important themes of student experience, the teacher detatches students from their reality and then represents the material for their systematic scrutiny" (100). For Shor, the classroom becomes a place where the "familiar" is presented as "unfamiliar," a transformation crucial to teaching in liberatory classrooms. But even though the classroom and the teaching practice are structured in "unfamiliar" ways, the classroom may not be critiqued as a part of the students' social reality, and students may attempt to transcend that reality, to provide a secure space and a sterile, abstracted distance from which to "solve" social inequities. I believe it is very important for the 
teacher to recognize her own place and power in the social hierarchy; no matter how well intentioned, no matter what the mission, the teacher is part of "the company," and teaching is manipulative. "Rather than a rigorous questioning of problematic social formations, there is the danger of reproducing the teacher's political concerns and merely replacing one static world view with another. For example, my students had no difficulty perceiving gender oppression in abstract, global terms. They could even all agree that women should be paid the same salaries as men for the same work, and that although the gap had narrowed, this inequality still existed and hurt women in material ways. But, when one female student questioned the fact that, even though she and a male student were in the same work study program, he was paid two dollars more an hour, he responded that his job was more difficult, more "technical" than hers. Her duties in Financial Aid demanded interpersonal skills, and he was a "lab rat" for the Academic Computing Lab. The class accepted this explanation and refused a discussion of a work study program that fostered a definition of interpersonal skills as "feminine" and, therefore, less valuable because after all male students "have those jobs, too." The teacher needs to recognize that, during class discussion, she is neither a spectator nor an unbiased facilitator. Students, like workers, may choose to resist her "management."

When asked to think critically about their roles at work, students' identities can become part of the reading of their social context. "My Dad is a construction worker," writes one female student in a journal entry about divisions of labor, "but I have a receptionist job. I am able to see both sides of the story. Most construction workers feel cheated because they have to work physically hard and don't get to sit in an air conditioned office. Most of the office workers look down on laborers." The class discussion that emerged when she read this entry aloud concerned both perceived difference and real economic differences between workers. The construction workers were often paid far more than the office staff, even when the office staff saw their roles as managerial. And yet an air-conditioned office, like multiple windows and a new computer, spelled status and garnered more respect for office workers. The construction workers' resistance to this social hierarchy often took the form of speaking in ways that marginalized the office worker; one of the students complained, "They are always speaking 'cabinet language."”

Refiguring the problem of the nature of the self within the hierarchical context of the workplace allows for the possibility of formulating personal narratives as a dialogue with the "real" world. As part of this dialogue, I ask students not only what their response is to a particular text, but where they think that response comes from, what in their work experience formed their responses to texts. 
This questioning of their own work experiences in relation to the larger culture and its institutions did not happen easily. After our first reading assignment-Sandra Ciserno's "My First Job" from The House on Mango Street -I asked the students to narrate their first job experience and then to see if there was a connection between that experience and their present attitudes towards work: "After reflecting on what your first job meant to you back then, write about how your first job affects your present employment and the way you define yourself as a worker." The students were very much invested in the work ethic that places all of the responsibility for work conditions on individuals rather than the institution's relationship with individuals and certain groups of individuals (i.e. women, those whose formal education ended with secondary school, single parents). One student wrote about her experiences in the army that "[i]nstead of getting wrapped up in the vicious circle of daily tasks, I think it is wise to understand the big picture .... Regardless of what job you hold, every workplace has goals and players in their particular game." None of the writers found a tension or contradiction between the work ethic they mimed on paper and their daily experiences at work and home: "I think that this job taught me persistence and perseverance. After a few months, I hated that job but I was too stubborn to quit .... Sometimes you have to endure unpleasantness to achieve your goals." However, if you have been a hard-working waitress for fifteen years it is "your own fault for not getting educated and acquiring other skills." The promise of a better life after college was an unquestioned myth in most of the students' papers. One student summed up this general attitude by stating "[w] hat I learned from my first job is that I should go to school and get a better job."

But in order to understand how their selves are determined by various institutions, including those educational systems that offer the hope of economic "rescue" to the lower classes, students need to first explore the events in their working lives as operating within the boundaries of a socio-economic context and to question their beliefs about work, especially when those beliefs come up against their or others' lived reality. Their assignment after reading and discussing Havel's The Memorandum asked them to explore the shifts of power and the differences in power between the characters: "Your essay should question whether or not power inherently resides in one's role at work or whether gender or class define the effectiveness of one's power struggles." The same student who summed up her experiences in the army as learning to understand her position on the team revised those same experiences in her paper on The Memorandum:

When I was in the army I always felt that there was too much paper-pushing and that no one really knew what to do with 
the paperwork once it was generated. I also felt that the wrong people were in the wrong positions. This seemed to be the case in the play. Gross didn't seem to be the executive type and had to be taken through a paper chase to have his memo translated .... You need to be able to see the whole picture to understand where you fit in the scheme.

Another student noted that "just as in Roger and Me paperwork was more important than people ... years of service don't mean anything in a big corporation. Maria was easily fired because she was a secretary, she wasn't part of the management. Mr. Ballas forgot that people are not machines."

Group research on the connections among labor unions, the women's movement, labor strikes, the International Ladies Garment Workers' Union, and the strike in Flint, Michigan that led to the formation of the United Auto Workers' Union encouraged the students to move from a recognition of "everyone's humanity" that posits workers as victims of factory owners - "If these people would have spent some time with the workers, they would have realized that not only were they human, they were also intelligent" - to the concept that workers can band together and revise their working conditions. The research groups gave their reports the same week we read Fragments From the Fire by Chris Llewellyn. The students were as angered and saddened by the poetry and photographs as I had been; however, their recognition that what divided the workers from the owners of the Triangle Shirtwaist Factory involved more than salaries. The difference in material conditions reflected in the class structure caused safety and health conditions that were intolerable and eventually led to 146 deaths: "Greed and the bad attitude towards the rights of women on the part of the owners led to poor working conditions, the lack of safety procedures, and fire codes." Perhaps more importantly, the historical perspective they had gained from the group reports encouraged the students to recognize that "victim" was just another social identity, a social identity that could be paralyzing and, in effect, still feed the status quo, or could be a starting place for social action. Wrote one student:

The day of the Triangle fire was a day of rebirth for the labor movement. According to Llewellyn, "Every Little Movement Has a Meaning of Its Own" (148), the movement that was born from the Triangle fire had the purpose of improving working conditions in the garment industry.

Perhaps more importantly, as the students compared their own work experience with the experience of garment workers at the turn of the century, they were able to see that poor working conditions and in- 
equalities were not all part of the past (something they tend to do when the class discusses women's issues) as many of the students had stories of accidents and unhealthy conditions at their own work places.

Our public selves contain various roles that continually merge, conflict with and contradict each other. Teaching working class students does not need to involve the construction of a strict victim/oppressor model, and in fact, that model needs to be problematized, for any worker can be both victim and oppressor depending on the circumstances. More importantly, that model can only ask for an unveiling of the system that promises the happy-ever-after life of a college degree and middle-class status: "I usually failed because of external factors in which I had no control over. Perhaps it was because I lacked education."

Toward the end of The Wizard of $\mathrm{Oz}$ Dorothy demands of the unveiled Wizard, "You must keep your promises to us!" Teaching writing cannot just involve using the instructor's particular power and authority to engage the positionality of the students she teaches. Connecting the classroom with "real life" means teaching students to take uncomfortable risks, to develop a critical perspective toward all institutional structures, to recognize the power relations that allow them to speak in particular ways, "to address their role as critical citizens who can animate a democratic culture" (Giroux PFC 255). James Berlin writes that "literacy enables the individual to understand that the conditions of human experience are made by human agents and thus can be remade by human agents" (101). In order to construct a particular political identity - one that can take action in the world-it is important for students to reflect on their own lives and negotiate their connections to the lives of others. This remaking is part of our mission as well for the negotiation must flow in two directions: the university cannot absorb working class texts without being altered by them.

\section{Note}

Ira Shor positions the teacher's knowledge under the role of "resource person." He writes in Critical Teaching and Everyday Life that "eventually there develops in class a desire for me to raise my profile, focus the debate on some questions, and share with them my starting points for appreciating Utopia. I propose to the class that we can study 
Utopia as a literary tradition, as a history of various counter-communities, and as a form of critical consciousness" (157). He never explores or questions his impulse behind this desire but states that his knowledge stands as an "appealing invitation" to students that "naturally" leads into his conceptual analysis (157-8).

\section{Works Cited}

Althusser, Louis. Lenin and Philosophy and Other Essays. Trans. Ben Brewster. New York: Monthly Review Press, 1985.

Bartholomae, David. "Inventing the University." In When A Writer Can't Write: Studies in Writer's Block and Other Composing Process Problems. Mike Rose, ed. New York: The Guilford Press, 1985.

Baum, Frank. The Wizard of $\mathrm{Oz}$. New York: Holt, Rinehart and Winston, 1982.

Berlin, James. Rhetorics, Poetics, and Cultures: Refiguring College English Studies. Urbana: NCTE, 1996.

Boal, Augusto. Keynote Address. The First Annual Pedagogy of the Oppressed Conference. University of Nebraska Education Center, Omaha, Nebraska. 10 Feb. 1995.

Cisernos, Sandra. The House on Mango Street. New York: Random, 1989.

Fish, Stanley. Is There A Text in This Class?: The Authority of Interpretive Communities. Cambridge, MA: Harvard UP, 1980.

Giroux, Henry. Border Crossings: Cultural Workers and the Politics of Education. New York: Routledge, 1992.

Postmodernism, Feminism, and Cultural Politics: Redrawing Educational Boundaries. Albany: SUNY Press, 1991.

Havel, Vaclav. The Memorandum. New York: Grove Press, 1980.

Herzberg, Bruce. "Composition and the Politics of the Curriculum."

In The Politics of Writing Instruction: Postsecondary. Ed. Richard Bullock and John Trimbur. Forstmouth, NH: Boynton/Cook, 1991.

Horner, Bruce. "Discoursing Basic Writing." College Composition and Communication 47.2 (May 1996): 199-222.

Llewellyn, Chris. Fragments From the Fire. New York: Viking, 1986.

Moore, Michael. Roger and Me. Warner/Dog Eat Dog Films, 1989.

Oresick, Peter and Nicholas Coles, Editors. Working Classics: Poems On

Industrial Life. Urbana: University of Illinois Press, 1990.

Pratt, Mary Louise. "Arts of the Contact Zone." Professions 91: 33-40. Shor, Ira. Critical Teaching and Everyday Life. Chicago: University of Chicago Press, 1987.

Stuckey, J. Elspeth. The Violence of Literacy. Portsmouth, NH: Boynton/ 
Cook, 1991.

Trimbur, John. "Collaborative Learning and the Teaching of Writing." In Perspectives on Research and Scholarship in Composition. Ben McClelland and Timothy R. Donovan, editors. New York: MLA Press, 1985. 
Nathaniel Norment, Jr.

\title{
SOME EFFECTS OF CULTURE- REFERENCED TOPICS ON THE WRITING PERFORMANCE OF AFRICAN AMERICAN STUDENTS
}

\begin{abstract}
This study analyzes the ejfects of culture-referenced essay prompts/topics on the writing quality of eleventh-and twelf h-grade high school students who participated in a collaborative project behween Temtple University's Writing Program and four Philadelphia public high schools. Trained raters scored 711 essays holistically. The students were also tested on a Cooperative English Reading and Writing Examination which the University administers to all of its entering students. Essays of twenty-five students who tested in their jumior and senior years zvere analyzed using an analytical scale. The results snggest that the culture-referenced topics elicited better quality essays (i.e., in terms of fuency, colverence, organization). The findings indicate that culture-referenced prompts do make a difference in the writing performance of African American students.
\end{abstract}

\section{Introduction}

... one could argue that the kind and degree of writing ability assessed by a specific prompt may be determined by the nature of that prompt, particularly by its cognitive, linguistic, and rhetorical demands and by the nature of the social context in which the prompt places the writer.

Karen L. Greenberg

Mastery of language affords remarkable power.

Frantz Fanon

Nathaniel Norment, jr. is an associate professor at Teniple University zuhere he teaches courses in African American literature, racial und cultural relations, and the core. He is past director of the composition program at the City College of New York and a former director of writing programs at Temple University. 
The importance of topics and prompts to the writing performance of students has been emphasized by many composition theorists and researchers (Brown, Hilgers and Marsella; Gabrielson, Gordon and Engelhard; Greenberg; Hoetker; Hoetker and Brossell; Huot; Keech; Ruth and Murphy; Smith, Hull, Land, Moore, Ball, Durham, Hickey and Ruzich; White; and Williamson). Many researchers have also implied that the modes of discourse and rhetorical specifications in essay topics and prompts affect students' writing performance (Brossell; Engelhard, Gordon and Gabrielson; Murphy and Ruth; Oliver; Prater and Padia; Quellmalz, Copell and Chou; and Ruth and Murphy). Oliver further stated that writing topics may also "affect students in ways which are often difficult to predict or control. Ethnic or racial background may influence the writers' perspective regarding the writing task. However, how writing assessment affects specific groups is not at all clear" (426). In addition, other reseachers suggest that the writing performance of African American students may be affected by certain language and communicative incongruences in the writing tasks (Brown; Fox; Hoover and Politzer; Taylor and Payne; Taylor and Lee; and Vaughn-Cooke). ${ }^{1}$ Taylor and Lee questioned the "incongruencies between the communicative behavior or language (context and content) of the tests and test constructors and the students who take the tests" (67). They point out that

African American students are faced with a two-fold challenge: a) performing required tasks and $b$ ) demonstrating abilities on the tasks by manipulating communicative and language codes which are frequently different from their indigenous systems. ${ }^{2}$ Because of these language and communicative incongruencies, African American students are frequently assessed invalidly. Either they fail to demonstrate the desired cognitive, social or linguistic behavior because of flawed (or low) expectations or of their misinterpretations, or they fail to demonstrate the desired behavior within the communication and language frameworks demanded by the tests [topics and prompts]. (80)

Greenberg reported that the research evidence did not clarify the connections between specific features or dimensions of writing prompts and students' writing performance. There is relatively little consensus among researchers and practitioners about what constitutes an effective writing prompt-for either instruction or assessment ("Prompt" 5). The effect of the cultural reference or cultural context of the wording of essay topics has not been investigated. Consequently, this study was designed to examine directly whether (and how) culture-referenced topics affect the writing of African American students. Ruth 
and Murphy suggest that the topic functions as a springboard-a prompt. Thus the "meaning potential" of any given task is relative to linguistic, cognitive and social (cultural) reverberations set off in the respondents (413).

Much of the research in composition during the past two decades has focused on some aspects of students' writing proficiency and writing performance; yet considerably few studies have examined the effects of essay prompts or topics on the writing performance of students (Brossell and Ash; Conlan and Chambers; Greenberg; Hoetker and Brossell; Hoetker; Murphy and Ruth; Ruth and Murphy; Smith, et al.) and on the rhetorical specifications in topics (Brossell; Engelhard, et al.; Oliver; Prater; Quellmalz, et al.). This research has been influenced directly by the large-scale writing assessments used to place students into basic writing and freshman composition courses. Millward noted that while acknowledging the need of placing students in their proper courses, many of us remain concerned about the ways in which the testing situation affects writing performance. There is concern, too, that these exams have a greater impact than simply determining proficiency levels (100). Even though various studies have examined the writing performance of African American/Black students (Ball; Chaplin; Cooper; Cunningham; Fowler; Norment; Scott; Smitherman and Wright; Wilson; and Zeni and Thomas), none has investigated the direct effects of essay prompts or topics on their writing.

Since it is accepted that any prompt or topic used to elicit writing samples will give some students an advantage, and that no one prompt or topic significantly influences the writing performance of students at different grade levels, and in different modes of discourse, this researcher proposes that topics designed to incorporate positive culturally oriented references may develop and enhance self-esteem and thus build confidence in African American students to produce more proficient writing samples. Throughout this paper, the term "culture referenced" will be used to describe any topic or prompt that incorporates values, attitudes and information relevant to African American culture. Furthermore, culture referenced includes a combination of culturally, socially, linguistically and historically determined aspects of African American culture.

\section{Rationale}

Although there may be some difficulty in determining the degree to which linguistic patterns and culture ${ }^{3}$ correlate, there are some direct effects of culture on the language and knowledge of a particular group of individuals. ${ }^{4}$ That is, culture is not just shared, it is intersubjectively shared, so that everyone within a particular cultural group assumes that others within the same group see and interpret 
objects, concepts, or experiences in similar ways. According to Geertz "culture is an historically transmitted pattern of meanings embodied in symbols of inherited conceptions expressed in symbolic form by means of which people communicate, perpetuate, and develop their knowledge about and attitudes toward life" (89). Modes of communication among members of a particular group can mark an unconscious linguistic process that permits individuals to interpret and describe their experiences and form the basis of a world view in common with these individuals; yet we ought to be able to determine when linguistic patterns and cultural references, beliefs, or experiences converge in the production of written language.

Nobles defined culture as "the process which gives a people a general design for living and patterns for interpreting their reality; it implies that there are cultural laws which are consistent with the requirements of the people's cultural deep structure" (23). We can think of these "cultural laws" as creating structures and concepts of family and institutional roles, ethics, behavioral norms, and historical information. Nobles continues, "The African worldview comprises the fundamental assumptions, beliefs and attitudes toward life, all of nature, and the universe that characterizes African [American ]people, and thus constitutes the philosophical-ideological basis of African [American] culture" (53).

Essay topics that, through cues embedded in the text, are constructed to refer to African American cultural heritage and identity may promote positive self-esteem and self-image and, in turn, affect the writing performance of African American students. Research by composition specialists and linguists suggests that aspects of African American culture are reflected in the grammatical, stylistic, and discourse features of African American students' written language (Ball; Chaplin; Cooper; Cunningham; Fowler; Linn; Lipscomb; Norment; Smitherman and Wright; Scott; Wilson; and Zeni and Thomas). ${ }^{5}$ Cooper reported that cultural and dialectical differences affect the writing styles of African American college students in several ways. Culturally-based stylistic aspects of their writing are indicative of cultural history and values.

The present study differs from previous research on the writing ability of African American students in several ways. First, it addresses the gap in both qualitative and quantitative research since, although there has been research on the effects of Black English Vernacular (BEV) dialect on the quality of African American students' writing, no research has been conducted on the effects of culture/ethnicity referenced essay topics contributing to their written language performance. Second, much of the research on the characteristics of African American students' writing has focused primarily on the effects of grammar/mechanical errors. ${ }^{6,7}$ Third, most of the research has classified 
African American students as basic, remedial, or inexperienced writers.

\section{The Present Study}

\section{Purpose}

The purpose of this study is to examine the effects of culturereferenced essay topics on the quality of writing produced by African American students in the 11th and 12th grades within the context of an urban university placement examination. Culture-referenced topics establish a context framework for African American students' responses in which a common linguistic, cultural, and social frame of reference is shared. This study examined specific characteristics of the writing tasks: (1) the overall quality of writing produced by the students (e.g., development, content, usage and mechanics) and (2) the content, structure, and task of the topic. The specific research questions addressed were as follows:

Question 1: Are there interactions among the prompts and topics that incorporate African American culture-referenced content and the quality of students' writing samples elicited within a university placement examination?

Question 2: Is there a relationship between the prompts and topics that incorporate African American culture-referenced content and the syntactic complexity, organization, and length of essay in 11th and 12th grade students' writing elicited within a university placement examination?

Based on a review of literature related to the effects of prompts and topics on students' writing performance, it was expected that the quality of writing would be different for each grade level and that female students would receive higher ratings on each of the variables. It was also expected that the level of writing quality on the university's placement topics would range from pass to fail, that the cultural-referenced writing prompt would be the most frequently chosen by the students, and that these essays would receive the highest scores. Finally, it was expected that the 12th grade students would receive higher ratings than 11th grade students, regardless of the writing task.

\section{Method}

\section{Subjects}

Seven hundred and eleven African American students from four Philadelphia high schools participated in the study. More than $95 \%$ of the students in each of the participating high schools are African Ameri- 
cans from various socio-economic backgrounds. Subjects included male and female students in the 11 th and 12 th grades. Five 11 th grade classes from three high schools (62 females and 41 males) and four 12th grade classes from two high schools ( 52 females and 39 males) were included in the sample the first semester. Four 11th grade classes from four high schools ( 84 females and 73 males) and four 12 th grade classes (60 females and 48 males) were included in the sample the second semester. Seven 11th grade classes from four high schools ( 73 females and 58 males) and four 12th grade classes (72 females and 49 males) were included in the sample for the third semester.

\section{Essay Topics}

The writing prompts were designed and piloted by the researcher. The culture-referenced topics incorporated characteristics presented in the research literature (Brossell and Ash; Conlan and Chambers; Greenberg; Hoetker and Brossell; Hoetker; Ruth and Murphy; Smith, et al.) and research related to language patterns influenced by cultural and linguistical contexts (Ball; Chaplin; Cooper; Carson; Eller; Fowler; Hoover and Politzer; Linn; Norment; Park; Scott; Smitherman and Wright; Wilson). The culture-referenced topics selected for use as placement examinations adhered to similar guidelines suggested by Conlan and Chambers, who recommended that topics should be: 1) clearly stated, using language familiar to the audience, 2) appropriate to the population being tested, 3) reasonable for the allotted writing time, 4) suited to the purpose of the test, 5) accessible to the broadest range of students, 6) interesting to write about, and 7) capable of producing writing across the range of student abilities. For the purpose of the study, culture-referenced essay topics were defined as those related to the African American cultural knowledge base. The writing placement examination also included nine prompts not identified as African American culture-referenced. The prompts/topics appear in Appendix A.

\section{Testing Procedures}

The testing supervisor and proctors from the Measurement and Research Center (MARC) administered the university's English Composition and Reading Placement Examinations at each participating school site. ${ }^{8}$ The same testing and scoring materials and procedures used to test entering freshmen at the university were used in this study. Students were notified by their teachers of the purpose and requirements of the examinations. They were asked to consider the testing procedure as a pre-testing situation similar to what they would experience for placement at college. Temple University agreed to accept the results of the scores (if students enrolled at Temple) as valid assessment of their reading and writing levels for placement into freshman courses. Information about the writing and reading tests was distributed to each class one week before the test date. Two forms of 
essay topics were distributed at testing sessions, the English Writing (essay, usage and mechanics) and Reading tests were administered during test sessions (one hour for the essay, 35 minutes for usage and mechanics, and 30 minutes for the reading test).

\section{Scoring Procedures}

\section{Analysis of Essays}

All placement essays were read by a group of six senior readers who were experienced teachers of composition trained in the assessment of writing. All essays were scored holistically; the test reader assigned a number that indicated his/ her overall judgment of the quality of the essay, taking into consideration such things as the student's ability to handle ideas logically, to write in a style appropriate to the audience and situation, and to use standard grammar, spelling, and punctuation. Two trained readers gave each essay a numerical score from one through six, based on a set of specific criteria (see Appendix B) used to score the essay holistically. Readers made no marks or corrections on the essay. The scores given by the two readers were first added together, giving a total that ranged from a low of two to a high of twelve. Any essay that readers scored more than one level apart (for example, an essay given a 3 and a 5) was third-read by another reader, and the score was adjusted as appropriate. Throughout the year, the readers' scores on essays were selected randomly from the total sample of approximately 5,000 students and were checked for inter-rater reliability. The overall reliability scores (coefficients) of ALPHA for readers' ratings ranged between .87 and .92 .

\section{Analytical Scoring of Essays}

A modification of Diederich's analytic scale was used to measure writing quality. The scale consists of seven features or qualities of writing: ideas and details, organization, syntax, vocabulary, style and tone, grammar and usage, and spelling and mechanics. An essay could receive a low score of 10 or a high scale of 50 for all items on the scale. (Contact the author for more information on the scale.) The first three features - ideas and details, organization, and syntax have twice the number of points as do the last four features. An essay that received a high score in ideas and details, for example, had a clear focus and appropriate ideas with relevant explanation or development, whereas an essay with a low score lacked focus and development. Similarly, a high score for organization indicated a discerned pattern of development, whereas a low score indicated no discernible logic or organizational pattern. A high rating for syntax suggested a command of sentence construction/structure; a low rating indicated sentences that were often rudimentary or unclear. A high rating for vocabulary indicated word choice/diction relevant to the topic; a low score indicated limited vocabulary and misused words. A high score for style/tone re- 
vealed the writer's individuality; a low score indicated language without any recognizable "voice." A high score on grammar/usage indicated adherence to the conventions of standard written English; a low score indicated a high frequency of errors. Similarly, a high score for spelling/mechanics indicated correct spelling and appropriate punctuation; a low score indicated many misspelled words and misuse of punctuation. Three of the senior experienced raters who scored the essay holistically were trained to score the essays of the 25 students who wrote on topics in the eleventh and twelfth grades.

\section{Results}

Table 1 presents the means and standard deviations of the scores that the sample received on the Cooperative English Test Writing and Reading.

\section{Table 1: Cooperative Reading and Writing Placement Results for Four High Schools}

\begin{tabular}{|c|c|c|c|}
\hline & \multicolumn{3}{|c|}{ COOP Writing Examination } \\
\hline & N-Tested & Mean & SD \\
\hline H.S.: 01 & 131 & 23.12 & 8.12 \\
\hline H.S.: 02 & 167 & 28.47 & 8.36 \\
\hline H.S.: 03 & 89 & 33.67 & 8.03 \\
\hline \multirow[t]{3}{*}{ H.S.: 04} & 354 & 30.97 & 8.40 \\
\hline & \multicolumn{3}{|c|}{ COOP Reading Examination } \\
\hline & N-Tested & Mean & SD \\
\hline H.S.: 01 & 128 & 10.69 & 5.10 \\
\hline H.S.: 02 & 165 & 13.01 & 6.35 \\
\hline H.S.: 03 & 35 & 17.34 & 5.98 \\
\hline H.S.: 04 & 249 & 13.73 & 6.45 \\
\hline
\end{tabular}

\section{Examinations}

The mean scores for the Writing Test ranged from 23.12 for H.S. 01 to 33.67 for H.S. 03. The Reading Test means ranged from 10.69 for H.S. 01 to 17.34 for H.S. 03. For the 711 students who took the Writing Test, the standard deviation was 8.21. For the 577 students who took the Reading Test, the standard deviation was 5.97. Table 1 reveals a significant difference among the scores reported for the high schools on each of the Writing and Reading Examinations. 


\title{
Table 2: Frequency Distribution of Essay Pass/Fail Ratio by Sex and by High School
}

\author{
Number Number \% \% \\ N-Tested Passing Failing Passing Failing
}

$\begin{array}{lrrrrr}\text { H.S.: } 01 & & & & & \\ \text { Males } & 49 & 5 & 44 & 10.2 & 89.7 \\ \text { Females } & 81 & 9 & 72 & 11.1 & 89.1 \\ \text { Total } & 130 & 14 & 116 & 10.7 & 89.2 \\ & & & & & \\ \text { H.S.: } 02 & & & & & \\ \quad \text { Males } & 68 & 10 & 58 & 14.7 & 85.3 \\ \text { Females } & 75 & 18 & 57 & 24.1 & 76.1 \\ \text { Total } & 143 & 28 & 115 & 19.5 & 80.5 \\ & & & & & \\ \text { H.S.: 03 } & & & & & \\ \text { Males } & 32 & 8 & 24 & 25.2 & 75.2 \\ \text { Females } & 57 & 16 & 42 & 28.1 & 72.1 \\ \text { Total } & 89 & 24 & 65 & 26.9 & 73.1 \\ & & & & & \\ \text { H.S.: 04 } & & & & & \\ \text { Males } & 159 & 45 & 114 & 28.3 & 71.7 \\ \text { Females } & 190 & 78 & 112 & 41.2 & 59.1 \\ \text { Total } & 349 & 123 & 226 & 49.3 & 50.7\end{array}$

The pass/fail ratio by sex and high school of 711 students who took the Essay Placement Test are presented in Table 2. One hundred and eighty-nine students $(26.6 \%)$ passed the University's Placement Examination. A score of 6 places a student in the Basic Writing course; a score of 8 places a student in Freshman Composition; and scores of 10 or higher exempt the student from taking writing at the university. At each high school more female students participated in the study than male students. Of the 308 males, sixty-eight $(22 \%)$ received a passing score. One hundred twenty one (30\%) of the 403 female students received a passing score on their essays.

Table 3 shows the frequency of topics selected and the percentage of pass rates for each topic. Twenty-three percent of the students (161) wrote on the topic (quotation 3B) by Malcolm X; twelve percent of the students (89) wrote on the topic (quotation 2E) by Dr. Martin 
Luther King, Jr.; and twelve percent (83) wrote on the topic (quotation 3C) by Marcus Garvey. The Writing Placement Examination included nine prompts that were not identified as African American culture referenced. Six percent of the students (46) wrote on the topic (quotation 2B) by Epictetus; four percent (33) wrote on the topic (1B) about free tuition for all high school graduates. In total, thirty-four percent (244) of the students selected the nine non culture-referenced topics and sixtysix percent (467) of the students wrote on the six African American culture-referenced topics: Each form (A-E) of the University Writing Examination included at least one culture-referenced topic. Form A included two prompts identified as culture referenced. Form B topics were selected by $34 \%$ of the sample. Form $D$ topics were selected by $16 \%$ of the students. The culture-referenced topics elicited the highest number of passing scores. The six culture-referenced topics $(1 \mathrm{~A}, 2 \mathrm{~A}$, $3 \mathrm{~B}, 3 \mathrm{C}, 3 \mathrm{D}$ and $2 \mathrm{E}$ ) accounted for nearly $70 \%$ of the topics selected and $80 \%$ of the total passing essays. (For examples of student essays, see Appendix C.)

\section{Table 3: Comparison of Pass Rates by Choice of Essay Topics}

\begin{tabular}{cccccc}
$\begin{array}{l}\text { Topic } \\
\text { Form A }\end{array}$ & Number & \% of Total & \% of Topic & $\begin{array}{c}\text { Number } \\
\% \text { of Pass }\end{array}$ \\
\hline 1A & 29 & 4.1 & 12.2 & $5(2.6)$ \\
2A & 59 & 8.4 & 30.5 & $18(9.5)$ \\
3A & 30 & 4.2 & 16.7 & $5(2.6)$ \\
$\frac{\text { Form B }}{1 B}$ & & & & & \\
2B & 33 & 4.4 & 18.2 & $6(3.2)$ \\
3B & 46 & 6.5 & 23.9 & $11(5.8)$ \\
$\frac{\text { Form C }}{1 \mathrm{C}}$ & 161 & 22.8 & 36.0 & $58(30.7)$ \\
2C & 23 & 3.3 & 13.0 & $3(1.6)$ \\
3C & 19 & 2.6 & 15.8 & $3(1.6)$ \\
$\frac{\text { Form D }}{1 \mathrm{D}}$ & 83 & 11.7 & 18.1 & $15(8.1)$ \\
2D & 27 & 3.8 & 22.2 & $6(3.2)$ \\
3D & 23 & 3.3 & 8.7 & $2(1.0)$ \\
$\frac{\text { Form E }}{1 \mathrm{E}}$ & 46 & 6.5 & 37.0 & $17(9.0)$ \\
2E & 28 & 4.0 & 25.0 & $7(3.7)$ \\
3E & 89 & 12.4 & 36.8 & $31(16.4)$ \\
TOTAL & 15 & 2.0 & 13.3 & $2(1.0)$ \\
& 711 & $100 \%$ & & $189(100.0 \%)$
\end{tabular}




\section{Table 4: Results of Writing and Reading Placement Exams for High School Students who Tested in their Junior (Spring 1990) and Senior Years (Fall 1991)}

\begin{tabular}{|c|c|c|c|c|c|c|}
\hline \multirow{2}{*}{$\begin{array}{l}\text { Test/Measure } \\
\text { COOP Test }\end{array}$} & \multicolumn{2}{|c|}{ Junior Year } & \multicolumn{3}{|c|}{ Senior Year No. of } & \\
\hline & Mean & $\mathrm{SD}$ & Mean & SD & Studer & s t-value \\
\hline Effectiveness & 12.87 & 4.21 & 10.20 & 3.10 & 30 & $-2.89 * *$ \\
\hline Mechanics & 19.43 & 5.88 & 15.00 & 5.32 & 30 & $-4.24^{\star \star}$ \\
\hline Writing & 32.30 & 8.67 & 25.20 & 6.45 & 30 & $-4.81^{\star *}$ \\
\hline Reading & 15.50 & 5.70 & 11.47 & 4.91 & 30 & $-4.05^{\star *}$ \\
\hline Essay & 6.15 & 0.54 & 6.69 & 0.97 & 26 & $3.03 * *$ \\
\hline
\end{tabular}

Percent Pass

$\begin{array}{lrrrc}\text { Writing } & 7.69 & 34.62 & 25 & 3.03^{\star *} \\ \text { Reading } & 20.00 & 10.00 & 30 & -1.36 \\ { }^{* *} \mathrm{p}<.01 & & & & \end{array}$

Table 4 presents the means and standard deviations of the placement scores of twenty-five high school students who tested in both their junior and senior years. The essays and examinations of these students were selected from the total sample.

For each of the sections of the Cooperative Test, students' scores were higher in the junior year. ${ }^{9}$ The Essay Placement scores were higher in the senior year. Essay Forms A, C and E (1990) were used in the junior year. Forms A, B and E (1991) were used to test the students in the senior year. As Table 4 shows, there were significant differences between each of the sections of the COOP Test. The mean for effectiveness in the junior year is 12.87 compared to 10.20 for the senior year; for mechanics 19.43 compared to 15.00 ; for writing $32.30 \mathrm{com}$ pared to 25.20; for reading 15.50 compared to 11.47; and for the placement essay 6.15 compared to 6.69 . In the junior and senior years the scores on each of the three sections (effectiveness, mechanics and reading) of the Cooperative Test were significantly different at $\mathrm{p}<.01$.

Table 5 presents the results of the sample of 25 high school students (14 females and 11 males) who wrote essays in the 11th and 12th grades. The essays for the 25 students were analyzed to determine the number of words, sentences, and paragraphs and average words per sentence and paragraph and number of sentences per paragraph.

Significant differences were obtained for five of the aspects ana- 
lyzed of the essays of the eleventh and twelfth grades. Generally, the statistical results indicate that twelfth graders did better for words $[\mathrm{T}=5.01, \mathrm{p}<.05]$; for sentences $[\mathrm{T}=+3.64, \mathrm{p}<.001]$; for paragraphs $[\mathrm{T}=1.87, \mathrm{p}<.05]$; and for words per sentence $[\mathrm{T}=-1.81, \mathrm{p}<.05]$. The writing quality of students who wrote essays in response to culturereferenced topics differed markedly from those students who wrote on the other topics. The culture-referenced essays generated more ideas about the topic. They were longer (number of words and sentences). They contained more information and specific details relevant to the topic. Specific references were made and developed about the content. The culture-referenced essays were more focused, more organized and rated as better than essays produced in response to the non culture-referenced topics.

\section{Table 5: Selected Aspects of Essay Performance for High School Students who Tested in their Junior (Spring 1990) and Senior Years (Fall 1991)}

\begin{tabular}{lccr} 
Words & Mean & $\begin{array}{c}\text { Standard } \\
\text { Deviation }\end{array}$ & T value \\
\hline Grade 11 & 201.01 & 57.92 & $+5.01^{\star *}$ \\
$\begin{array}{c}\text { Grade 12 } \\
\text { Sentences }\end{array}$ & 275.54 & 86.23 & \\
\hline Grade 11 & 12.46 & 3.47 & $+3.64^{\star *}$ \\
$\begin{array}{c}\text { Grade 12 } \\
\text { Paragraphs }\end{array}$ & 16.32 & 5.63 & \\
Grade 11 & 3.34 & 1.51 & $+1.87^{*}$ \\
$\begin{array}{c}\text { Grade 12 } \\
\text { Words/Sentences }\end{array}$ & 3.64 & .95 & \\
$\begin{array}{c}\text { Grade 11 } \\
\text { Grade 12 }\end{array}$ & 16.14 & 4.02 & $+1.81^{*}$ \\
Words/Paragraphs & 17.12 & 3.04 & \\
Grade 11 & 75.64 & 45.41 & -.23 \\
$\begin{array}{c}\text { Grade 12 } \\
\text { Sentences/Paragraph }\end{array}$ & 74.10 & 21.60 & \\
$\begin{array}{c}\text { Grade 11 } \\
\text { Grade 12 }\end{array}$ & 4.81 & 2.91 & -1.12 \\
* p $\leq .05$ & 4.29 & 1.24 &
\end{tabular}

Table 6 presents the results of the analytical scoring of the stu- 
dents who wrote essays in the 11th and 12th grades. The essays for the 25 students were analyzed to determine the quality of writing, e.g. organization, syntax, vocabulary and grammar/ usage. This table shows the frequency of results of the essays which were analyzed using the modified Diederich scale.

\section{Table 6 Composite Analytical Scores of Writing Quality for High School Students Who Tested in Their Junior (Spring 1990) and Senior Years (Fall 1991)}

$\begin{array}{cccccc}\text { Quality } & \text { Low } & & \text { Middle } & \text { High } \\ \text { Ideas and Details } & 2 & 4 & 6 & 8 & 10 \\ \text { Grade 11 } & (0) & (3) & (18) & (3) & (1) \\ \text { Grade 12 } & (0) & (2) & (17) & (4) & (2) \\ \text { Organization } & 2 & 4 & 6 & 8 & 10 \\ \text { Grade 11 } & (0) & (3) & (17) & (4) & (1) \\ \text { Grade 12 } & (0) & (2) & (15) & (6) & (2) \\ \text { Syntax } & 2 & 4 & 6 & 8 & 10 \\ \text { Grade 11 } & (0) & (6) & (11) & (7) & (1) \\ \text { Grade 12 } & (0) & (3) & (14) & (7) & (1) \\ \text { Vocabulary } & 2 & 4 & 6 & 8 & 10 \\ \text { Grade 11 } & (0) & (5) & (16) & (3) & (1) \\ \text { Grade 12 } & (0) & (7) & (14) & (4) & (0) \\ \text { Style/tone } & 2 & 4 & 6 & 8 & 10 \\ \text { Grade 11 } & (0) & (4) & (16) & (4) & (1) \\ \text { Grade 12 } & (0) & (7) & (15) & (1) & (2) \\ \text { Grammar/usage } & 2 & 4 & 6 & 8 & 10 \\ \text { Grade 11 } & (0) & (6) & (14) & (4) & (1) \\ \text { Grade 12 } & (0) & (6) & (15) & (3) & (1) \\ \text { Spelling/mechanics } & 2 & 4 & 6 & 8 & 10 \\ \text { Grade 11 } & (0) & (3) & (18) & (3) & (1) \\ \text { Grade 12 } & (0) & (6) & (16) & (3) & (0)\end{array}$

\section{Discussion}

The current study revealed that more than two-thirds of the participating students chose to write on culture-referenced topics. The African American students who selected these topics wrote a greater number of sentences and words than those who selected other more standard topics. Generally, the culture-referenced topics seemed to facilitate increased fluency and topic development. Greater conceptual elaboration (development and fluency) occurred with culture-referenced topics. Compared to the standard topics, these topics elicited 
an increased number of ideas, ideas that appeared to come from the culture-based knowledge of the students. Therefore, the present results support the use of specific culture-referenced topics for African American students rather than the standard prompts and topics that are generally used in large-scale assessment and locally developed tests. Essay topics that are specific to a particular culture presumably do facilitate greater fluency, coherence, and clarity. It appears that culture-referenced prompts are effective in encouraging African American writers to include more culture-based knowledge of self and community.

However, the author recognizes that the topics used in the present study represent only a small number of African American culture-referenced topics/prompts. Future research might investigate the development of culture-referenced topics that examine the influence of experiential demand, a feature of topics described by Greenberg (1981) that signifies the kind of knowledge a writing task demands and ranges from personal experiences to facts and generalizations (outside knowledge, direct experience, and imagined experience). Research should also be conducted to determine the effects of culture-referenced topics that incorporate cognitive demands required by different writing tasks and different modes of discourse (e.g., narration, exposition, definition, and argumentation). Additionally, research needs to be conducted to determine whether African American culture-referenced prompts would also facilitate the writing of non African American students.

It must be recognized that the present research does have some limitations. First, questions remain concerning the use of culture-referenced topics to enhance African American writers' self-esteem and confidence in writing. In addition, the culture-referenced topics were derived from statements, quotations, or proverbs of African American culture. Further research might investigate students' attitudes toward different kinds of culture-referenced topics (content/demand) and students' preference, if any, for a particular topic type. We also need to determine which kind of topics are most effective in revealing African American writers' differing reading and writing ability levels.

\section{Implications}

The results of this study have led the researcher to make several suggestions relevant to teaching and assessment of the writing of African American students. It seems appropriate to recommend that teachers develop knowledge of African American students' (language) linguistic competency and linguistic environments so that they may plan activities to improve African American students' written language skills. Millward suggested that 
by working with the teachers, by providing students with specific feedback to their essays, by meeting with students to discuss their performance, and by providing the opportunity for revision, we not only send a clearer message about purpose and audience, but we enable students and teachers alike to participate in a pedagogical enterprise. (111)

Activities and strategies aimed at identifying cultural language influences need to be developed.

The purpose of this study was to examine the effects (if any) of culture-referenced essay topics on the writing quality of African American students. The results of the study may provide several implications for the training of raters, writing pedagogy, assessment and curriculum:

\section{Writing Pedagogy}

Culture-referenced prompts (reading and writing) should be used for developing ideas for writing in all situations and in each mode of discourse. The use of topics and texts by African Americans would connect students with a realistic and relevant writing prompt. Fox suggested that

writing teachers who recognize the urgent need to reconceive writing pedagogy can look to [African] American literacy theory for strategies of reading and interpreting African American student writing that are free from a narrow understanding of dialect interference, strategies free from the residue of deficit theories of language that still govern the reading of African American student writing, strategies that instead see African American literacy in social, economic, and historical contexts. (292)

Ladson-Billings suggested that "culturally relevant teaching requires the recognition of African American culture as an important strength upon which to construct the education of African American children" (314). She views this culturally-referenced teaching as "a pedagogy of opposition that recognizes and celebrates African and African American culture" (314)..

\section{Curriculum}

The incorporation of African American cultural materials in the writing/ English curricula would provide African American students a content knowledge that could facilitate critical thinking skills and 
enhance analytical thinking and writing among high school students. Through these cultural materials and through reading texts by African American writers, students would become more aware of the sociopolitical relationships among race, culture, and history, what Fox refers to as "positions." Fox advocates teaching "positions ... [that] present intersections between race and history and history, race and institutions, race and gender ... that would help writing teachers and their students map cultural and historical positions ... as a means of exploring the relationship between self, race, language and education" (292-296).

\section{Assessment}

It is widely recognized that the choice of topics and prompts is critical to the effective assessment and placement of students. We need to keep in mind the goal of large -scale assessments, and this goal should help determine the nature of the prompt or topics used in the testing. Knowing the consequentiality of pre-college testing, we need to provide prompts and topics that will elicit a fair and accurate assessment of students' abilities. When assessing African American students, we should keep in mind stylistic devices, syntactic, knowledge and organizational structures that may be linguistically and culturally specific for African American students. This research suggests that one way to improve the testing and placement of African American students is to incorporate culture-referenced prompts (reading and writing). Oliver tells us that "we need to investigate the ways in which African American students view various 'positions' when they are asked to produce writing samples for placement. Researchers need to examine the particular discourse features of African American students' written language to relate these features (if relevant) to cultural positions" (443). To do this, we need to examine whether discourse features as evidenced by African American student writers "have cultural implications [and implications for designing topics, prompts, teaching and assessment] ... [and whether African American] students have different ways of meaning, and if so, . . . [whether] these variations become evident in a linguistic analysis of their written compositions" (Eller 344). This study is intended as a springboard for future research into the implications of culture-referenced topics in large-scale testing and in curriculum development.

\section{Notes}

This study owes so much to the dedication and the research of Karen Greenberg; to the conversations (arguments) we shared even when she wasn't present; and to Lois Cronholm, the former Dean of 
the College of Arts and Sciences, who initiated collaborative projects between Temple University and the Philadelphia Public Schools.

1. Taylor and Lee described several possible sources of culturally based communication and language bias in standardized tests: (a) situational bias, (b) linguistic bias, (c) communicative style bias, (d) cognitive style bias, and (e) interpretation bias (68).

2. The study of language within the social context (i.e., the communicative (cultural) environment) led to the identification of variances in the manner in which information is imparted among and within cultural groups. The manner of imparting information is often referred to as communicative style. The communicative style used by an individual results from a combination of socially and culturally determined factors such as values, interactional rules and perceptions of events. Such differences of communicative style may interfere with the standardized testing process (Taylor and Lee, 71-72).

3 . The Whorf hypothesis suggested that languages not only report information but shape our perceptions of reality (linguistic relativity). Linguistic communities differ in their perceptual experiences of their environment. Language functions like a filter, thus molding our perception of reality. Whorf also suggested that language determines thought (linguistic determination).

4. Culturally determined differences within a language can occur at the levels of phonology, syntax, vocabulary, or referential context. The variables that account consistently and predictably for these differences include social status, age, sex, and ethnicity (cultural) and their possible interaction (Wolfram and Fasold).

5 . Cooper suggested that cultural and dialect differences affect the writing styles of African American writers in several different ways. Some stylistic features involve confused word choice, grammatical deviation, or incorrect word order. Others, culturally based stylistic aspects of writing, include extensive use of imagery in expository and argumentative writing.

6. It is important to note that none of the syntactic problems which have been suggested to appear in AAE appeared in the writing samples of these students' writings: (1) the redundancy or doubling of forms (2) incorrect adverb placement and (3) incorrect relative pronouns.

7. Most linguists acknowledge the "legitimacy" of African American English (AAE), Black English (BE), Black English Vernacular (BEV), Black English or Dialect (BED), as a correct, grammatical, normal model of communicating African American culture. For further discussion of the AAE or BEV influence on students' writing performance, see Fasold and Wolfram; Hartwell; Lipscomb; Morrow; Scott; Smitherman and Wright; Wilson; and Wolfram and Whiteman.

8. I gratefully acknowledge the support and assistance of Jim 
Degnan, Sally M. Frazee, Donna Cohn and the proctors from Temple University's Measurement and Research Center (MARC), without whom this study would not have been completed. Also thanks to the ELECT staff: Derrick Johnson, Mary McCoy, and Dorothy Eckler. Many thanks to the high school teachers who organized the project in their schools: Lynn Dixon, Verna Edwards, Margaret Klock, and Ernest Waugh. I thank them for their time and effort. A special thanks to Gloria Basmajian.

9. This result was not expected. We expected that writing quality and scores would improve between the eleventh and twelfth grades. Zeni and Thomas reported similar results. In their study, "the 12th graders' performance was slightly weaker in both years. This may reflect the special nature of the senior year - the omission of students who have completed their English requirements, and the inclusion of those whom must take one last course after repeated failures. The performance of 11th graders seems more representative of high school completion" (37).

\section{Works Cited}

Ball, Arnetha F. "Cultural Preference and the Expository Writing of African-American Adolescents." Written Communication 9 (1992): 501-532.

Brossell, Gordon. "Rhetorical Specification in Essay Examination Topics." College English 33 (1982):165-173.

Brossell, Gordon and Barbara Hoetker Ash. "An Experiment with the Wording of Essay Topics." College Composition and Communication 35 (1984): 423-425.

Brown, James Dean, Thomas Hilgers, and Joy Marsella. "Essay Prompts and Topics: Minimizing the Effect of Mean Differences." Written Communication 8 (1991): 533-556.

Brown, Jr., Roscoe C. "Testing Black Student Writers." Writing Assessment: Issues and Strategies. Eds. Karen L . Greenberg, Harvey S. Wiener and Richard A. Donovan. New York: Longman, 1986, 98108.

Carlson, Sybil B. "Cultural Differences in Writing and Reasoning Skills." Writing Across Languages and Cultures: Issues in Contrastive Rhetoric. Ed. Alan C. Purves. Newbury Park, CA: Sage, 1988, 227-260.

CCCC Committee on Assessment. "Writing Assessment: A Position Statement." College Composition and Communication 46.3 (1995): 430437.

Chaplin, Miriam. "Identifying the Writing Strategies Used by Black Students in NAEP and NJHSPT." The National Testing Network in Writing, Atlantic City, November, 1987. 
Conlan, Gertrude and Pamela Chambers. "Selecting the Best Essay Topic." The National Testing Network in Writing, Atlantic City, November, 1987.

Cooper, Grace C. "Black Stylistic Features in Student Compositions." The National Council of Teachers of English, New York, November, 1977.

Cunningham, Sylvia J. "Language as Culture: Writing from an African-American Perspective." Unpublished M.A. Thesis, Bowling Green State University, 1995.

Diederich, Paul B. Measuring Growth in English. Urbana, IL: National Council of Teachers of English, 1974.

Eller, Rebecca G. "Ways of Meaning: Exploring Cultural Differences in Students' Written Compositions." Linguistics and Education 1 (1989): 341-358.

Engelhard, Jr., George, Belita Gordon, and Stephen Gabrielson. "The Influences of Mode of Discourse, Experiential Demand, and Gender on the Quality of Student Writing." Research in the Teaching of English 26.3 (1992): 315-336.

Fowler, Robert J. "The Composing Process of Black Student Writers." Tapping Potential: English and Language Arts for the Black Learner. Ed. Charlotte K. Brooks. Urbana: NCTE, 1985,182-186.

Fox, Thomas. "Repositioning the Profession: Teaching Writing to African American Students." Journal of Advanced Composition 12.2 (1992): 291-303.

- - "Basic Writing as Cultural Conflict." Journal of Education 17.2 (1990): 65-83.

Gabrielson, Stephen, Belita Gordon, and George Engelhard, Jr. "The Effects of Task Choice on the Quality of Writing Obtained in a Statewide Assessment." Applied Measurement in Education 8 (1995): 273-90.

Geertz, Clifford. "The Way We Think: Towards an Ethnography of Modern Thought." Local Knowledge. Ed. Clifford Geertz. New York: Basic Books, 1983.

Greenberg, Karen L. "The Effects of Variation in Essay Questions on the Writing Performance of CUNY Freshmen." New York: City University of New York, Institutional Research Center, 1981.

- - . "Some Relationships Between Writing Assignments and Students Writing Performance." The Writing Instructor 2 (1982): 7-13

- - . "The Prompt on the CUNY Writing Skills Assessment Test: Theory and Praxis." New York: City University of New York, Instructional Resource Center, 1993.

Hartwell, Patrick. "Dialect Interference in Writing: A Critical Review." Research in the Teaching of English 14 (1980): 101-118.

Hoetker, James. "Essay Examination Topics and Student Writing." College Composition and Communication 33 (1982): 377-392. 
Hoetker, James and Gordon Brossell. "The Effects of Systematic Variations in Essay Topics on the Writing Performance of College Freshmen." College Composition and Communication 40 (1989): 414-421.

- - . "A Procedure for Writing Content-Fair Essay Examination Topics for Large-Scale Writing Assessments." College Composition and Communication 37 (1986): 328-335.

Hoover, Mary R. and Robert C. Politzer. "A Culturally Appropriate Composition Assessment: The Nairobi Method." Variations in Writing: Functional and Linguistic-Cultural Differences. Ed. Marcia Whiteman. Hillsdale, N.J.: Lawrence Erlbaum, 1982, 189196.

Horowitz, Daniel. "Essay Examination Prompts and the Teaching of Academic Writing." English for Specific Purposes 5 (1986): 197-220. Huot, Brian A. "The Literature of Direct Writing Assessment: Major Concerns and Prevailing Trends." Review of Educational Research 60 (1990): 232-263.

- - . "Toward a New Theory of Writing Assessment." College Composition and Communication 47 (1996): 549-560.

Keech, Catharine. "Topics for Assessing Writing Through Writing Samples." Bay Area Writing Project, School of Education, University of California, 1979.

Ladson-Billings, Gloria. "Reading Between the Lines and Beyond the Pages: A Culturally Relevant Approach to Literacy Teaching." Theory into Practice 31 (1992): 312-320.

Linn, Michael D. "Black Rhetorical Patterns and the Teaching of Composition." College Composition and Communication 26 (1978): 149153.

Lipscomb, Delores H. "Perspectives on Dialects in Black Students' Writing." Curriculum Review 17 (1978): 167-169.

Millward, Joy. "Placement and Pedagogy: UC Santa Barbara's Program." Journal of Basic Writing 9.2 (1990): 99-113.

Morrow, Daniel Hibbs. "Dialect Interference in Writing: Another Cultural View." Research in the Teaching of English 19 (1985): 154180.

Murphy, Sandra and Leo Ruth. "The Field-Testing of Writing Prompts Reconsidered." Validating Holistic Scoring for Writing Assessment: Theoretical and Empirical Foundations. Eds. M. Williamson and Brian Huot. Cresskill, NJ, 1993, 266-302.

Nobles, Wade W. "African Philosophy: Foundations for Black Psychology." Black Psychology. Ed. Reginald A. Jones. Berkeley, CA: Cobb and Henry Publishers, 1991, 47-63.

- - . Africanity and the Black Family: The Development of a Theoretical Model. Oakland: Black Family Institute Publications, 1985.

Norment, Nathaniel, Jr. "Discourse Features of African American Students' Writings." Journal of Black Studies 25.3 (1995): 558-576. 
- - . "Syntactic and Discourse Features of African American Students Writings: A Longitudinal Study." Conference on College Composition and Communication, Chicago, March 1990.

Oliver, Eileen I. "The Writing Quality of Seventh, Ninth, and Eleventh Grades, and College Freshmen: Does Rhetorical Specification in Writing Prompts Make a Difference?" Research in the Teaching of English 29.4 (1995): 422-450.

Park, Young Mok. "Academic and Ethnic Background as Factors Affecting Writing Performance." Writing Across Languages and Cultures: Issues in Contrastive Rhetoric. Ed. Alan C. Purves. Newbury Park, CA: Sage, 1988, 261-272.

Prater, Doris and William Padia. "Effects of Modes of Discourse on Writing Performance in Grades Four and Six." Research in the Teaching of English 17 (1983): 127-134.

Quellmalz, Edys S., Frank J. Capell, and Chin-Ping Chou. "Effects of Discourse and Response Mode on the Measurement of Writing Competence." Journal of Education Measurement 19 (1982): 241-258.

Ruth, Leo and Sandra Murphy. Designing Writing Tasks for the Assessment of Writing. Norwood, N.J.: Ablex Publishing Corp., 1988.

- - . "Designing Topics for Writing Assessments: Problems of Meaning." College Composition and Communication 35 (1984): 410-42.

Scott, Jerrie Cobb. The Influence of Spoken Language Patterns on the Writing of Black College Freshmen. Urbana, IL. National Council of Teachers of English, 1981.

Smith, William L., Glynda A. Hull, Robert E. Land, Jr., Michael T. Moore, Carolyn Ball, Donald E. Durham, Linda S. Hickey, and Constance W. Ruzich. "Some Effects of Varying the Structure of a Topic on College Students' Writing." Written Communication 2 (1985): 73-89.

Smitherman, Geneva and Sylvia Wright. "Black Student Writers, Storks, and Familiar Places: What Can We Learn from the National Assessment of Educational Progress?" The National Council of Teachers of English, Detroit, November, 1984.

Taylor, Orlando and Dorian Lee. "Standardized Tests and African American Children: Communication and Language Issues." Testing African American Students. Ed. Asa G. Hillard. Morristown, N.J.: Aaron Press, 1991, 67-80.

Taylor, Orlando and Karen Payne. "Culturally Valid Testing: A Proactive Approach." Topics in Language Disorders (3) (1983): 8-20. Vaughn-Cooke, Fay Anna. "Improving Language Assessment in Minority Children." ASHA 25 (1983): 29-34.

White, Edward. Teaching and Assessing Writing (2nd ed.). San Francisco: Jossey-Bass, 1994.

- -. "An Apologia for the Timed Impromptu Essay Test." College Composition and Communication 46 (1995): 30-45. 
Whorf, Benjamin L. Language, Thought and Reality. Cambridge, MA: MIT Press, 1956.

Williamson, Michael M. "The Worship of Efficiency: Untangling Theoretical and Practical Considerations in Writing Assessment." Assessing Writing 1 (1994): 147-74.

Wilson, Allison. "Black Dialect and the Freshman Writer." Journal of Basic Writing 4.1 (1985): 44-54.

Wolfram, Walter and Marcia Whiteman. The Role of Dialect Interference in Composition. Washington, DC: Center for Applied Linguistics, 1971.

Wolfram, Walter and Ralph W. Fasold, Jr. The Study of Social Dialects. Englewood Cliffs, NJ: Prentice-Hall, 1974.

Zeni, Jane and Joan Krater. "Suburban African-American Basic Writing: A Text Analysis." Journal of Basic Writing 9.2 (1990): 15-39.

\section{APPENDIX A: PHILADELPHIA HIGH SCHOOL PLACEMENT TOPICS}

HS-91-A-1

Directions: Below are three topics. Be sure to choose only one to write about. Read the topic carefully so that you understand exactly what it is asking you to do. Don't forget to write on every other line of the bluebook and to underline any word whose spelling you' re not sure is correct. You should write about $350-400$ words.

\section{FORM A}

1A Discuss whatever meaning the following quotation has for you: "No person is your friend who demands your silence, or denies your right to row."

\section{Alice Walker}

2A Discuss whatever meaning the following quotation has for you: "Not everything that is faced can be changed; but nothing can be changed until it is faced."

James Baldwin

3A In the "Declaration of Independence," Thomas Jefferson says that all individuals are entitled to "life, liberty, and the pursuit of happiness." Write an essay in which you argue that these rights are not absolute or guaranteed.

\section{$\underline{\text { FORM B }}$}

1B Some individuals believe that a college education should be a 
right like elementary school and high school. They argue that the government should pay college expenses for all citizens regardless of their ability to pay or their ability to do collegelevel work. Write an essay in which you present your position on this topic.

2B Discuss whatever meaning the following quotation has for you: "Only the educated are free."

\section{Epictetus}

3B Discuss whatever meaning the following quotation has for you: "Education is our passport to the future, for tomorrow belongs to the people who prepare for it today."

Malcolm X

\section{$\underline{\text { FORMC }}$}

1C To some people the Declaration of Independence still accurately reflects America's political philosophy and way of life; to others it does not. What is your position? Write an essay in which you discuss your analysis of the Declaration of Independence's contemporary relevance.

2C Discuss whatever meaning the following quotation has for you: "Act in such a way that your principle of action might safely be made a law for the entire world."

\section{Immanuel Kant}

3C Write an argumentative essay on the following topic:

"Chance has never yet satisfied the hope of a suffering people. Action, self-reliance, the vision of self and the future have been the only means by which the oppressed have seen and realized the light of their own freedom."

\section{Marcus Garvey}

\section{$\underline{\text { FORM D }}$}

1D Write an argumentative essay on the following topic: Should all high school students be required to take a course that discusses racial and cultural issues?

2D The following subject is the basis of sharp differences of opinions: Write an essay in which you argue the position you favor. You must make clear your point of view. You must provide sufficient support and details for your argument. 
"The current campaigns to eliminate drug problems are admirable, but greater social problems are now being ignored. The government should stop over-reacting to the drug problem and spend more money on child-care and education."

3D Discuss whatever meaning the following quotation has for you: "When you control a man's thinking you do not have to worry about his actions."

Carter G. Woodson

\section{$\underline{\text { FORM E }}$}

1E Write an argumentative essay on the following topic:

"Should writers, painters, musicians, poets, and rappers have their works censored for obscenities of nudity, profanity and defamation of the U.S. flag by local and state agencies?"

2E Discuss whatever meaning the following quotation has for you: "Injustice anywhere is a threat to justice everywhere."

Martin Luther King, Jr.

3E The following subject is the basis of sharp differences of opinions. Write an essay in which you argue the position you favor. You must make clear your point of view. You must provide sufficient support and details for your argument.

"Some states require that students pass a competency exam before they can graduate from high school. If students can't read and write at a certain minimum level, as measured by the test, they aren't allowed to graduate."

\section{APPENDIX B: TEMPLE UNIVERSITY'S PLACEMENT ESSAY SCORING CRITERIA}

\section{A Score of One}

These writers clearly lack the linguistic resources needed to translate speech into formal written language. They do not grasp the topic or the task. Essays are extremely short and read like an internal monologue; it is as if the writers were writing to themselves. They respond to the topic almost entirely in terms of extremely personal experience but do not formulate general ideas based on that experience. Consequently, no position or only the most vaguely defined position appears. Other than chronology, there is no discernible patterns of organization. Problems with grammar, punctuation, spelling, and vocabulary are so severe that readers find it impossible, at times, to arrive at the 
writers' intended meaning. Sentence structure is rudimentary.

\section{A Score of Two}

These writers still have difficulty translating speech into formal written language. At best, they address one aspect of the topic as it relates to the writers' personal experience. They are still unable to demonstrate that they can take a position on an issue. Organization remains rooted in chronology; general ideas, if present, are not clearly stated or supported. Grammar and usage problems, though generally less severe than in a one essay, are still wide-ranging and distracting, obscuring the writers' intentions. On the other hand, the extremely limited range of sentence patterns employed by some writers may conceal further difficulties with grammar, punctuation, and sentence construction.

\section{A Score of Three}

These writers demonstrate some awareness of what is needed to take and hold a position on a public issue, but lack the skill to perform the task adequately. Many fail to maintain a consistent position. Though they can, generally, achieve a public voice, some remain inappropriately personal: the language may be inappropriately conversational, with lapses in internal organization, or confusing jumps in time, space, and logic that obscure relationships between ideas and illustrations, reason and support. Supporting ideas remain implicit and vague when they should be stated explicitly; OR the obvious is stated unnecessarily. These writers' limited vocabulary is not adequate to the requirements of a position paper. Common words are used incorrectly; necessary words or letters sometimes omitted. Punctuation errors obscure sentence boundaries. These essays generally reveal recurrent sentence-structure problems; if there are only occasional problems, this fact may be due to the limited range of sentence patterns employed.

\section{A Score of Four}

These writers demonstrate minimal competence in addressing an issue and holding a position. Positions are taken and supported plausibly, writers using a clear, if formulaic, structure that allows readers to follow the paper's reasoning. Development of ideas remains superficial, their connections tenuous. Writers generally avoid taking controversial stands or exploring the implications of their ideas. Though these writers do demonstrate a "public" voice, they often fail to address the specified audience realistically, a failure that results in the superficiality described above. With respect to the conventions of grammar, spelling, and mechanics, fours are relatively fluent. Readers are not frequently distracted by major errors. Those that do appear are errors common to usage handbooks rather than idiosyncratic to 
the writers. Vocabulary is usually appropriate, though writers occasionally run into difficulty by selecting words, which are inappropriately or ineffectively used. Some essays lapse into slang or colloquialisms, though writers usually indicate the switch.

\section{A Score of Five}

In addressing an issue and taking a position, these writers demonstrate a degree of fluency over and above minimal competence. These writers are more clearly in command, both with respect to their material and to the strategies employed for communicating it. Organization develops from the topic and from the writers' intentions, not from an artificially imposed formula. These writers are willing to undertake complex development or adopt controversial stands, to explore implications and to recognize other points of view. They respond more realistically to their readers' needs for information and to their possible objections. These essays reflect a reliable knowledge of conventions in writing. Errors that do occur seem to result from the haste of writers attempting a more complex - and often longer-essays with a limited time.

\section{A Score of Six}

Unlike essays scored five, these writers' performances are marked by a fluency which suggests mastery in writing. These writers are, without a doubt, in command and demonstrate assurance in their choice of rhetorical strategies. These essays show a well-developed sense of perspective. Positions taken are carefully qualified, and reasons given, as well as the support for those reasons, are thoughtful, resulting in complex, crafted development. The reader has a clear sense of being addressed realistically, and that readers' reactions are, to a degree, anticipated by the writer. Few errors in spelling, grammar, or mechanics appear. The reader is almost never distracted by them.

\section{APPENDIX C: EXAMPLES OF STUDENTS' COMPOSITIONS}

\section{H.S. 01: Female: Holistic Score_ 6 Coop Score $\_2$}

Discuss whatever meaning the following quotation has for you: "Not everything that is faced can be changed; but nothing can he changed until it is faced."

James Baldwin

This quote means a variety of things to me, it brings out the more 
personal aspects of my life. I know about facing things and trying to change them. Topics of my life which I've tried to cope with, from School to Family to coping with deaths.

If a person is born in my neighborhood, this person is taught to be educated and street wise from day one. This is because of the problems he will undoubtedly face when he grows into a young adult. There is the problem of drug selling and drug abuse. There is always a want and need for this problem to be erased from the face of the Earth. What you have to realize is that if no one recognizes the problem and if everyone just turns their back on it, it will never be solved. People of today have to face their problems, this is the first step to overcoming them. It is true that you may not get rid of it, but you'll feel an inner warmth knowing that you have at least contributed to the destruction of it.

We may also look at this quote in a more positive view. Picture this, a young woman striving to be on top. She wants to enroll in college, Temple maybe. There may be a fear inside of her, a fear of entering the real world and getting started on her own. She will no longer be under mama's protective wings. If this girl looks at all the opportunities she will have, then maybe she can over come her fears. If she analyzes her feelings and thinks of her future then maybe she'll feel more secure. Sure she'll have that unbearable longing to go home and to be nurtured, she may not be able to change that. If she faces her problems then she has a great chance of solving them. She couldn't have solved her problem if she didn't realize it first.

Also this quote can be related to family problems and other teen related problems. A Death in the family, an unwanted pregnancy, or even drug abuse. This may bring sorrow and depression to victims of these sorrowful burdens. I feel that a person has to look at these things as exactly what they are, problems. They need to be solved or coped with. Every problem cant be changed automatically, but it can be worked out if it is brought to attention and if it isn't ran away from. A Death can be coped with if a family sticks together and mourns together. Teen pregnancies can be coped with in three different ways, adoption, abortion, or raising it yourself. Drug abuse can be coped with by going to a rehabilitation center. All these things can be worked out if you face them (which is the first step) and if you make the effort to change them.

\section{H.S. 04: Male: Holistic Score_6 : Coop Score_ 39}

Discuss whatever meaning the following quotation has for you: "Education is our passport to the future, for tomorrow belongs to the people who prepare for it today."

Malcolm X 
The passage by Malcolm X, "Education is our passport to the future, for tomorrow belongs to the people who prepare for it today," is a verbal expression for his beliefs and my beliefs also. Malcolm X is a man of great deeds. He tries to get his point across to the youth and elders. Malcolm X never descriminated. No matter what your race or color was, he believed that we would all unite. Malcolm X believe we should all move as one. To do this we must abide by the rules set by our society such as: great morals and knowledge of who you are.

Malcolm X preached great morals to our young, black youth. He believed that a man with a good heart would endeavor and achieve good things in life. To do so he taught, not to kill one another and also to respect each other. When Malcolm X was alive there were many racial tension in the community. People did not respect one another. The worst kind of crime that was done, and still done today, was black on black crime. This meant that the black race was killing the black race. We will never succeed this way. The black race would soon be demolished. "We should come together and unite first as a race then as one." Malcolm X believed and taught just that. To unite as one, we must be given an opportunity. We can give ourselves this opportunity through knowledge.

Knowledge is the key to life. Without knowledge and awareness of who you are you will not overcome the difficulties in life. Malcolm $\mathrm{X}$ has taught the African-Americans to be proud of who they are, for there is nothing to be ashamed of. If everyone (would become) proud of their own race and color, and also respect others, we will have prepared for the future. A good education can eduate you with any human being upon this earth. Various subjects such as math, English, and history are very important for math is some what similar to life: We must know how to analyze certain problem in life. English is need to communicate with the world: History is need to learn about the past and succeed in the future.

People who believe these thing will not have problems. Malcolm $\mathrm{X}$ spreaded this message to everyone. He has lived an died for the liberation of our land.

\section{H.S. 04: Female: Holistic Score_6}

Write an argumentative essay on the following topic: "Chance has never yet satisfied the hope of a suffering people. Action, self-reliance the vision of self and the future have been the only means by which the oppressed have seen and realized the light of their own freedom."

Marcus Garvey

Marcus Garvey, believed that, blacks are oppressed, and have long suffered. But have a chance, if we as people and a whole, would 
come together, and builded, so we can became reconcizable, to this country and to others "To get back Respect." Something blacks have yet to received, He believed going, but to Africa, and building our own again.

Change is only the beginning, of liberty and justice. A change, and a chance to build, self help, self respect. We as a people have to realized, that even though we had been deprogram, on every ability, and every self culture, such as our hair, our clothes, our songs. And even though we have been treated, and cheated out of every self thought one could learn about, themselves, their family members (dencended). Marcus Garvey gave the black people a self vision about ourselves and some would say. That's beening selfish because there are whites that want to learn about us. But whites fail to realized that this ours. Our, culture and heritage are the only thing we as black people have left. And me and my people are going to hold on and believe that if we reprogram ourselves and give ourselves back the our original names, our clothing, songs, and dance even our worshipped.

Yes Marcus Garvey tried to put us on our shippes and send us back but even then they were not satisfied with. If we left then who would buy your products and builded your only the oppressed so you stopped that, and cont_look at as an say. Their okay. And not asked, but told to take care of your children, your home, and plantation. And after that, just cut loose, and not no than you or even, a welcome. Would have been greatly appreciated, respect. When the other one does, not recognized, another one reality.

And the reality, is that we just want our own. And not just taking about. Those things that material listic, America is offering. But that "glow," of understanding, when it was okay to put your "woman" up on the peddle stool and show her off to world. And not to be ashamed to be "Black" or your children to be black. Because some one does not, understand, that, this how are born. And we should love each other, and help each other to grow. With the understanding, that, my culture is your. And respect that. This is the realzitation of one's freedom. Marcus Garvey write in one of his, brillant speeches "Rise Up You Mighty Race" 


\title{
Lynn Briggs and Ann Watts Pailliotet
}

\section{A STORY ABOUT GRAMMAR AND POWER}

\begin{abstract}
There is little research about how pre-service teachers write about grammar and understand conventionality. Understanding pre-service teachers' beliefs about grammar and conventionality through studying the way they write about it is important since their beliefs as pre-service teachers will likely influence the kind of teachers they become. Examination of samples of 50 pre-service teachers' written discourse about grammar and conventionality revealed that they had largely negative attitudes toward zuriters who made conventional errors. However, rather than considering this simply as an issue of rhetoric or even pedagogy, this article proposes that such attitudes are reflective of academic power dynamics.
\end{abstract}

\section{Discovering the Grammar Dynamic}

Ann Berthoff told a story about a faculty member who was asked by her dean to "stop what she's been doing ... and instead ... teach to a multiple choice grammar test" (5). This exercise of power by the dean over the material that the faculty member chose to teach is an example of how grammar can be used to exercise power over people of lower status. If the faculty member chose to acquiesce to the dean's request and focus on the exam, attending seriously to every error her students made, she would have used grammar to exercise power at another level. Because so much of the English curriculum for those students labeled "basic writers" involves grammar instruction, the way that academics use grammar to exercise power is of special importance to basic writers. We'd like to share a tale that will illustrate how grammar can be used as a tool of oppression, even by those who should know better.

Lynn Craigue Briggs and Ann Watts Pailliotet were azvarded the Citation for Excellence in Teaching by Conference on College Composition and Communication in 1994 for their work zvith an interpretive schema called "deep viezving." Lymn Briggs is the Director of the Writers' Center, Associate Director of Composition, and Assistant Professor of English at Eastern Washington University in Cheney, Washington. Much of her scholarship revolves around response to zuriters. She is co-editing a volume on zoriting center narratives, and is the author of a Writing Lab Newsletter article on the use of narrative as a response technique. Ann Watts Pailliotet is Assistant Professor of Education at Wittman College in Walla Walla Washington. She is the past zinner of the National Reading Conference Graduate Student Research Award for her investigation into pre-service perspectives on literacy. She has zuritten articles about pre-service beliefs for The Teacher Educator, English Education, National Reading Conference Yearbook, and the International Visual Literacy Association Yearbook She has recently authored a book chapter for Our Own Recognizance: Students and Teachers Creating Knowledge, edited by Shirley Steinburg and Joseph Kinchloe (forthcoming from Routledge, Spring 1998). 


\section{Lynn's Story}

It was almost an aside, the news that, as part of my duties in my new job as Assistant Professor and Writing Center Director, I would give the required departmental grammar exam. I was handed a dogeared ditto master of a mass-produced multiple choice grammar test. At this point, the meeting about my responsibilities was adjourned.

A day or two later I got up the courage to ask the chair, "How about a portfolio instead?" "No," was the reply, "it must be taken at a single sitting. It must be spontaneous." Apparently more powerful people had been complaining. "They" had been horrified when our students (pre-service teachers) had made errors in notes to parents or while writing on the board. The department needed a cover-its-tail exam. I got to provide the fig leaves.

I was opposed to the idea of a grammar exam. The messages it sent about what was valued and how competence could be detected were at odds with everything I believed about writing. The exam suggested that it was appropriate to deal with grammar in a decontextualized manner. I believed in the importance of context. But I was also boxed in by the professional and economic power my director, chair, and dean had over me. Surely I'd have bigger battles ahead. $I^{\prime} \mathrm{d}$ better pick my fights.

Although I lost round one, I was determined to win round two and create a new exam, one that was at least a little more ecologically valid than the one I had been handed. I worked on it constantly, unpaid, in the summer prior to starting my employment. I developed an exam that, despite being an exam, might send some more useful and complex messages about conventionality to the students. The exam had two major components: error identification in passages of text, and essay commentary on those passages. For the error identification components, students had to cite 122 errors in ten separate passages. There were five essay questions, and four of the questions involved essays for which the errors served as data for discussion. In the essays, students were asked to (a) describe patterns of errors; (b) prioritize errors; (c) take on the role of a teacher writing to a student about errors in a passage of text; or (d) give a rationale for using and teaching conventional written English. My hope was that the structure of the exam would communicate some of what I valued in teaching conventionality. For example, by asking students to identify patterns of errors, I hoped to plant the seeds that writers made errors in intelligible and intelligent patterns. By asking students to prioritize errors, I hoped to suggest that not all errors were equal in importance.

After I had spent the summer composing the exam, I met Ann, who had been assigned as my graduate assistant. She agreed with my perspectives on writing. We both emphasized content and context in 
our teaching and response to writers. We got along famously from the start. However, my complicity in using grammar as a tool of power had begun. I foisted much of the responsibility for the logistics of the exam on Ann. The cycle of using grammar to reinforce existing power structures had continued.

The exam was arduous for students. They said it was the first time they had seen anything like it, although the directions (sans error-ridden passages) were available up to three months in advance. The penalty for not passing the exam was high and imposed by the Education Department. Students were not allowed into the program, or, if their parents or advisers complained loudly enough, they were allowed to enroll in the program but would receive an incomplete in Language Arts methods (the course I taught) if they didn't pass the exam by the time their first semester in the program was completed.

The exercise of power had moved to another level. Much as our administrators had forced the exam on us, as it had been forced on them by public school placement officials, we forced it on the students. As our administrators were intransigent with us, we became so with the students. We were often less than sympathetic with explanations for failure or excuses for not taking the exam.

But our lack of charity did not go unpunished, for the exams were torturous to score. The handwritten essays, often in pencil, were physically difficult to read. The corrections on the dittoed passages were often challenging to interpret. Counting pages of passages used for error-identification as well as student essays, each exam was 15 pages long. Because students' academic lives depended on their scores, we were careful with each exam. It was hard and tedious work. The whole process made us cranky and resentful. We didn't enjoy the exam or believe in its purpose. Our only hope, it seemed, was to learn something from it. We hoped that whatever we discovered would either validate our experience with this exam or provide us with persuasive data for why an exam should be disposed of altogether. We decided to look closely at the language in the student essays to discern preservice teacher beliefs about grammar. We discovered that our students followed our lead and used grammar as a way to wield power over those of lesser status. We believe that this is an important and frightening discovery since our students were training to be teachers.

\section{Review of the Literature}

In preparation for our examination of the way that our student informants wrote about grammar, we reviewed literature on response to writers. In our search we discovered that when given the opportunity to respond to anything in students' texts, most teachers (71\% for 
Applebee, about 75\% for Anson) chose "surface features" (Anson 344). These studies indicated that teachers often chose error as the focus of their commentary. Given this, understanding the way that people who planned to be teachers wrote about errors seemed important. Our study differed significantly from these studies since our informants were required to respond only to error.

In order to understand what motivated our students to respond to error in particular ways, we looked at the scholarship on pre-service teacher belief systems. Such belief systems (and the values behind them) are considered to be the root of teaching behavior. Pajares says that beliefs develop from myriad elements including emotions, imagined alternatives to reality, prior knowledge, and application of information (309). Ross describes beliefs as "theories of action" and "practical theories of teaching" that are usually unconscious in student teachers' minds and implicit in their practices (19-31). Scholars like Bullough and Kottkamp differentiate beliefs from knowledge by saying that beliefs are unconscious and largely unexamined while knowledge is conscious and can be examined. We hoped that by reading student essays we could discern some of our students' beliefs about teaching writing and writers.

An examination of discourse patterns can also reveal the beliefs of a writer. For example, use of pronouns like "I," "we," or "you" can indicate where a writer places responsibility. The repetition of a word can indicate what a writer deems important. Such examinations of discourse patterns are becoming more common. A large group of researchers has attempted to identify student teachers' knowledge and beliefs through an analysis of the language they use (e. g. Freeman; Goodman; Nespor and Barslyke; Protherough and Atkinson; and Van Sledright and Putnam). Marilyn Cochran-Smith noted how student teachers detailed their practices, while Kagan and Tippins explored how student teachers described their problem-solving strategies. Manning and Payne considered student teachers' perceptions of past experiences. Christensen examined how student teachers talk with their supervisors. In addition, our interest in what pre-service teachers wrote as a clue to their beliefs is consistent with other current research. "Recent efforts by teacher educators and researchers... have focused attention on student teacher (and teacher...) discourse patterns... as a means to understand their sense-making experiences as educators" (Van Sledright and Putnam 117). Therefore, we decided to examine discourse patterns in our students' essays to better understand beliefs.

While there is substantial research on pre-service teachers' beliefs, and significant research on the language used by teachers, there is no research on language choices in the grammar-focused writing of pre-service teachers. Such research is important to the field because it could contribute to an understanding of how future teachers envision 
convention. Studying convention is useful and important. It would be hard to isolate another single area of composition that can stir up controversy so quickly. Because of convention's polarizing effects, a study of the way pre-service teachers approach convention might provide some understanding of pre-service teachers' initial perspectives on convention's role in composing. We believe that pre-service teachers' beliefs about conventionality are connected to their beliefs about language, literacy, and learning. Furthermore, pre-service teachers' beliefs will influence the kind of teachers they become (Britzman). We also think that pre-service teachers' approaches to conventionality provide insights into their view of power relationships.

\section{Methods}

The informants in this study were 50 pre-service Elementary/ Inclusive Education majors at a large, private university. Informants were completing academic minors in many disciplines including history, English, anthropology, and sociology. These students had not taken any education methods courses at the time they served as informants. Nearly all of the informants had taken the same two required university writing courses. The informants were generally 18-22 year old white women, mostly from the eastern United States, $80 \%$ in their sophomore year, $20 \%$ in their first semester of graduate study. These demographic characteristics reflect many traits shared by most teacher candidate populations in the U.S. (Brookehart and Freeman; Su).

The informants were expected to pass the three-hour exam as one of the required tasks for entrance into the program. The exam was designed to determine their competency in identifying and responding to conventional error. It also sought to assess their ability to write conventionally in a time-pressured situation. Data were collected over a one-year period. Fifty informants wrote five essays per exam. These 250 essays, which ranged in length from one handwritten paragraph to one page, formed the core of our data. However, an additional 200 essays, written by a portion of these same students on subsequent attempts to pass the exam, served to verify and extend our initial findings.

The informants were asked both to identify errors in passages on the exam and to write essays about the errors in those passages. See Appendix 1 for the exam questions.

Descriptions of the types of questions on the exam, as well criteria for evaluation, were available to the informants at the time they signed up for one of the four exam dates scheduled each semester. The student informants could sign up for the exam (and thus receive the description of the tasks) as early as three months prior to taking it. 
We both gave directions and fielded questions for each of the eight exam sessions. We also provided informants with logistical information about receiving scores. We gave numerous oral and written reminders about what to focus on in the exam. For example, we talked about how we might prioritize various kinds of errors, we used the pronoun "I" to frame our responses, and favored words like "explain," "respond," "lack of conventionality," or "patterns of error" instead of verbs like "correct," "grade," or "fix." We also asked informants not to respond to "style," but only to note error. We also modeled responses which demonstrated a variety of possible approaches to sections of the exam. Informants were able to ask us questions at any time.

\section{Analysis}

Once we collected the nearly two-foot high stack of exams, we began our analysis. We employed Bogdan and Biklen's constant comparative analysis on the written language in informants' essays from the exam. Our procedures included reading, categorizing, charting, discussing, and revising the emerging patterns and themes we found in the data. We analyzed data guided by the following questions: (a) What were the repeated words and word combinations within and between informants' responses? (b) How did the phrasing and structure of the responses position the informants and hypothetical students? Did the informants sound as if they were writing as friends, parents, peers, or authorities?

For our initial reading we divided the exams between the two of us. We each read $75 \%$ of the total, with $50 \%$ of all texts read by both of us. We began by reading the first attempts of the 50 students and moved on to later attempts by initially unsuccessful students only after we had discovered patterns and themes. In our tabulations of patterns and themes, we independently assigned similar descriptors $85 \%$ of the time. In our analysis we focused on these felicitous overlaps.

\section{Findings}

The phrases and tone of our informants' responses were consistently hierarchical, monologic, and even haughty. They wrote as if they viewed errors as deeply rooted in individuals, and as if they themselves were the ones with the answers the writers needed, but expressed few doubts about their own abilities or knowledge. They expressed many doubts about the abilities and knowledge of the writer. Sometimes this doubt bordered on scorn. 


\section{Phrasing}

Phrasing patterns in our informants' responses to error suggested some of their beliefs about conventionality. We noted several repeated words, among them "problem," "needs," and "tendency." None of these were words that we used in the exam. The term "problem" was used freely and frequently in nearly every exam text. It was used to indicate major issues as well as minor ones. Here is a sampling of the informant responses (the names "Chris," "Pat," and "Terry" refer to the hypothetical writers of the passages on the exam): "One of Chris' main problems seemed to be forgetting a period at the end of the sentence. ... He also had a few problems concerning capitalization. ..." Another passage firmly located the "problem" in the writer: "The problems Chris had were mainly starting and ending sentences. He also had problems writing commas where he shouldn't have." The next two passages imply that the writer has a problem by virtue of the aspects of writing that are identified as problematic: "A pattern of your writing I noted that is problematic is identifying when to capitalize and when not to. Another problem is ending sentences with the proper punctuation." Still another informant said: "The main problem here is improper use of punctuation. ... Problems make it extremely difficult to grasp the meaning of the text."

These "problems" were usually framed as something that the writer had - not something that the reader had. The "problem" was usually considered to be universal, rather than situation-specific. Only occasionally was the "problem" confined to "this passage" or "in this section."

"Problem" is related to another repeated word, "tendency." The informants stated that the writer might have a "tendency" to use sentence fragments, or a "tendency" to use contractions incorrectly. Here is a sample of what our informants said: "Terry has a tendency not to be fully explicit with his information." The next passage also locates the "tendency" in the writer: "Pat has a tendency to do things. ..." The notion of "tendency" was also used as a verb: "Chris tends to leave out periods. ..." Chris also had another tendency: "He tends to run things together."

The use of such words indicated the assumptive nature of our informants' responses. We were struck by how these pre-service teachers repeatedly focused on how a writer had "tendencies" and "problems." Rarely was there a "problem" with the text or the reader. Our informants seemed to assign blame to the writer for "problems." They also used the words "need" or "needs" to warn the writer not to go astray in the future. Such reference to "problems" might be evidence of a "particular schema [i.e. 'problem solving']" which our informants 
"perhaps acquired as pupils" (Florio-Ruane 1-2).

"Needs," as in "Chris needs to use commas less frequently," or "Terry needs to learn that you have to use quotes when someone is speaking" was also a word we saw much of. Informants said things like this: "This paper is a jumble. Terry needs to gain some 'reader empathy' --i.e., he needs to put himself in the place of the reader. ..." Sometimes the comments were addressed directly to the "needy": "You need to freshen up on the proper use of apostrophes to show possession...." Another indicated that caution was needed: "You need to be more cautious as to where you put your commas...."

Reference to "needs" made correcting and avoiding errors seem urgent - it sounded like a requisite for survival. This repeated reference also rarely offered actual examples or procedural advice. Instead "needs" was a veiled warning about the necessity of change without instruction for how to change. Writing from a position in which one identifies someone else's problems, needs, and tendencies indicates a sense of superior power. Our informants apparently envisioned themselves as more powerful than Pat, Terry, or Chris.

In the essays we also found frequent allusions to "work." Frequently work was mentioned in phrases like "If you work hard, you will be able to solve these problems," or, "you need to work on apostrophes." In all of these instances work was a good thing, the path to virtue and a conventional, error-free existence. It was also often something urgent, something that was "needed." There were never any admonitions not to work too hard, or to remember that writing shouldn't be all work and no play. Instead, work was the answer, the solution to writers' "problems." Again, explicit examples of the kind of work "needed" to solve "problems" was rarely offered.

\section{Tone}

There seemed to be a surprisingly negative tenor to most of our informants' responses. While we were not surprised that the informants found and commented on error (the task mandated it), we noted the consistency of the negative approaches. Many passages seemed harsh or haughty in tone, as in the following examples: "Be more consistent with your use of contractions. Sometimes you used them in your text and other times you did not. If you are not sure, do not use them at all." (Informant emphasis.) Sometimes relatively minor issues seemed to have great importance: "If (paragraphs) are not indented, there will be one big mess with no order or form." And this informant seemed to want to communicate her boredom: "The author should watch out for monotonous repetition of an idea or repetition of examples." 
"Do not," "big mess," and "monotonous repetition" are comments that place the blame on the writer. Other comments bordered on rudeness or made personal attacks on the writer: "You are making very basic errors. I am tempted to believe they are due to inattentiveness." In the next passage, the informant implies that the writer's thought processes are less than ideal: "Think carefully before you choose a word just because you need one."

These responses carried within them an assumption that the writer was somehow purposely making errors. Many informants seemed angry with the writers. For example, one informant said: "Your paper's ... main flaw was in the area of run-on sentences. The most severe of which was the fact that most of your article ended with a comma and it should have stopped. It got very tiresome to read."

We wondered where this consistently negative tone came from, but it wasn't only the repeated words that surprised us. We also noted absence of certain words. Missing from our informants' essays were words teachers commonly use to create images of movement and collective participation, like the pronoun "we," and "give," "show," "share," "extend," "move," "convey," "growth," or "build." Instead, informants often used words which connoted isolation, confinement, and lack of movement or exchange. The informants often repeated terms like "still," "base" or "basis," "structure," "organization," "stuck," and "foundation." Authors were advised to "slow down," and to "stop" (to "think," "plan," or "be more careful"). Words like "flow" and "fluidity" were mentioned only as negatives or in the context of conditional rhetoric, like "this section doesn't flow," or, "it would flow better if you..." We never encountered positive references to learning or growth. As we read these essays, we puzzled about the common tone in them. Although the individuals who had written them came from diverse disciplines, most seemed to speak with a common voice. Was this the way they thought teachers of writing should sound?

\section{Discussion}

We were surprised by these dominant, negative patterns in phrasing and tone in our informants' writing. We found them notable in several ways. Our findings were often dissonant with our assumptions. We believed that an examination of those expectations and a comparison of them to the findings would illuminate the beliefs of preservice teachers about responding to conventional error.

We assumed that the rhetoric our informants chose would reflect the rhetoric of the exam. The language of the exam was process focused. We used the words "error" and "conventionality" to empha- 
size that what was represented were minor mistakes in a social code. In addition, the exam asked for role playing (both explicitly in question \#4 and implicitly by designating writers as "Pat," "Terry," and "Chris"). Finally, the passages that we chose to put the errors into were interesting and often humorous. Because of the process language and the invitation to role play, we anticipated the language of reflection and speculation in informants' essays. We thought they would use words like "why" to reflect and "wonder" to speculate, but those kind of words were not present.

We also expected diverse perspectives among the essays. We figured that informants' language would reflect various degrees of commitment to the process approach to teaching writing. Our findings challenged these assumptions.

First, we assumed we would find process-oriented language. We traced our assumptions both to the language of the exam and to our sense of the educational systems in which these students received instruction. The exam's format came out a Shaughnessy-esque tradition which treated error not as something which occurred because of laziness, stupidity, or bad intention, but as something that happens because of a flawed set of internalized rules. The exam, in the language it used and in the tasks it required, tapped into this tradition. For example, the exam used the term "conventional errors" to describe what the informants needed to locate, correct, or respond to. We didn't use descriptors like "grammar mistakes" or "problems." Nor did we instruct informants to find anything "wrong" or even "incorrect" in the passages on the exam.

Bartholomae suggested that rhetorical choices are indicative of a writer's sense of norms in a discourse community. He described how writers, when entering a new discourse community, seek to appropriate, but are often appropriated by the discourse. We believe that the norms of the discourse community are related to the paradigmatic beliefs held in that community. Over a decade and a half ago Maxine Hairston hailed the change in the discourse of composition, describing the shift from the current-traditional to the new paradigm in writing instruction. However, the repeated words and images that we found in the texts did not seem to reflect the values of the new paradigm, with its emphasis on process, recursiveness, productive chaos, and cooperation. Our informants' repeated words and phrases seemed instead to reflect the values of the current-traditional paradigm like product, linearity, and neatness.

The exam was purposefully devoid of any descriptions of error that connoted a moral or intellectual deficit. In addition, the tasks on the exam emphasized the cognitive (not psychological or pathological) aspects of error. Included among the tasks were (a) a request to look for patterns of error across passages written by a single writer, (b) 
a question asking for the prioritizing of error, and (c) an inquiry into rationale for teaching conventional English at all. These rather process-focused words (like "respond" or "explain") and requests (like "find patterns" or "prioritize errors") dominated the rhetoric of the exam. We expected this to be reflected in the responses.

The language of the exam was not the only reason we expected the rhetoric of process to emerge. It seemed logical to us that our informants would reflect the process-oriented approaches of their previous teachers. Nearly all of the 50 informants had taken two writing courses in the university's writing program. These courses used the rhetoric and methods of process and post-process approaches. Because we knew the perspective of the courses our informants had taken, we expected that our informants' academic background would lead them to use words and phrases which reflected their experience as students in process/post-process classrooms. That was not the case.

The repetition of "problems," "needs," and "tendencies" indicated that informants viewed writers who made errors as people who had something wrong with them. A writer with "problems" assumedly always had those problems - they were simply dormant when she was not writing. This approach seemed at odds with the values of process and post-process teaching, approaches which emphasized a more positive view of writers, and the situatedness of each composition site, respectively. Instead, the personalized, moralizing language used by our informants seemed bent on pointing out and focusing on enduring absences.

We don't think that it is stretching the point to suggest that writers who are conditioned to believe that they are people with problems, needs, and tendencies become less powerful writers. Writers who are taught that they have deficits are unlikely to take risks in their writing. Writers who don't take risks are less likely to challenge the status quo in print. Convincing writers of their enduring inadequacies can silence them.

In addition to those words present in abundance, we noted that those we expected to find in teaching discourse, but did not. The absences we noticed included words connoting community, flexibility, and growth. These were words we associated with the process/post process approaches which privilege development, context, personal empowerment, and voice. Our informants' discourse also echoed the current-traditional paradigm in the words they avoided.

\section{Interpretations}

We were smug when we looked at what we found in our informants' essays. They were so haughty and arrogant. Our informants 
had so much to learn, and we had so much to teach them. We would have the chance, too, in Language Arts Methods. We looked glibly forward to that. We bemoaned the fact that despite how much the academy had done for them (presenting them with an enlightened exam and providing composition classes that were taught from an enlightened perspective), they still failed to "get it." Clearly, these were problematic students, with tendencies to judge, who needed redirection.

We then turned our disdain on their teachers. Our informants had to learn these types of response somewhere, and since they had been engaged in an apprenticeship of observation for 13 or 14 years, their responses must echo their teachers' responses (Lortie). We lamented the existence of those uninformed and dangerous teachers who churned out bloodied texts, who scorned their students, who abused the power vested in them by the institution.

Whoa! Wasn't that what we were doing? Weren't we using our higher status on the academic food chain to wield the grammar exam? And wasn't the severity of our wielding, and our eventual belief that the exam gave us important information about these students, the same kind of exercise of power that our administrators used with us?

Ironically, or perhaps fittingly, we were alerted to this by folks who are higher on the academic food chain than we were. Senior colleagues who were readers of earlier drafts of this document reacted against our solicitousness toward the students. They also picked up on our insincerity when we considered this largely a rhetorical issue. But it is not simply rhetorical; it is systemic and political. English and other types of education reinforce hierarchy; they emphasize status in and out of the classroom. Our informants showed us that they were very good students of the educational system. Although the language of the exam was different, the students read the subtext: Grammar can be used to make you more powerful.

Attributing our informants' approach to their teachers was probably right. But upon reflection, who can blame teachers for grabbing power wherever they can? In a system that doesn't even allow high school teachers the same opportunities to use the bathroom as students, who can fault teachers for asserting their power with the red pen?

There is much to be resisted here, and much that seems irresistible. While many teachers have, no doubt, conditioned themselves to move away from picayune and petty responses to grammar errors (we thought we had!) we doubt that it is merely a matter of "education" to change this trend. We did not circle repeated errors on the exam, we didn't write snotty notes in the margin, but we did use grammar to gain power, and we did so because it had been used to assert power over us. While thinking of it in this way seems more sensible to us, it seems depressingly large. 
We believe that teachers and teacher educators can help break the cycle of using grammar as a thumbscrew by ceasing to be scornful in response to error. Instead, teachers can be charitable and helpful. Teacher educators can help pre-service teachers learn to respond in this way through modeling, various ungraded writing assignments, peer response, and journaling in varied formats (Pailliotet).

We both know teachers who are charitable and provide useful comments about grammar to their students. Charitability can be as easy as inserting the letter " $\mathrm{I}$ " into a comment. We have seen students become more consistently conventional when they received comments about errors that are owned by their teachers. Even words like "problems," "needs," and "tendencies" can be transformed with the word "I." Comments like: "I had a problem following this section because of where commas were placed," and "I'm a reader who needs all the punctuation to be correct in order to understand a point," or "When I read I have a tendency to get distracted from the meaning by errors," can be seen as charitable by student writers. In addition, these kinds of comments can also be helpful, for they provide writers with information about how their writing has been read. Writing goals, metaanalyses, conferences, writing teams, fishbowling, and dialog journals further contribute to procedural understanding.

These owned comments can be even more useful when combined with information about conventions. Teachers can help students change their patterns of error by focusing on one or two errors in a paper. We've seen students learn quickly once they realize that their beliefs about usage are unconventional. For example, a student who routinely puts periods and commas outside of quotation marks can easily change that pattern with a little bit of information. We think that a useful response to that error (which our informants made often) might look like this:

I noticed that most of the commas and periods in quotations are placed outside of the quotation marks. Actually, they go inside. I can understand how you might get confused since semicolons and colons go outside. I have a strategy to remember the conventional way, though. I think of commas and periods as the "meat" in a sandwich with the quotation marks as the bread. I picture this "." and "," to help me remember.

A comment like this could help a writer change that error pattern forever. If teachers only attend to one or two error patterns per paper, it doesn't take much longer to respond in this way than it does to circle every error and write "You have a problem with quotations" in the margin. 
Using conventional English is indeed important. Writers need to know that errors can cause them to lose credibility with readers. But writing in school should be designed to help writers learn rather than to produce pretty prose. Attention to convention in writing instruction should keep the role of grammar in perspective. We think an analogy is useful. Conventionality is like a tie for a man at the door of a four-star restaurant: He can't get in without wearing a necktie, but he can't get in wearing only a tie, either. If teachers choose to sacrifice students' motivation and morale in order to discourage unconventionality, they may end up with students clad only in ties.

Instead, we recommend helping students learn conventional patterns while they develop as writers. We suggest this be done by attending to conventionality only briefly, charitably, and after issues of content, focus, and organization are considered. We believe this will help all student writers gain admittance to the four-star restaurant.

\section{Epilogue}

Nearly all of our informants eventually became students in Language Arts Methods. In that class we tried to practice response methods that seemed charitable and useful. After informants discovered they could learn about conventionality from such responses, we helped them learn how to respond similarly to their own students.

While we were reasonably pleased with our informants-turnedstudents' change in response to conventional error by the end of the course, we do not believe that rhetorical changes get to the root of what made them - and us - use grammar as a way to wield power over those of lesser status. As long as teachers are considered to be next to the bottom of the academic food chain, the impulse to feel more powerful by being scornful to those below them will be present. A real change in the way that teachers exercise power will occur when there is a change in the way that power is exercised over them.

\section{APPENDIX 1}

1. Correct the errors in these passages. (Three paragraph-length passages were adapted from popular magazines to include a total of $44 \mathrm{er}$ rors.)

2. Identify the errors in the passages written by hypothetical writers Terry, Pat, and Chris. Next, write a description of the patterns of errors that you noted for each passage. Please be conventional in your own writing. (Each passage was 1 double-spaced typewritten page 
long. Each passage was taken from a popular magazine like Allure or Consumer Reports, and attributed to either Pat, Terry, or Chris. The errors were planted in the passages according to patterns. Pat's 18 errors were with commas, apostrophes, and homophones. Terry's 15 errors were with quotation marks and titles. Chris's 29 errors were with capitalization and end punctuation.)

3. Identify the errors in this passage and write a note directed to the student writer of this passage which prioritizes the errors that you have noted. Include a rationale for why you considered some errors to be more important than others. (A passage from a magazine included 18 different types of errors that we planted.)

4. Write a brief statement about why you think it is important to use and teach conventional written English. Be sure to be conventional yourself in this essay. (Space was provided for the students to write an essay by hand on the exam sheet.)

\section{Works Cited}

Applebee, Arthur. Writing in the Secondary Schools: English and the Content Areas. Urbana: NCTE, 1981.

Anson, Chris. "Response Styles and Ways of Knowing." Writing and Response. Ed. Chris Anson. Urbana: NCTE, 1989.

Bartholomae, David. "Inventing the University." When a Writer Can't Write. Ed. Mike Rose. New York: Guilford, 1985.

Berthoff, Ann. "What Works? How Do We Know?" Journal of Basic Writing 12.2 (1993): 3-17.

Bogdan, Robert C., and Sari Knopp Biklen. Qualitative Research for Education. 2nd ed. Boston: Allyn and Bacon, 1982.

Brookehart, Sarah, and Donald Freeman. "Characteristics of Entering Teacher Candidates." Review of Educational Research 62.1 (1992): 37-60.

Britzman, Deborah. Practice Makes Practice: A Critical Study of Learning and Teaching. Albany, NY: SUNY P, 1991.

Bullough, Robert, Jr. "Exploring Personal Teaching Metaphors in Preservice Teacher Education." Journal of Teacher Education 42.1 (1990): 43-51.

Christensen, Patricia. "The Nature of Feedback Student Teachers Receive in Post-Observation Conferences with the University Supervisor: A Comparison with O'Neals' Study of Cooperating Teacher Feedback." Teaching and Teacher Education 4 (1988): 275-86. 
Cochran-Smith, Marilyn. "Reinventing Student Teaching." Journal of Teacher Education 42.2 (1991): 104-18.

Florio-Ruane, Susan. Personal Correspondence. March 9, 1993.

Freeman, Donald. "To Make the Tacit Explicit: Teacher Education, Emerging Discourse, and the Conceptions of Teaching." Teaching and Teacher Education 7 (1991): 439-54.

Goodman, John. "Constructing a Practical Philosophy of Teaching: A Study of Pre-service Teachers' Professional Perspectives." Teaching and Teacher Education 4 (1988): 121-37.

Hairston, Maxine. "The Winds of Change: Thomas Kuhn and the Teaching of Writing." College Composition and Communication 33 (1982): 76-88.

Kagan, Donna, and Deborah Tippins. "How Student Teachers Describe their Pupils." Teaching and Teacher Education 7 (1991): 455-66.

Kottkamp, Robert. "Means for Facilitating Reflection." Education in Urban Society 22.2 (1990): 182-203.

Lortie, Dan. C. School Teacher: A Sociological Study. Chicago: U of Chicago P, 1975.

Manning, Brenda H., and Beverly D. Payne. "A Correlational Study of Pre-service Teachers' Reported Self-Talk Reactions to Teaching Dilemmas." Teacher Education Quarterly 19.2 (1992): 85-95.

Nespor, Jan, and Judith Barylske. "Narrative Discourse and Teacher Knowledge." American Educational Research Journal 28 (1991): 80523.

Pajares, M. Frank. "Teachers' Beliefs and Educational Research: Cleaning up a Messy Construct." Review of Educational Research 62 (1992): 307-32.

Pailliotet, Ann Watts. "Personal Stories or Plastic Sheets: Pre-service Teachers' Perspectives on Journals and Portfolios." National Reading Conference Yearbook. Ed. Charles Kinzer, Donald Lev, Kathleen Hinchman, (forthcoming) 1998.

Protherough, Robert, and Judith Atkinson. "How English Teachers See English Teaching." Research in the Teaching of English 26 (1992): 385-407.

Ross, E. W. "Critical Constructivism and the Use of Knowledge about Teaching." Teacher Education Quarterly 19.2 (1992): 19-31.

Shaughnessy, Mina. Errors and Expectations: A Guide for Teachers of Basic Writing. New York: Oxford University Press, 1977.

Su, Justine, Z.X. "The Study of the Education of Educators: A Profile of Teacher Education Students." Journal of Research and Development in Education 26.3 (1993): 125-32.

Van Sledright, Bruce A., and J. Putnam. "Thought Processes of Student Teachers." Teaching and Teacher Education 7 (1991): 115-18. 


\section{TOWARDS A CONSCIOUSNESS OF LANGUAGE: A LANGUAGE PEDAGOGY FOR MULTI- CULTURAL CLASSROOMS}

ABSTRACT: Despite their complex language histories, writers from diverse cultural backgrounds often tend to believe that language's primary function is to convey information. This essay describes a language pedagogy which can help basic writers to understand language's potential to shape, not just to convey information about, social experience. Students from diverse backgrounds can then more effectively critique the relationships of language's uses in a variety of social contexts.

With the publication in 1974 of Students' Right to Their Own Language, composition scholars have acknowledged, even celebrated, their students' multiple languages, dialects, and complex language histories. But acknowledging students' rights to their own language does not mean that teachers still don't expect them to accommodate to the dominant uses of written language within the university. Susan Miller argues that the primary function of required writing courses since the earliest years of the modern university has been to teach students from less privileged social classes to accommodate to the norms of university speech and writing. The continuing use of basic writing courses as minority students' pathways into a more uniform language use has been debated afresh in the 1990s, and as one result, the profession is more aware of the issues involved for students when we unreflectively teach them to assimilate to dominant discourses. We are now far more conscious that learning standard English includes repositioning oneself in relation to community and heritage: adopting different styles also involves negotiating different senses of self. In particular, scholars' literacy narratives dramatize how accommodating to new ways with words can require substantial psychological and social dislocation for writers (Brodkey; Gilyard; Lu; Shen; Sommers).

For the last four years, I have been considering these issues in the

Mary Soliday is an assistant professor of English at the City College of New York. She has published essys in edited collections and in College English, College Composition and Communication, and The Writing Center Journal. With Barbara Gleason, she is writing a book about the project described in this essay. 
context of co-directing, with Barbara Gleason, a pilot project at the City College of New York (CCNY). The Enrichment Approach to Language and Literacy, sponsored in part by the Fund for the Improvement of Post-Secondary Education, mainstreamed basic writers with freshmen students into a two-semester, college-level writing course. Between 1993-96, over 900 students enrolled in these year-long courses, which also featured classroom tutors, faculty development, and program evaluation. Barbara Gleason and I have described this pilot project and its evaluation elsewhere (Soliday \& Gleason). Here, I want to describe the curriculum and a language research project I developed during the two years I taught these courses. I will emphasize that one way to approach students' cultural differences is to focus on students' language use in social contexts. But I want to suggest that, before most students can critique the relationship between their own and dominant languages, they have to move towards a consciousness of language's potential to shape, not just to convey information about, social experience.

The Enrichment Approach "curriculum" might better be called "curriculums," since it evolved throughout three years, and since the twenty-eight professors who taught in the project imagined their courses differently. Still, at the project's conclusion we identified three common emphases. One was that teachers emphasized the descriptive study of language in one or more assignments, usually in the first semester. The second was that approaches to research began in the fall semester with ethnographic study in settings familiar to students and concluded with more traditional library research in the spring. The third emphasis was a developmental consideration of students' growth as writers over nine months. Along with portfolio evaluation, this developmental emphasis meant that most teachers also sequenced assignments across several weeks. For example, teachers usually conceived their research projects as a series of shorter assignments that sequenced different skills across time and that culminated in essays ranging from ten to twenty pages.

The student population at $\mathrm{CCNY}$ is among the most multicultura1 in the country, so that our urban classrooms reflect a high degree of difference in terms of spoken language: English as a Second (or third or fourth) Language, "border" languages, and nonstandard dialects of English. Within one classroom, up to sixteen different languages could be represented. Thus, one of the places we started with this curriculum was to gather more specific information about students' language histories. We surveyed students to ascertain what languages they and their families speak and which languages they can read and write as well as speak. We also asked teachers to assign literacy narratives in the first semester, and this became, by the teachers' vote, a mandatory feature of the curriculum. The literacy narrative assignment paral- 
leled other language research assignments that teachers developed in which students described language in the multiple settings of work, church, home, school, street, or neighborhood. Some teachers assigned literacy narratives by writers from Gloria Anzaldúa to Malcolm X and asked students to reflect upon issues of language, culture, and identity. Others asked their students to analyze the differences between their spoken and written language. One class wrote poems in their first languages and/or English dialects, translated them into standard English, and then wrote about the translation process. Another professor's students constructed "language code books," guides for speakers new to the student's language. These assignments allowed students to narrate their language biographies and sometimes ambivalent relationships to the academy; they also gave teachers a fuller view of their students' linguistic backgrounds.

By emphasizing the descriptive study of language as a framework which enriches rather than replaces more traditional, prescriptive views of language, we hoped that our curriculum could draw upon the language expertise that students already possess as speakers in their own communities. As Eleanor Kutz, Suzy Groden, and Vivian Zamel write,

Seeing only what the entering students don't know, colleges have created a variety of "Learning Centers," "Resource Centers," "Writing Centers," "Developmental Studies Programs," and "Reading and Study Skills Courses" as isolated enterprises that disconnect the study of these linguistic practices both from the community that uses them and from the knowledge and competence students bring from other communities. Such efforts reflect a lack of understanding about how an individual is drawn into a community and into its conversations, as an active participant. (6)

Kutz and her colleagues establish a sociolinguistic framework which focuses upon the nature of language acquisition and the ways in which speakers acquire new competencies. These scholars begin by acknowledging students' competence as language users in everyday life and then develop inquiry-based assignments which help to keep the students' languages and those privileged by the academy in rich, active dialogue. Thus, their curriculum rejects the writing course as a simple means of accommodating different languages to dominant discourses.

One potential of the dialogue that Kutz and her associates describe is a critique of the relationship between dominant and subordinate languages in our society. If, as Richard Courage argues, we "bring literacy research into the classroom," we may then "develop a critique of the rigid demarcation of public and private spheres of life and lan- 
guage and a narrow definition of public life" (494). But this critique does not flow naturally out of assignments focusing upon students' language histories. Over the years in our faculty workshops, several teachers commented that, while students narrated their language and/ or literacy histories in detail, they had difficulty situating their own stories within a broader cultural context. The assignment itself did not necessarily provoke critique of the relationship between students' private and public languages.

After reflecting on this problem, I decided to embed the literacy narrative within a broader language project focusing on heightening students' awareness of language's social and cultural uses. I began with the sociolinguistic commonplace that speech is no more natural than writing because, like written texts, speech is embedded in a rich social context. "[L]earning to use written language," write Marcia Farr and Harvey Daniels, "shares a common language base with learning to use oral language; consequently, the teaching of literacy must be founded, among other things, on a substantial understanding of the nature of human language" (42). For the fall semester, I decided to base the curriculum on increasing students' understanding of the nature of human language.

One principle of human language use as it is has been studied by anthropologists is that the ability to analyze, so privileged in expository writing classes, is not exclusively connected to or caused by the written uses of language: the interpretive use of language cuts across cultures and across the orality/literacy divide (Finnegan). From this perspective, literacy does not cause analytical thinking. Instead, it may be a speaker's awareness of language's multiple possibilities that promotes that person's ability to speak critically about an event from a distance. Such possibilities would include the use of language to convey information, but also its ironic and metaphorical dimensions. This ironic possibility, the awareness that language can say more than is literally said, may be a precondition for achieving literacy rather than a direct consequence of learning to read and write. Robert Pattison speculates that it is this awareness of the disjunctions between reality and language that underlie the development of literacy. "Reading and writing may be parts of literacy but do not constitute the whole," Pattison argues: "Consciousness of the uses and problems of language is the foundation of literacy" $(7,6)$. Pattison's definition of literacy does not exclude mastery of the conventional features of learning to write college prose, since to be fully literate in any society means exhibiting control over a set of conventions. But Pattison argues that what precedes this control is a "literate attitude" towards language use, either spoken or written. A heightened awareness of "the perception of the original discontinuity between language and events and the attempt to resolve it are early stages of literacy" (10). 
My goal in the first semester of this year-long course was to foster students' literate awareness of the uses and problems of language within their everyday social experience. Our common ground is language's use and value within our daily lives. I assumed that students could study their own language use from an academic perspective, bringing what they already knew into dialogue with different ways of knowing. But rather than begin by focusing on the possible friction between their language and mine, I wanted to emphasize how even the most mundane language can mean more than it appears to say. Thus, I suggested to the students that the language of everyday life is saturated with subtextual meanings: what we actually say in casual talk is never the whole story. In fact, the interesting story may be what speakers mean when they talk and not what they actually say.

I developed a Language Research Project, divided into seven separate assignments. I sequenced these across the second half of the first semester of the course, though assignments four and five were ongoing:

(1) A language narrative in which the student described his or her history as a language user and membership within a language group.

(2) A description of a language group. This paper focused upon what people looked like, how they dressed and behaved, where they gathered, what their environment felt and looked like, and so forth.

(3) A set of language samples used by the members of the language group (these could include written texts, such as song lyrics). Students had to keep a field notebook with dated entries and bring this to class.

(4) Summaries of the chapters in Peter Trudgill's Sociolinguistics.

(5) An assessment of each assignment, usually completed in class.

(6) An analysis draft which focused on interpreting the language samples. This draft was followed by conferences with teacher and tutor.

(7) A final research paper which incorporated the most significant parts of these assignments and that reflected revision over a period of time. Manuscript preparation was stressed in this typed, final draft.

In addition to reading the Trudgill book, we watched Yeah, You 
Right, a documentary about New Orleans dialects, and listened to presentations by graduate students who had completed thesis projects on the subjects of gay men's language in New York City and Brooklynese in Sheepshead Bay. I created handouts about language use for the students such as a summary of the features of Black English Vernacular as Geneva Smitherman describes them. We also discussed two ethnographic projects focusing on language use in a restaurant and a laundromat, written by students from another teacher's class.

The first essay in the Language Research Project, a literacy narrative begun in class, acted as a heuristic for reflecting informally upon language attitudes and histories and for identifying a language group for further research. The next assignment, a descriptive draft about their chosen language group, required students to practice observing details and notetaking and then using vivid/specific language when turning notes into a draft. I asked students to focus on behavior, dress, and physical settings, emphasizing the traditional goal of showing rather than telling about a group of people for an outside audience. In the third assignment, a set of language samples, students had to develop ways to gather and begin to organize their samples, which they would eventually analyze. When they gathered these samples, students practiced basic research skills, including developing ways to study their language groups--surveying, interviewing, and observing individuals over a period of time and recording what happened in a notebook.

Throughout this portion of the project, we also discussed some of the concepts in Trudgill's book and students completed summaries of individual chapters. In addition, I gave students weekly self-assessments which asked them to answer questions such as "what will a reader learn from your paper about language use," or "what have you discovered about language and/or behavior so far that is new or interesting to you." These early assessments revealed that the challenges were those typical to doing research: some students had trouble settling on a particular group; others resisted the painstaking process of notetaking and tried to commit conversations to memory; and several had difficulty understanding how the individual assignments would culminate in a single product. These assessments also revealed that students were surprised to discover their own language habits, especially their own and their peers' use of slang.

As students completed the third assignment, I xeroxed individual language samples for the class. We discussed a dialogue which took place on a basketball court and two interviews about attitudes towards dialects conducted in Chinese and Caribbean neighborhoods. Here I emphasized that students could "read" their samples in the same way they would read literary texts because an interview with a Chinese-American businessman reflecting on the uses of correct En- 
glish is not necessarily any more self-sufficient than the figurative language of a poem: all represent stretches of language that can be interpreted. In preparation for the next assignment, the analysis draft, I emphasized that language is not just a literal instrument: we could not communicate effectively if we didn't mean more than we say. Within the academy, interpreting the language of written texts explicitly is a prized activity. Throughout these discussions, I also used the samples to show students the conventions of introducing and incorporating quotations into the syntax of their prose, commenting on samples, and connecting a general statement to a specific sample.

The sixth assignment asked students to develop a thesis that interpreted their language samples through connected, fully developed paragraphs. As students' drafts began to emerge, I duplicated these for discussion of how writers were interpreting, and could further expand their interpretation of, their samples. In the seventh and final assignment, students transformed the analysis draft into the final research paper, often by incorporating the descriptive draft into their introduction and then developing their analysis drafts further for the body of the finished research paper. With this assignment, I emphasized manuscript preparation, blocking long quotations, and proofreading.

At the end of this project, most students completed all the assignments and wrote ten to fifteen-page research papers, excluding the pages they had already generated earlier. By turning common language into formal texts, every student practiced the close reading of language that they will be expected to perform in required literature courses at $\mathrm{CCNY}$. Some students were also able to interpret their findings through the concepts Trudgill establishes in his book. And, despite the differences in achievement, all the students had the opportunity to examine issues of language and cultural difference and to reflect upon their own language use while simultaneously acquiring the conventions of college essay writing.

This project highlighted a range of attitude and self-awareness towards language that my students possess. Some of the students revealed negative and contradictory attitudes towards their own language use. During class discussions, this group condemned nonschool talk; several claimed that they didn't use slang or speak Spanglish, and many doubted that subcultural uses of language could have social or political purposes. Language, they thought, conveys information, and they resisted Trudgill's or my desire to attribute meaning and purpose to a functional instrument. Other students, however, embraced the idea that nonschool uses of language are complex and rule-governed, and these students were particularly interested to learn that a subcultural use of language such as slang could express countercultural resistance and potentially act as a critique of main- 
stream languages.

Below, I've summarized the students' findings from one class, which provide a glimpse into their nonschool linguistic experiences:

(1) Different language groups develop code languages in order to survive within mainstream cultures. In this way, bilingual speakers are able to preserve their cultural heritage. Immigrant families in New York City develop "border" languages in their new country to succeed in business, for example. Border languages include Spanglish, mixtures of French Creole and English, Cantonese and English, and "Bangrage," or Bengali and English. A student who conducted research in a bodega found that the owner, from Bangladesh, sprinkled his daily talk with phrases from Cantonese, English, and Spanish in order to enhance his business. The student concluded that a good deal of language learning and creative use of language occurs outside schools. One student studied the profanity used by women in a homeless shelter, and concluded that their harsh speech was "the language of a mask," or a defense against difficult circumstances. Another studied "the language of necessity" in a restaurant, concluding that servers developed a code that helped them to cope with stressful, unrewarding jobs.

(2) Several students investigated Peter Trudgill's summary of research which finds that women tend to speak more correctly than men. Most concluded that teenage girls speak more circumspectly than boys, although others argued that this depended upon the particular group being studied and the audience that the girls had when speaking.

(3) Street slang is pervasive, and many of the students were surprised to learn how unconsciously they and their peers use it in their everyday lives. Several analyzed their transcripts to see how street language fosters a particular kind of urban identity inflected by popular culture; others found that slang unifies different ethnic groups in the same way that "border" languages do.

(4) Language use by individuals and families isn't monolithic and depends heavily upon situation. One student followed his girlfriend for a day and found that she switched languages three times. At home, she spoke Haitian Creole with her father; with her boyfriend, she spoke English; with her girlfriends, she switched into an amalgam of Creole and English peppered with an aggressive street slang he had never heard her use. What especially surprised him was that neither she nor he had ever noticed this code switching. 
(5) Family, peers, and community members profess strong opinions about language use; sometimes attitudes are conflicted and inconsistent, as in the case of Spanish speakers who condemn Spanglish and believe they don't use it but actually do in casual conversation. Although attitudes and use are complicated, speakers do not recognize this complexity.

The students who found the assignment particularly satisfying were those who affirmed the value of language use in familiar nonschool settings and explored the premise that language does more than convey information. Thus, for instance, the author of "The Language of a Mask" experienced a sea change in her thinking about the "rough talk" of the single mothers she lived with in a homeless shelter. At first, this student expressed dismay over the women's profanity and their aggressive postures, and she ascribed their speech to a lack of ambition and education. But as this student analyzed the women's conversations, she began to develop the thesis that their hostile speech masked the loneliness and struggle of their everyday lives. The women had developed a way of speaking that helped them to negotiate within their social worlds and that meant more than it appeared to say on the surface.

Here are two excerpts from final drafts about Spanglish and street slang, which, along with rap music and gender differences, are usually the most popular topics in my classes. In the first excerpt, the student returned to her high school in East Harlem, where she studied students' language use and bilingual teachers' attitudes towards Spanglish, the language which reflects, she asserts, "a dual cultural identity." In the early part of her paper, she identifies two uses of Spanglish, using several samples to illustrate two patterns--one where speakers mix the languages, and another where speakers speak for longer stretches in either language. The student writes,

Almost all the Hispanic students [in the high school I studied] speak their native language as well as English. Most of the time, when they are communicating they use both languages combined or mixed, and make use of what we call Spanglish:

1st speaker: "Hello," [student's name] Como estas? [Hello! How are you?]

2nd speaker: "Fine," y tu? [Fine, and you?]

1st speaker: Ahi, Como se dio el "party" anoche? Me dijeron que se dio "nice." [So-so, how was the party last night? People told me it was nice] 
2nd speaker: Ese "party" se dio "heavy." [That party was heavy, meaning great]

In this example, notice how [the first speaker] mixed the languages; instead of using "hola" she used "hello." And then [the second speaker] said "fine" meaning "bien." [The first speaker continued using English words: "party" and "nice" instead of "fiesta" and "bueno," and [the second speaker]: "heavy" instead of "pesado." This is the epitome of Spanglish and the most common use of Spanglish among bilingual speakers.

In the second excerpt, a student investigated the different ways in which men and women in a mixed African-American and Latino neighborhood in the South Bronx use slang according to situations defined by the speaker's status, gender, and behavioral codes, especially the non-verbal. After describing how a young man uses language to communicate respectfully to an elderly woman, the student turns to consider what happens when males feel they are "dissed":

Another side to this situation [described in the previous paragraph] is when Hispanics feel that they are being disrespected. Sometimes this happens when another Hispanic looks "dead" at them. Dead meaning looking straight into someone's eyes in a mean way. This totally changes their tone and vocabulary:

Hispanic male: What the fuck you looking at?

2nd male: An ugly-ass nigger.

Hispanic male: Fuck you, bitch.

2nd male: What you said?

Hispanic male: You heard me, bitch.

In this sample, the importance of respect for Hispanics is displayed. Hispanic teenagers are very much into the receiving of respect. Their attitude of respect is that to give respect, respect must first be received. When disrespect and not respect is given, disrespect is returned in the form of anger. The result of their anger is the language of taboo. 
These novice writers have accommodated to the demands of conventional academic essay writing. Each attempts to use writerly cues to involve their unknown readers in the process of reading ("In this sample, notice how"; "Another side to this situation"). Both structure their paragraphs conventionally to present the context for each sample and their interpretation of a pattern they discovered from a welter of data. Both practice the close reading of text in order to arrive at a generalization ("This is the epitome of Spanglish"; "The result ... is the language of taboo"), and both are aware of the coherence between their paragraphs.

Equally important, these students practiced academic writing and thinking in the context of reflecting upon and scrutinizing language use in their everyday lives. The first writer categorized different kinds of Spanglish and related them to the complex cultural identity of Latino immigrants in New York City. The second writer attempted to show how speakers in the South Bronx shifted codes according to situation, which included gender, age, and nonverbal cues. In this way, both students move between their ways with words and those of the composition classroom. And both writers affirm the value of subordinate languages by acknowledging that each plays a social purpose within a subcultural group: neither writer views Spanglish or English slang as the random linguistic activity of uneducated speakers.

The Language Research Project increased these students' awareness that language is not just a functional instrument. A functional attitude towards language is also common among students from white, middle-class homes. But for my students, reflecting upon the nature of language involves a more complex reflection upon self and relationships to different groups or communities. It is vital that this sort of reflection occur, partly because, to succeed within the academy, students have to contend with the fact that language is not literal or self-sufficient.

For many of my basic writing students, the struggle to interpret a passage from Pride and Prejudice (a required text in one of their literature courses) involves a struggle with an aspect of language use that is ordinary but appears to them to be extraordinary. Through discussions with students about their projects, I grew to see that they resent professors who expect them to dig for "hidden" meaning in texts. From this perspective, Austen's novel appears to say what it says, and to expect otherwise goes against the grain of how language seems to work in everyday life. It is language itself, rather than just the academic text, that is self-sufficiently meaningful for many basic writing students.

My overarching goal for language research projects, then, is to lay the groundwork for an alternative rhetoric for reading and writing that challenges students to consider how speech in everyday life--as Austen's dialogues so often foreground--never just says what it ap- 
pears to say: a deep structure of social gesture, implicit cues, context, and possible interpretation governs even the most mundane conversations. My students believe that nonliteral or "hidden" meaning resides solely in canonical texts and in aesthetic language. I believe that a writing class can help them to see that language's suggestiveness is a feature of human communication that they have already achieved some competence with and that is foregrounded, not exclusively possessed, by literary language.

This emphasis upon the sociolinguistic nature of language is also significant for my students because it provides them with a foundation for reflecting upon their own language in relationship to the language of mainstream institutions. Given the increasing diversity of our classrooms, helping students to think about language as language can also help them to articulate possible language conflicts. As Patrick Bruch and Richard Marback point out, the 1974 Students' Right to Their Own Language rests in part on a concept of linguistic competence that is both liberating and limiting. It is limiting, they argue, if, in affirming our students' communicative competence, we merely re-establish a traditional framework of liberal pluralism where students are invited to master more than one language and then choose to use the one suitable to a particular social occasion. We need to examine a traditional linguistic concept of competence more critically so that students can understand that not all competencies are valued equally. This would mean, for example, that the language of taboo my student describes, using a discussion from Trudgill's book, could be further analyzed in relationship to its linguistic other, polite institutional talk. From a critical perspective, profanity is not just a competence that some speakers have achieved: it is also a potential critique of or resistance towards mainstream uses of English.

Although this critical impulse is implicit in the Language Research Project, in revising this project for future courses, I intend to add a final assignment which explicitly asks students to reflect more completely on the relationships between the language use they studied and language use in mainstream domains such as school. I am also working to integrate matters of style into this curriculum in order to help new students develop a richer sense of personal voice within the daunting framework of writing a long research paper. I have found that CCNY students in advanced writing classes can situate themselves in complicated ways in relation to mainstream values and languages, possibly because, over time and through multiple writing situations, they have become far more aware of the uses and problems posed by the English language. As important, because these advanced writers are in the process of developing idiosyncratic voices that they can employ within the context of academic writing, they are also more intellectually able to examine the relationship between style and cultural 
value.

The different ways in which advanced and novice writers locate themselves in relation to mainstream uses of language are, in part, developmental. This developmental emphasis helps us to see that the goal of critique is one that should unfold over time as new students gain a surer sense of themselves as college students and, as one consequence, a richer sense of language's possibilities as they read and write throughout different disciplines. In the first-year course, my primary goal is to ask my students to become researchers of their own language use and through this research to move beyond familiar, functional attitudes toward language. I hope that the result of their research is the growth of a literate attitude towards language. This literate attitude is one way for students to begin to consider their own relationship to dominant ways of speaking and writing. Ideally, at the beginning of students' sojourn through CCNY, I hope to bring different languages and their implicit values into a productive dialogue--a dialogue based upon students', and my own, increasing consciousness of language's power to shape as well as to reflect our experience.

\section{Works Cited}

Brodkey, Linda. "Writing on the Bias." College English 56 (1994): 527-47. Bruch, Patrick and Richard Marback. "Race Identity, Writing, and the Politics of Dignity: Reinvigorating the Ethics of Students' Right to Their Own Language." JAC: Journal of Composition Theory. 17.2 (1997): 267-281.

Courage, Richard. "The Interaction of Public and Private Literacies." CCC 44 (Dec. 1993): 484-496.

Farr, Marcia and Harvey Daniels. Language Diversity and Writing Instruction. Urbana, IL: ERIC Clearinghouse, 1986.

Finnegan, Ruth. Literacy and Orality: Studies in the Technology of Communication. London: Basil Blackwell, 1988.

Gilyard, Keith. Voices of the Self: A Study of Language Competence. Detroit, MI: Wayne State UP, 1991.

Kutz, Eleanor, Suzy Q. Groden, and Vivian Zamel. The Discovery of Competence: Teaching and Learning with Diverse Student Writers. Portsmouth, NH: Boynton/Cook, 1993.

Lu, Min-Zhan. "From Silence to Words: Writing as Struggle." College English 49 (1987): 433-48.

Miller, Susan. Textual Carnivals: The Politics of Composition. Carbondale, IL: Southern Illinois UP, 1991.

Pattison, Robert. On Literacy: The Politics of the Word from Homer to the 
Age of Rock. NY: Oxford UP, 1982.

Shen, Fan. "The Classroom and the Wider Culture: Identity as a Key to Learning English Composition." CCC 40 (1989): 459-66.

Smitherman, Geneva. "'The Blacker the Berry, the Sweeter the Juice': African-American Student Writers." The Need for Story: Cultural Diversity in Classroom and Community. Ed. Anne Hans Dyson and Celia Genishi. Urbana, IL: NCTE, 1994.

Soliday, Mary and Barbara Gleason. "From Remediation to Enrichment: Evaluating a Mainstreaming Project. JBW 16 (1997): 64-78. Sommers, Nancy. "Between the Drafts." CCC 43 (1992): 22-31.

Students' Right to Their Own Language. CCC Special Issue. 25 (1974): 1-32. Trudgill, Peter. Sociolinguistics: An Introduction to Language and Society.

Rev. Ed. New York: Penguin, 1983. 


\section{CONNECTIONS BETWEEN READING AND SUCCESSFUL REVISION}

ABSTRACT: This essay discusses $\mathrm{n}$ study conducted to determine whether students who reread their drafts aloud as they revise compose essays that are stylistically superior to thiose of students who do not do so. It was found that this activity does seem to make a difference for students with adequate to proficient reading skills, but does not make a difference for poor readers. The implications of the study's findings are that basic zuriting courses should focus on reading and style, in addition to the principles of organization and grammar that such courses are usually restricted to, and should encourage students to reread alond as they revise.

\section{Background and Hypothesis}

In the spring quarter of 1994, I was assigned, in lieu of one of my regular developmental composition classes, tutoring responsibilities in the writing lab run by the division in which I teach - the University of Georgia's Academic Assistance (formerly Developmental Studies) Program. The lab is a place where students in our basic writing courses can go to get help with their writing or to compose their essays on the computer. This particular quarter, a student, whom I will call William, regularly attended the lab to work on his essays in progress. Because he was often the only student there during my assigned hours, I had an opportunity to observe his composing habits closely, and what I witnessed fascinated me. Unlike most of the students attending the lab, who would usually just type a first draft and then run the spelling checker, William spent a great deal of time on revision. He would recast a sentence or a sequence of sentences and then stop and read aloud the larger passage containing his changes. He would read with expression and emphasis, and if his changes didn't sound right, he would usually sigh or mutter "No" and then rewrite the sentence yet again, repeating the whole process several times until he was pleased with the sound of his writing. His final drafts, though by no means

Mary (Molly) Hurley Moran is associate professor in the Division of Academic Assistance at the University of Georgia, where she teaches courses in dezelopmental writing and grammar. She has published articles and book chapters concerned with composition, rhetoric, fechnical writing, and modern British fiction and has authored books on the fiction of contemporary British novelists Margaret Drabble (SIU Press, 1983) and Penelope Lively (Twaync, 1993).

(c) lournal of Basic I Vriting, Vol. 16, No. 2, 1997

DOI: 10.37514/JBW-J.1997.16.2.06 76 
perfect, were always notably smoother and more fluent than his early drafts.

Curious as to how William had developed this revision habit, I questioned him about his educational background. I learned that he was an older student, in his mid twenties, who was just starting college after several years in the Navy. He said he had been an indifferent high school student who had always had a difficult time in his English courses but that in the Navy he had discovered the pleasures of books. At sea for days, he would spend hours reading the works of famous authors, and gradually he developed the desire to become a writer himself. Someone suggested to him that in order to achieve his goal he needed to attune his ear to good prose style and that the best way to do this was to read books aloud. He heeded this suggestion, and allegedly read the entire Autobiography of Benjamin Franklin aloud, as well as portions of other non-fictional and fictional classics. In trying to improve his own writing style, then, he found it helpful to listen to the rhythm of his prose and thereby detect whenever a sentence or a sequence of sentences sounded awkward.

Talking with and observing William caused me to reflect on my own composing habits, and I realized that I too rely on my ear at a particular point in the writing process. In the latter stages of a writing project, when I am fine-tuning the work, I usually read through my draft listening to the rhythm and fluency of my prose and making changes in phrasing or word order whenever a construction or passage strikes me as awkward or unpleasing. Although I generally do not read my drafts at the volume William did his, I do read in such a way that I can hear rather than merely see the words, usually in a barely audible whisper. I suspect many experienced writers do the same, and I speculate that one of the differences between weak writers and effective writers may be that the former do not go through this aural rereading process. It is this hypothesis that I decided to test.

\section{Stage One: Observation of Basic Writers' Composing Habits}

I began my investigation in an informal way, by observing my students over the next three quarters whenever they wrote in-class essays (these essays are usually stretched out over three or four class periods) and questioning many of them about their revising habits when I held student conferences. What I learned from my observations of and conversations with them was that the poorer writers generally wrote only one draft and then, rather than truly revising, proceeded to make merely superficial changes, such as correcting spelling and punctuation errors and substituting fancier synonyms for words they considered too plain. Furthermore, they did this "revising" in a 
piecemeal fashion, rarely stopping to read over larger passages to see whether their changes fit coherently and fluently into the whole. Once finished making these changes, they would simply copy over their marked-up draft and turn it in. The result would be a choppily or awkwardly written piece, marred by problems with both coherence and sentence structure.

My better writers, on the other hand, revised more, and revised more comprehensively. In their early drafts they would usually focus on improving content and organization, and in their subsequent drafts they would turn their attention to style, sentence structure, and fluency. Whereas the weak writers just kept marking up their first draftcrossing out, squeezing in revised phrases, weaving arrows all over the page to connect with changes inserted in the margins - the stronger writers often rewrote their drafts or portions of their drafts. These clean new copies were easier and more inviting to read through than the confusing, marked-up drafts of the poor writers. Not surprisingly, then, the better writers did tend to read through what they had written before embarking on another revision, and while revising, especially in the later drafts, they would frequently stop and reread sections to assess whether their changes fit in. When writing in class, these students of course would not read their drafts out loud, but with many of them I did notice slight movements of the lips and prolonged expressions of intense concentration, suggesting that they were listening carefully to what they were reading. This behavior contrasted with that of the weaker students, who appeared to be merely scanning the page with an eye for errors or poor word choices and who continually interrupted their scanning to consult their dictionary or thesaurus or handbook.

\section{Stage Two: Survey of Research Done on the Composing Process}

The next step in my investigation was to do secondary research to ascertain whether any composition specialists have noted and explored the relationship between stylistic proficiency and the habit of aural rereading of drafts. From the 1960 s to the mid 1980s, much research was done on the writing process. This movement was triggered in good part by the urging of Braddock, Lloyd-Jones, and Schoer in their 1963 NCTE book Research in Written Composition, which was echoed in 1978 by Cooper and Odell in another NCTE book, Research on Composing. Pointing out that research in the past had focused almost exclusively on the written product, these authors emphasized the need for a greater understanding of the process that gives rise to this product. Accordingly, the '70s and ' 80 s saw a plethora of case studies that attempted to analyze the cognitive and behavioral stages people go 
through as they write. Beginning with Janet Emig's famous 1971 study of the composing processes of twelfth graders, numerous researchers (most notably, Linda Flower and John R. Hayes) used protocol analysis, in which subjects are tape recorded while composing aloud, as well as other methods, to observe and draw conclusions about the writing and revising behaviors of different levels of writers.

A major finding that came out of this period of intensive investigation of the writing process, and one which coincides with my own firsthand observations, is that proficient writers review and revise their pieces of writing much more extensively than do weak writers. In a 1981 article, Susan Wall and Anthony Petrosky report the results of a study they did of the revision habits of freshman writers that revealed that basic writers restrict their rereading and revising to isolated sentences, whereas superior writers reread and revise whole passages. Brian Monahan's 1984 article, "Revision Strategies of Basic and Competent Writers as They Write for Different Audiences," reports similar findings, as does Charles Stallard's "An Analysis of the Writing Behavior of Good Student Writers" (1974) and Ann Humes's "Research on the Composing Process" (1983). In a 1980 article entitled "Revision Strategies of Student Writers and Experienced Adult Writers," Nancy Sommers reports that of the four revision operations - deletion, substitution, addition, and reordering - weak student writers engage in the first two almost exclusively, and do so mainly on the word or phrase levels. Experienced adult writers, in contrast, engage in all four operations and do so on a much more global level. Much of the research into the composing process found that weak writers do not understand the meaning of the word "revision": they confuse it with editing. These writers thus jump prematurely to the editing stage. Researcher Sondra Perl studied the composing processes of five unskilled college writers and observed that editing intrudes so frequently that it constantly interrupts the student's composing rhythms.

Since the mid '80s the focus in composition research has shifted away from the cognitive aspects of writing towards the social aspects. Representative of this new approach are the works of Deborah Brandt (1990), Glynda Hull, Mike Rose, et al. (1991), and Anne Dyson (1994), which explore how social contexts, including race, class, and gender, influence writing. At least one composition theorist, however, has protested against this movement away from the cognitive: John R. Hayes argues that there is still much to be learned about the roles played by working memory, reading ability, affect, and other cognitive factors in the writing process ("A New Framework for Understanding Cognition and Affect in Writing" 12-13). I would have to agree, for although the cognitive research done in the ' 70 s and ' 80 s discovered much about the composing habits distinguishing weak writers from strong writers, no one precisely addressed the question that I am interested in- 
namely, whether another significant difference between such writers is that the latter reread their drafts aloud and the former do not. In fact, the very nature of most of these studies precluded the researchers' being able to draw conclusions about this question. That is, since most of these studies used protocol analysis, which requires subjects to compose aloud, there was no way to tell whether some subjects would have naturally reread their work aloud and some would not have. Thus, because the connection between style and aural reviewing has not been addressed, I decided to explore it and to devise a method other than protocol analysis with which to do so.

\section{Stage Three: Classroom Experiment to Test Hypothesis}

The classroom phase of my experiment was conducted in the fall quarter of 1995. On the first day of class, I had the students in two of my basic writing classes fill out a questionnaire concerning their extracurricular reading habits and their essay revising habits (see Table 1). Then throughout the quarter, every time they submitted an essay I had them turn in a statement indicating whether or not they had reread their essay aloud while revising. (I emphasized that by "aloud" I did not necessarily mean at a normal speaking volume but simply in such a way that they could hear what they had written - for example, in a very faint whisper.)

In addition, I divided my two classes into a control group class and an experimental group class. To the former I simply stated that I was doing research on the composing processes of freshman writers in an attempt to determine whether reading one's drafts aloud has any effect on the quality of the final product. To the latter I explained what my hypothesis was, and I urged them to read their drafts aloud while revising. But to both groups I emphasized that their grade on an essay would in no way be affected by what they said in their statement indicating whether or not they had read aloud, and I stressed the importance to my study of their being honest in their statements.

The last week of the quarter, I had both classes write a short inclass essay. They were given two periods for this and were urged to revise their essay at least once, as well as to edit the final draft. I then had three experienced composition teachers in our program do a holistic scoring of these esșays, evaluating them solely for style and mechanical correctness. The teachers were instructed to give a score of \#4 to essays relatively strong in both style and mechanics, a \#3 to essays relatively strong in style but not mechanics, a \#2 to essays relatively strong in mechanics but not in style, and a \#1 to essays weak in both style and mechanics.

At the outset of my experiment I made two tentative predictions. 
First, I predicted that the more proficient readers (as indicated by their answers on the initial questionnaire) would read over their drafts aloud more regularly (according to the statements submitted with their essays) and would receive higher scores on the final writing sample than would the less proficient readers. Second, I predicted that the experimental group would read their drafts aloud more regularly (because they had been urged to) than the control group and that, accordingly, the experimental group's final writing sample scores would be on the average higher than the control group's. As the discussion below and Table 1 indicate, students' answers to the questions on the questionnaire about their reading and revising habits were not reliable enough to ascertain the validity of my first prediction; however, my second prediction appears to have been borne out.

\section{Results and Findings of Classroom Experiment}

The questionnaire given on the first day of class began by asking students if they frequently do non-required or pleasure reading. Since the course is for students with weak writing skills, my assumption was that most of them would circle "no" in response, for, as researchers Lynn Quitman Troyka and John Butler have pointed out, poor writers are usually poor readers. I was therefore surprised to find that the vast majority of my students $(84 \%)$ circled "yes." However, their response to the follow-up question asking them to state the approximate amount of pleasure reading they do daily or weekly seemed to contradict this claim, indicating either that they have a mistaken notion of what frequent reading is or that they had circled "yes" simply because they wanted to make a good impression on the teacher at the beginning of the quarter. Specifically, the vast majority $(71 \%)$ of those who answered this question concretely and in terms of minutes per day or week indicated that they generally read less than 30 minutes a day, with some saying as little as 30 to 90 minutes per week. Furthermore, many indicated that their reading is done sporadically, a few minutes here and there when they get the chance, and that they mainly scan newspapers and magazines, dipping in and out of articles that interest them. In short, their descriptions of their reading habits reveal that, despite their affirmative response to question \#1, they in fact do very little reading and very little sustained reading.

A third question asked them to state what it is they read for pleasure. Their answers here were revealing too. By far the bulk of what they read is newspapers and magazines; specifically, newspaper and magazine articles constituted $73 \%$ of the types of reading material mentioned. Furthermore, their answers indicated that they read mainly the sports and entertainment section of the newspaper and-almost 
exclusively - popular magazines, such as Seventeen, Entertainment, and Jet. Some students even listed catalogues and T.V. Guide, and one student went so far as to include "junk mail" as one of his kinds of extracurricular reading! While a handful of students indicated that they also read books, their examples indicated that they do not read difficult or challenging works (romance, horror, and spy tales were the most common). Furthermore, many of those who listed books and novels gave the impression that they read this genre only occasionally or rarely; for example, many would first mention magazines and newspapers and then add something like "Last year I also read a good book; it was called 'such and such.'" In sum, the responses to my questions about the amount and kind of outside reading done suggest that for the most part students in basic writing courses do not engage in extensive, sustained reading of demanding prose.

The rest of the questionnaire pertained to the students' revising habits. The question asking them whether or not they reread their drafts aloud when revising met with a $50-50$ response; that is, $21 \%$ circled "always," $21 \%$ circled "never," and $58 \%$ circled "sometimes." However, their responses to related questions revealed that if in fact they do read aloud, they are probably not doing so in the way I meantwith an ear attuned to their style. That is to say, a $65 \%$ majority, when questioned about the number of drafts they usually write, indicated that they write two or fewer. Furthermore, nearly all of the students responded to the question about the kinds of changes they make when they revise by indicating that they concentrate on correcting surfacelevel errors. Since most of them, apparently, immediately go to work hunting for spelling, punctuation, and grammar errors, they doubtless do not go through a stage of revision in which they read over their writing listening to the rhythm and fluency of their prose. In fact, I suspect that many of them circled "always" in answer to my question about reading their drafts aloud for the same reason many circled "yes" to my question about pleasure reading: because they thought it was the answer I wanted.

Given the unreliability of the students' responses, I was unable to find positive correlations a.) between reading proficiency and the revision habit of reading aloud and $b$.) between reading proficiency and high scores on the final writing sample. My analysis and interpretation of the students' responses to the initial questionnaire did, however, allow me to draw the conclusion that basic writers tend not to be strong readers and tend not to be in the habit of reading over their essay drafts with an ear attuned to their own prose style. 


\section{Table 1: General Results of Questionnaire Concerning Students' Reading and Revising Habits}

1. Do you frequently do non-required or pleasure reading?

$\begin{array}{ll}\text { Yes } & \text { No } \\ 84 \% & 16 \%\end{array}$

2. Describe the amount and frequency of the non-required reading you do, in terms of minutes per day or per week.

$71 \%$ read less than 30 minutes per day.

3. Describe the kinds of materials you read for extracurricular reading (types of books, magazines, newspapers, etc.).

$73 \%$ of the genres mentioned were newspapers and popular magazines; only a few students mentioned novels or other kinds of books.

4. As you revise an essay, do you read aloud what you have written?

$\begin{array}{ccc}\text { Never } & \text { Sometimes } & \text { Always } \\ 21 \% & 58 \% & 21 \%\end{array}$

5. When you are assigned an essay to write, how many drafts (revisions) do you usually write?

$65 \%$ stated two or fewer drafts.

$33 \%$ stated approximately three drafts.

$2 \%$ stated approximately four drafts.

6. What kinds of changes do you usually make with each revision (content? organization? sentence structure? spelling? punctuation? or what?)?

Descriptions were too varied to tally, but very few students mentioned stylistic changes. Several claimed to correct spelling and punctuation first and then to add or delete details and find better words.

The findings of the comparison of the control group to the experimental group were more definitive. The students in the control 
group on average did less revising aloud and received lower final writing sample scores than the students in the experimental group. (See Table 2.) Students' written statements submitted with their essays throughout the quarter (and I regard these assessments as more reliable than their answers to their revising habits on the questionnaire because I did not explain what I meant by "reading aloud" until after they had filled out the questionnaire) indicated that on average only $47 \%$ of the control group students revised any given essay aloud, while $68 \%$ of the experimental group did so. And, with 12 the highest score possible on the writing sample (that is, if all three scorers gave an essay a score of 4 ) and 3 the lowest score possible (if all scorers gave a score of 1 ), the average for the control group was 8.5 , while the average for the experimental group was 9.1.

\section{Table 2: Comparison of Performances of Control Group and Experimental Group}

Control Experimental

Average number of students that revised an essay aloud

$47 \%$

$68 \%$

Average score for stylistic/mechanical proficiency on final writing sample (with 12 being highest possible and 3 lowest possible)

\section{Stage Four: One-on-one Observations of Students Revising}

For the next phase of my experiment I decided to observe students one-on-one so as to gain further insights into the relationship between revision habits and prose style. In the winter and spring quarters of 1996, each time an essay assignment was turned in I selected a few students to come individually to my office to read their essay aloud and make any changes they saw fit as a result of this exercise. I chose only students who, in response to my questioning, indicated that they had revised and edited their essays as best they could before turning them in. I excluded students who indicated that they had not had time to polish their essays because I wanted to ensure that the reading aloud 
and not merely the extra time was the significant factor in any improvements students would make in their essays.

When the student arrived at my office, I explained to him or her that I was conducting an experiment to try to determine whether writers catch stylistic, grammatical, and mechanical problems more easily if they read their writing aloud. I instructed the student to read his or her essay aloud, stopping to correct any grammatical or mechanical errors detected in the process and to recast any sentences found to be awkward. I also asked the student to - as much as possible - think out loud. For example, if a construction sounded wrong or awkward, the student was to voice aloud this judgment and to verbalize his or her various attempts at recasting the construction before writing down the revision finally settled on.

The student was given approximately 25 minutes to complete this exercise. Meanwhile, I sat at a nearby desk with a copy of the paper, jotting down in the margins the remarks and oral recastings of constructions the student made at various points in the essay. Later, when I analyzed the results, I considered both the changes the student made on his or her copy and the student's oral remarks I had recorded on my copy.

\section{Results and Findings of One-on-one Experiment}

The results of this experiment led me to the following broad conclusion: reading aloud appears to help the better basic writer hear problems with style he or she would not otherwise detect, but does not appear to make a significant difference in the detection of localized grammatical and mechanical errors. To be more specific, the same student who would note his or her mixed constructions, faulty parallelism, choppiness, or excessive subordination would often not note his or her subject-verb agreement errors, missing final $-s$ 's on plural nouns, and careless omissions of words. With many of these students, what reading researcher K.S. Goodman has called miscue reading appears to be at work: that is, the student supplies the correction as he or she reads and does not notice that something different is actually written on the page. With other students, the cause seems to be dialect interference: that is, because in their spoken dialect it is customary, for example, to leave off the $-s$ sound on a plural or a possessive noun or the $-d$ sound on a past participle, they do not perceive this omission in their writing as an error. But, interestingly, these same students can detect many of their awkward sentence constructions. The approach I had them take of voicing their thoughts aloud revealed that they can hear when a sentence sounds "off" even if they can't always recast it to their complete satisfaction. 
Let me repeat that the above description pertains to my better basic writing students. Another conclusion my experiment seems to point to is that the very weakest writers - my D and F students - cannot detect even their stylistic problems when they read aloud. In other words, for these students, reading their work aloud seems not to yield any benefits. One reason for this is that many of them have such difficulty reading that they stumble and stall and continually have to go back and start a sentence again; consequently, they do not hear their sentences as wholes and therefore cannot judge if there are structural problems with them. But what I think is probably the more significant reason weak students are unable to detect stylistic problems when they read their writing aloud is that they generally tend to be non-readers. These are the students who do virtually no extracurricular reading (I informally questioned students about their reading habits when they came to my office) and so have not developed an ear for effective and acceptable prose style. When I had these students read their papers aloud, they would plough through tangled or bloated sentences as though these sentences made perfect sense. When I would have them reread to me a particularly bad sentence and ask them if they could hear a problem with it, such students usually insisted that it sounded okay to them. Similarly, I've noticed that on other occasions when I've had a class critique an anonymous student's essay, the weak students often claim they do not hear anything wrong with awkward sentences that the stronger students point out.

\section{Overall Findings and Pedagogical Implications of This Study}

This study has explored and raised a number of questions:

1) Are better writers usually better readers? In other words, is there a correlation between mature, pleasing prose style and the quantity and quality of what a person reads?

2) Do those with a superior prose style tend to read their drafts aloud as they revise to a greater extent than do those whose writing is less fluent and less pleasing?

3) All other things being equal (that is, reading ability and quality and quantity of extracurricular reading), do students who read their work aloud as they revise possess writing styles that are superior to those of their counterparts who do not read aloud? In other words, is reading aloud the determining factor - or even a significant factor - in the achievement of superior prose style?

4) For the average to above-average student writer, will prose style improve if the student develops the habit of reading aloud as he or she revises? 
These questions need to be more fully explored. In particular, more advanced writers (advanced freshman writers as well as experienced adult writers) need to be observed in the writing process and to be questioned as to whether, and to what extent, they read their drafts aloud as they revise. Such investigation may reveal whether it is aural rereading or whether it is some other cognitive or behavioral factor that enables stylistically skilled writers to detect the infelicities of their prose when they are revising.

Although much investigation still needs to be done into the particulars of the connections among reading, writing, and prose style, my study does suggest that there are such connections and thereby points to certain pedagogical implications. It would appear from the results of my questionnaire that students in basic writing classes are poor writers in good part because they read very little and read very little quality prose; we therefore cannot hope to improve the writing of these students without helping them to become better readers. Unfortunately, however, many basic writing courses contain very little reading because the teachers know what a hard time students have writing and therefore do not want to overload them with reading assignments as well. Somehow, though - perhaps via a parallel required reading course, required attendance at a reading lab, or some other methodstudents in basic writing courses need simultaneously to be working on becoming better readers.

In addition, students in basic writing courses should be taught to go through more than two revisions of an essay and not to jump from the rough draft stage to the editing stage. The teacher could demonstrate the stylistic revision stage, showing how to read and reread the later drafts listening to the sound of one's prose. And the teacher should make clear the difference between doing this and proofreading for surface errors, which is a later activity and something that is perhaps better done with a careful eye than a careful ear.

In conjunction with training our students to read their work aloud to detect stylistic flaws, we should actually teach style, so that when they do notice awkward constructions, they will be equipped to analyze the cause of the problem and have at their command various structural options for revision. However, teachers tend to shy away from teaching style in basic writing courses. I have heard basic writing teachers dismiss style as something students will eventually be taught in English 101. The rationale is that there is too much else to cover in basic writing - namely thesis support, organization, and, above all, grammar and avoidance of error - and that teaching style is appropriate only for students who already know how to write a grammatically correct sentence. But I disagree. I think many students become enthused about writing only when they have developed a feel for style and the possibilities of manipulating sentence structures and sentence 
rhythms. It was an appreciation of style that motivated the student William, discussed earlier, to want to write and to want to improve his writing. Students can be introduced to style in a variety of ways, including listening to the teacher read aloud stylistically pleasing and powerful passages from literature; analyzing the factors that contribute to a style they find pleasing - for example that of Martin Luther King; being taught sentence variety options; working on sentence-combining exercises; and so on. Once students acquire a feel for style and for the possibilities of developing their own, many will be motivated to master otherwise boring points about grammar and punctuation. I witnessed this phenomenon firsthand with William, who worked hard to understand such concepts as dangling participles, conjunctive adverbs, restrictive versus non-restrictive clauses, and so on, once he saw how this understanding would help him achieve his goal of a clear, powerful prose style. I think that many basic writing students are like William and that in order to motivate them we need to help them see the connections among reading and writing and style. In conclusion, we can do this by helping them to become better readers, by training them to go through a stylistic revision stage in which they read their drafts aloud, and by introducing them to the elements of a pleasing prose style.

\section{Works Cited}

Braddock, Richard, Richard Lloyd-Jones, and Lowell Schoer. Research in Written Composition. Champaign, IL: NCTE, 1963.

Brandt, Deborah. Literacy as Involvement: The Acts of Writers, Readers, and Texts. Carbondale, IL: Southern Illinois UP, 1990.

Butler, John F. "Remedial Writers: The Teacher's Job as Corrector of Papers." College Composition and Communication 31 (1980): 270-77.

Cooper, Charles R., and Lee Odell, eds. Research on Composing: Points of Departure. Urbana, IL: NCTE, 1978.

Dyson, Anne Haas. "Confronting the Split between 'The Child' and Children: Toward New Curricular Visions of the Child Writer." English Education (1994): 12-28.

Emig, Janet. The Composing Processes of Twelfth Graders. NCTE Research Report No. 13. Urbana, IL: NCTE, 1971.

Flower, Linda, and John R. Hayes. "A Cognitive Process Theory of Writing." College Composition and Communication 32 (1981):365-87.

Goodman, Kenneth S., ed. Miscue Analysis: Applications to Reading Instruction. Urbana, IL: NCTE, 1973.

Hayes, John R. "A New Framework for Understanding Cognition and Affect in Writing." The Science of Writing: Theories, Methods, Individual Differences, and Applications. Ed. C. Michael Levy and Sarah Ransdell. Mahwah, NJ: Lawrence Erlbaum, 1996. 1-27. 
Humes, Ann. "Research on the Composing Process." Review of Educational Research 53 (1983): 201-16.

Hull, Glynda, Mike Rose, et al. "Remediation as Social Construct: Perspectives from an Analysis of Classroom Discourse." College Composition and Communication 42 (1991): 299-329.

Monahan, Brian D. "Revision Strategies of Basic and Competent Writers as They Write for Different Audiences." Research in the Teaching of English 18 (1984): 288-04.

Perl, Sondra. "The Composing Processes of Unskilled College Writers." Research in the Teaching of English 13 (1979): 317-36.

Sommers, Nancy. "Revision Strategies of Student Writers and Experienced Adult Writers." College Composition and Communication 31 (1980): 378-88.

Stallard, Charles K. "An Analysis of the Writing Behavior of Good Student Writers." Research in the Teaching of English 8 (1974): 20618.

Troyka, Lynn Quitman. "The Writer as Conscious Reader." $A$ Sourcebook for Basic Writing Teachers. Ed. Theresa Enos. New York: Random House, 1987. 307-17.

Wall, Susan V., and Anthony R. Petrosky. "Freshman Writers and Revision: Results from a Survey." Journal of Basic Writing 3.3 (1981): 109-22. 


\section{Karen L. Greenberg}

\section{A RESPONSE TO IRA SHOR'S "OUR APARTHEID: WRITING INSTRUCTION AND INEQUALITY"}

One of the problems in thinking about basic writing is that this term means nothing apart from its context. In "Our Apartheid: Writing Instruction and Inequality" (JBW 16.1 [1997]: 91-104), Ira Shor uses the term as a decontextualized and politically charged code word"BW" - oversimplifying the term and demonizing it. In reality, basic writing differs at every school; at each college, administrators, teachers, and students all participate in the process of constructing basic writing and basic writers. Together they determine the basic academic skills that students must master to function in the intellectual community that college represents. These skills include increasing students' understanding of academic language and concepts; helping students develop more sophisticated ways of thinking, based on induction, deduction, generalization, and evidence; and increasing students' sensitivity to the beauty and power of language and strengthening their positive attitudes toward reading and writing.

Given his understanding of situated literacies, Ira Shor should know better than to detach his analysis from the day-to-day reality of basic writers, making generalizations about their "undemocratic and immoral conditions" so sweeping as to be misleading. As basic writing teachers-described by Shor as "teachers in the trenches [who] do heroic labor" - know, our courses are not "curriculas for containment and control," firmly entrenched "to divide and deter non-elite students in school and in college." Before Shor wrote his piece, he should have sat in on some of the courses that he advocates eliminating; he should have reacquainted himself with basic writing students and the reality of their struggles. There is no lumpen mass of "basic writers" who conform to the stereotypes in his essay. Most basic writing students are not "Blacks" and "the children of poor and working families." Just as basic writing students come from a broad range of socioeconomic situations, they are ethnically and culturally diverse. They are also heterogeneous with respect to the nature of their literacy skills. Some have done little reading and writing of an academic nature in elementary or secondary school, so what they face is first-time learning rather 
than developmental mastery. Others read and write adequately when given enough time, but the timed nature of essay tests in college courses produces difficulties. And others-particularly transfer studentshave taken reading and writing courses, perhaps even in college, and have certainly been expected to read and write throughout their education, but the application of their skills to new subject areas in a new setting has disrupted their proficiency.

The majority of basic writing courses are not "grammar graveyards" (as Shor describes them), nor are they ghettos. Most are integrated within English Departments, whose mission is the development of students' abilities to appreciate language and to use it creatively and effectively. The basic writing course is the beginning of an integrated sequence of required English courses, all of which are based on similar theories of linguistic and rhetorical development. Students in basic writing courses understand that they will progress through a series of courses that present and re-present increasingly complex academic literacy skills. Basic writing courses present reading and writing as processes of systematic inquiry, in which students gather new ideas, attempt new perspectives, and internalize the conventions of academic discourse. The goal in these courses is often the same as the goal in upper-level courses: to empower students to use language fluently and authoritatively to transform their lives.

However, the pedagogy of most basic writing courses is unique. Teachers devote much time and energy to helping students gain confidence in their ability and their commitment to using writing as a vehicle for thought and self-expression. Students write frequently, and their writing receives multiple responses from classmates and the teachers. The stages of the writing process are explored through a variety of activities including journals, themes, double-entry notebooks, reports, essays, and practice essay tests. Most basic writing courses are workshops in which students plan, compose, and revise collaboratively in small groups. Students are active rather than passive learners, providing each other with multiple perspectives and responses and working together to negotiate knowledge and meaning. And with smaller class sizes than other courses, the basic writing course provides each students with individualized attention from the teacher. And basic writing teachers are quite distinct in their willingness to listen to and learn from their students and in their ability to value and validate different ways of thinking, doing, reading, and writing. Furthermore, teachers who choose to work with underprepared college writers are usually those who understand the developmental nature of academic literacy acquisition and the linguistic and rhetorical overloads and bottlenecks that occur as students master various language production skills and processes.

Moreover, basic writing courses, unlike most other college 
courses, are places where students' ideas are taken seriously, regardless of the dialect or register in which they are expressed. They are "safe" contexts that provide multiple opportunities for students to participate in academic dialogues, reflect aloud on their realities, and try out a multiplicity of discourses and voices. These courses also introduce students to Standard English - not as the absolute standard of grammatical correctness, but as a mode of discourse within a particular social, historical, and political context. Linguistic choices are usually analyzed in terms of social situations and reader/writer role relations. In sum, basic writing courses help students acquire the knowledge and "tools" they need to empower themselves - the ability to write clearly and convincingly about issues that matter to them, to understand and respect other people's perspectives and points of view, to use writing to understand the world and to challenge ideas and people. But now, at schools across the country, funding for basic skills instruction is being cut; underprepared and inexperienced writers are being denied access to courses that prepare them to succeed by teaching them the linguistic, cognitive, and social components of academic literacy necessary to make the transition to college-level coursework: If these courses are slashed, where are students going to get the help they need? Does anyone really believe that students will be able to get this help in freshman composition courses, where the class size is larger, where dialect variation is often perceived as "error," and where the demands are for college-level conceptualization, organization, fluency, and mastery of English conventions?

What is Shor's alternative to basic skills courses for students who may not have read a book or written an essay during their twelve years in elementary and secondary schools? He would put them in collegelevel "Critical classrooms [that] would invite students to focus on their everyday life in the system causing our problems." There are two problems with his recommendation: First, Shor and his colleagues are really not part of this "our"; they have little in common with these students; thus, his assertion that what these students really need is a curriculum focusing on political empowerment and cultural democracy is suspect. Second, I doubt that most basic writers would agree with the statement that their "everyday life in the system" is what is causing their problems. Most of the basic writers I have taught, advised, and observed believe that the cause of their problem is the inadequacy of their reading and writing skills. Political enlightenment may help these students want to improve their "local conditions"; however, the academic literacy instruction that they get in basic skills courses will help them achieve their potential in college and help them find and use their voices in the world beyond school.

Students who are unfamiliar or uncomfortable with the academic community that college represents need practice in arguing logically 
and sounding credible in writing. Unlike Shor, they cannot rely on their status in this community to convince others of their beliefs, nor can they use pathos and inflammatory language to support their assertions; these may help sell Shor's books, but they don't help students. Let's address the fact that the demands and costs of higher education in this country are rising much faster than funding and that students who cannot pay full tuition are being denied access to a college education. Calls for a "farewell to basic writing" and recommendations that underprepared students be mainstreamed directly into college-level courses sound exactly like the recommendations urged by the national panels on the future of higher education. The RAND Council for Aid to Education recently issued a report urging college administrators to reexamine their missions and "streamline" their services to serve those missions (Commission on National Investment in Higher Education, Breaking the Social Contract: The Fiscal Crisis in Higher Education [New York: RAND Council, 1996]). Will mainstreaming basic writers and ESL writers lead to their being "streamlined"? "BW-advocate Greenberg" - who has been teaching basic writing "in the trenches" for twenty-three years - thinks so.

And if Mina Shaughnessy were alive today, I believe she would think so too. Here is what Mina had to say to colleagues who were calling for the elimination of basic writing courses twenty-one years ago:

These are discouraging times for all of us, most particularly for the teachers who have been working with underprepared students on basic skills. Both students and teachers are already discovering that they are expendable, and the programs they have helped to build over the past five years to remedy the failure of the public schools (and the society of which those schools are an extension) now begin to shake and fracture under the blows of retrenchment. . . But they [basic skills students] cannot go back. CUNY extended a right, six years ago, that has been revoked, and we appear to be back where we started in 1970, only much poorer. But no one can revoke what has gone on in us and in our students. ("The Miserable Truth," JBW3 [1980]: 114).

If colleges accept for admission students with serious basic skills deficiencies, then they are morally obligated to provide them with the developmental instruction that they need to succeed in their college courses. To deny this instruction implies a "right to fail" - that students should have the freedom to take college-level courses of their choice, even if there is a low probability of their succeeding in these courses. This philosophy - which Shor advocates - translates into ef- 
fective policy only under two conditions: (1) when students have an appropriate understanding of their strengths and weaknesses and of the standards and requirements of the courses that they plan to take and (2) when college "content area" courses are taught in small sections by teachers willing to give extra assistance to underprepared students and willing to include literacy development activities in their curricula and pedagogy. Neither condition exists in most American colleges, nor is there much likelihood that either will. I believe that Shor's "sink or swim" approach is pernicious: It ignores students' problems and allows them to revolve right out of our open-admissions door. The instruction provided by basic writing courses enables students to acquire the academic literacy skills, motivation, and self-confidence to persevere and to succeed in college. Until there is a marked improvement in the academic skills of high school graduates, transfer students, and adults returning to school; basic skills instruction will continue to be necessary to improve students' success in college. The majority of new and continuing college students need careful, continuing attention to developing literacy skills, not only up to but beyond minimal competency.

Suppose Shor's vision came to pass; suppose that there were no entrance standards and no testing to place and exit students in developmental courses leading to college-level work. If this were the case, at least half the students now entering the university where Shor and I teach (CUNY) would be barred. The University, far trimmed down in size, would probably return to the elite institution it was before 1970, when open admissions began. Of course, there are reactionary political forces currently trying to achieve precisely this barring of access and precisely this reduction in size in colleges across the country. Eliminating testing would, in fact, justify the curtailment and the consequent reduction or elimination of basic skills programs. Students would either fail admissions standards or, given the appearance of open access, would fail college-level courses because of inadequate academic writing skills. No one should make the mistake of believing that the current atmosphere of draconian cutbacks would not operate in this way if opponents of basic skills courses are successful in their goal. 


\section{A RESPONSE TO IRA SHOR'S "OUR APARTHEID: WRITING INSTRUCTION AND INEQUALITY"}

Ira Shor's "Our Apartheid: Writing Instruction and Inequality" (JBW 16.1) is both stimulating and frustrating. The piece is so right about the ways in which higher education and Composition can be manipulated to serve entrenched, classist interests that, while reading it, I nearly lost sight of why Shor is so emphatically wrong in his generalizations about Basic Writing as agent of educational apartheid. My response has two parts: clarification of an erroneous point about Basic Writing at the University of Minnesota-Twin Cities used in Shor's article, and related to that, a comment on the artificially homogenized Basic Writing landscape presented by the article.

As I read the piece, I found myself frequently in agreement with the argument, as I have been on numerous other occasions when reading Shor's books, listening to him speak, or conversing on a listserv, admiring his wide ranging discussion that brings together current economics, labor theory, and Composition history. Then I stumbled. Shor writes:

... find out how big a surplus your local BW/comp programs are generating each year, like the $\$ 1$ million generated by the former comp program at Minnesota, I was told. BW/comp is a cash cow - full tuition paid by students while part-time wages are paid to teachers. No costly equipment needed as in engineering labs or nursing departments. BW/comp is like the former colony of India, the jewel in the crown, a territory generating lots of wealth for the imperial metropoles of lit, grad school, and administration." (99)

Confronted with Shor's general assertions about the economics and labor conditions of "BW/comp" in the familiar neighborhood of my own institution and its Basic Writing Program (which I helped build and which I coordinated for 16 of the last 21 years) I was startled. He simply got it wrong. At the University of Minnesota-Twin Cities, there is no "BW/comp program." There are actually three writing programs 
with different institutional purposes and locations: a Basic Writing program in the relatively open-admissions General College, where I work; the larger Composition Program in the English Department of the very selective College of Liberal Arts (most likely what Shor has in mind in his statement about a million dollar budget surplus - the CLA program certainly does create a surplus for the College of Liberal Arts if one's analysis is based on directly attributable program costs vs. tuition revenue); and there is a smaller-enrollment freshman writing sequence offered in the Rhetoric Department (College of Agriculture) in conjunction with the excellent Scientific and Technical Communication program.

Anyone can make a factual mistake, to be sure, and the tangled collegiate structure at Minnesota might foster mis-statements by outsiders, like that which Shor makes. But what's really interesting is that the Minnesota experience is just opposite of what Shor posits about the economics and labor conditions of Basic Writing programs and the educational purposes they serve. We do indeed like to think of our Basic Writing program as a curricular crown jewel (to reapply Shor's term) which operates as a supportive social-intellectual home base for our open-admissions students, but Basic Writing here in the General College is hardly a cash cow. I formulate and manage instructional budgets for the entire college, and I can tell you very confidently that Basic Writing here is an equitably funded enterprise. A two quarter credit-bearing sequence offered to all General College students without punitive placement exams, the Basic Writing course enrollments are capped at 18 or 19 per section. These Basic Writing workshops are all offered in a well-supported instructional environment. All sections meet exclusively in up-to-date, computer networked writing classrooms where the student-to-workstation ratio is 1:1, rivaling anything our engineering or nursing colleagues (using Shor's comparison points) might have available in their teaching environments. The teachers and students get reasonable training and tech support, and the Basic Writing courses are supported by a free, walk-in tutorial center in the same building as the classrooms. If anything, Basic Writing is supported with class size, tutorial assistance, and technology in ways which elicit envy from General College colleagues in the sciences, social sciences, and humanities.

Furthermore, we certainly operate within the spirit of what Shor proposes for a CCCC "Labor Policy." The Basic Writing staff is comprised of four full time, tenured or tenure track Faculty who teach six quarter-term courses per year, whose tenure and promotion decisions are grounded in the quality of their research and teaching in Basic Writing, and who are among General College's best-paid faculty. The Faculty work with four full-time academic professionals on annual nontenure-track appointments at reasonable load (nine quarter sections 
per year, no research requirements) and with respectful pay, paid health benefits, and good working conditions. In addition to full time faculty and staff, we work with nine half-time graduate students from a variety of disciplines who are paid a stipend consistent with the graduate salary ranges for the entire University, health benefits, and full tuition waiver (which alone averages $\$ 4,800$ ), a defensible, though admittedly not lavish, package for half-time nine-month graduate assistant work. The program is administered collaboratively among full-time faculty and staff, and graduate students are trained, mentored and evaluated collaboratively. Our least experienced ESL students, primarily refugees from southeast Asia and eastern Africa, are taught in a year-long comprehensive program, also credit-bearing, which emphasizes writing, speech, and reading in content area subjects via linked courses, taught by a combination of full time professional staff and graduate students.

Recurring institutional research tells us that General College students like our Basic Writing courses, see them as both challenging and valuable, and, in retrospective assessments, attribute significant power to these courses in accounting for their eventual college success. We know that $100 \%$ of the General College students who successfully transfer into degree-granting colleges at Minnesota complete the Basic Writing sequence (data based on Fall 1996 cohort). And we know that those who find a way to avoid the Basic Writing courses or who postpone enrolling tend to fail to transfer into degree programs, and they drop out at elevated rates. In this regard, I see our program in a light consistent with Ed White's meta-analysis of positive student progress in the California State University system as correlated with enrollment in recommended writing course sequences ("The Importance of Placement and Basic Studies," JBW 14.2 [1995]: 75-84). We who work in Basic Writing at the University of Minnesota do not see ourselves and are not seen by our students - as a barrier or as a tool through which the institution retards degree progress among our financially strapped, racially diverse, largely urban student population. Quite the contrary, we work with fairly good institutional investment to help students move toward timely, more effective completion of degree requirements.

Financially, Basic Writing at Minnesota operates at the same level of support as does the rest of the General College curriculum, not as a colony feeding belletristic or administrative "metropoles." The Basic Writing program is (dis)advantaged no more or no less than is the rest of General College's multi-disciplinary general education curriculum by the fiscal arrangements of undergraduate education at Minnesota.

Granted, Shor made a relatively minor mis-statement or unclear association regarding the situation at Minnesota. That it sponsored my admittedly defensive re-reading of the article and led to the pre- 
ceding program description is interesting, I think, only because I found myself less convinced of the article's overall notion of Basic-Writingas-apartheid as I re-read it. Like so much of the anti-Basic Writing discourse associated with the current mainstreaming moment in Basic Writing history, Shor's article posits a monolithic entity, a "Tidy House of BW Inc." of sorts, omnipresent in higher education, operating uniformly coast-to-coast in a kind of post-Shaughnessy mindlessness which serves to oppress its students. We know that this is simply not the case. In fact, the article itself makes the point that there is a great deal of diversity in how institutions support the work of inexperienced writers. Shor points to the work of Soliday and Gleason, Fox, Grego and Thompson, Glau, and others, all of whom have built on knowledge generated by research in Basic Writing programs to build creative local solutions to the situation of inexperienced writers on their varied campuses. Various critics of traditional discourses of Basic Writing, such as Horner ("Discoursing Basic Writing" CCC 47.2 [1996]: 199-222), suggest the limits of a CUNY-based redrawing of the landscape of institutional response to students whom elites define as outsiders to the enterprise of higher education. Likewise, Hunter Boylan, although to different purpose, in his survey of developmental education, notes that $74 \%$ of colleges and universities offer some sort of supportive work for students who are seen as underprepared, an enterprise involving three million students and one hundred thousand staff and faculty, reflecting a wide range of approaches and status markers ("The Scope of Developmental Education: Some Basic Information on the Field," Research in Developmental Education 12.4 [1995]: 1-4). The Basic Writing landscape is far more varied that Shor suggests, as he relegates it to the status of "a containment track below freshman comp, a gate below the gate" (94).

Does this variety of locally situated work on behalf of basic writers signal an end to Basic Writing? Hardly. While there may have been homogenizing episodes in Basic Writing (such as curricular reforms following publication of Wiener's The Writing Room or Bartholomae and Petrosky's Facts, Artifacts, and Counterfacts), there has never been a homogeneous Basic Writing entity which ought now to be "mainstreamed." There have been only local realizations of writing pedagogy in local structures, some designed well and some designed badly, in support of inexperienced writers about whom traditionalist faculties have expressed doubt or hostility (vid. the spate of "how to kill a college" articles which greeted open-admissions at CUNY). Indeed, had there ever been the kind of homogenized practice that Shor asserts or that Bartholomae sets up as straw man in his "The Tidy House: Basic Writing in the American Curriculum" (JBW 12.1 [1993]: 4-21), it would have morphed by now into dozens of situated iterations. The process of local realization of innovation, in fact, 
seen from an anthropological or linguistic perspective, would predict the very multiplicity of responses to local conditions that Shor applauds in the work of Grego and Thompson, Soliday and Gleason, and others, and which in its multiplicity is more like the actual situation in Basic Writing nationally (see Peyton \& Bruce, "Innovation and Social Change," in Bruce, Peyton, and Batson, eds., Network Based Classrooms: Promises and Realities [Cambridge, 1993], 9-32).

At the University of Minnesota-General College, Cathrine Wambach is currently midstream on a study of how large Midwestern universities work with students defined as "underprepared" by site standards (for further information, contact <wamba001@tc.umn.edu>). She is discovering a rich combination of institutional approaches, variously anchored by access programs, involving mostly credit-bearing writing courses, summer bridge programs, specially supported first year writing programs, and other ongoing supports. Her work reinforces the notion that there is nothing monolithic about Basic Writing, nothing so congealed as to warrant the homogenizing critique or the offensive (to some, at least) implication of apartheid politics in service of such students.

Shor is surely right that there is a history of exclusionist practice in higher education, grounded in race, class, and gender assumptions, and some practices in writing instruction and tracking are undoubtedly tied to this history. It is an unfair corollary that there is a Basic Writing industry acting out a cynical apartheid agenda. Rather, there are any number of situated, institutionally constrained iterations of things like "Basic Writing," some more fortunately located than others, some more successful in resisting pariah status than others, some formed with more authentic educational purposes than others.

Shor urges us to find our allies and to work with them. I couldn't agree more wholeheartedly. Basic Writing programs were born in many institutions as a function of access initiatives, sometimes out of a genuine attempt to open higher education, sometimes as a cynical reinscription of status demarcation in a time of social change. Surely, it is in "safe house" access programs that we are most likely to find our current allies in common resistance to regressive closure of higher education, as recently reasserted by Canagarajah, among others ("Safe Houses in the Contact Zone," CCC 48 [1997]: 173-196) .

While reading Shor's piece I was reminded of Deborah Mutnick's warning to be careful in how we mount educational critique from the left, that in impolitic critique of Basic Writing we risk crawling into bed with the very elements of right wing elitism which access programs and many Basic Writing programs were founded to counteract (Writing in An Alien World [Boynton Cook, 1996], xiv). Mutnick's warning echoes the question Michael Moore (Downsize This and "TV Nation") asks again and again: Is the left nuts? (Most recently in "Is the 
Left Nuts? [Or Is It Me?]" The Nation 265.[16 November 17, 1997]: 16). We who teach from the left are peculiarly fond of beating each other up while the right wing eats our lunch. Shor's piece is a thrilling synthesis of disparate perspectives on how students get sorted and ground up in a factory model of higher ed, but in its strained assertions about Basic Writing practice it will likely serve simply to distract us from direct action against more pressing forces of exclusionism. Its view of Basic Writing is at least in one instance wrong in its implication, and may well be guided by a too-local, too-homogenized sense of how we all have created Basic Writing from our multiple perspectives in our multiple sites. 
Call for Papers: 1998 Rocky Mountain Modern Language Association Meeting. Salt Lake City, Utah, October 8-10, 1998. Session on Writing Across the Curriculum. Send proposals for individual papers or panels to Susan McLeod, Chair, Department of English, Washington State University, Pullman, WA 99164-5020; mcleod@wsunix.wsu.edu; FAX: 509-335-2582. Deadline is Feb. 13, 1998.

Predictions and Possibilities: The Theory and Practice of Teaching Composition in the Next Century will be the topic of SAMLA Composition Section meeting in Atlanta, Georgia 5-7, Nov. 1998. Possible areas of inquiry include: the future role of writing labs; the effect of technology on composition; cultural studies and composition; innovative approaches to writing about literature; the role of grammar in writing instruction; teaching freshman composition; the future of WAC programs; post-process theory. Send complete papers or abstracts by March 1, 1998 to Bonnie Devet, English/Communication, SAMLA, College of Charleston, 66 George Street, Charleston, SC 29424; fax: 803-953-3180. Preference will be given to speakers who present rather than read their papers; please describe how the presentation will be made.

National Association for Developmental Education 22nd Annual Conference, March 4-8, 1998, Atlanta, Georgia. Developmental Education: Rising to the Challenges of a New Millennium. Conference Speakers: Melissa Fay Greene and Sandra M. Ayaz. For more information contact NADE, Program Committee, Georgia Southern University, PO Box 8132, Statesboro, GA 30460.

1998 CCCC Annual Convention, April 1-4, Chicago, Illinois: Ideas, Historias y Cuentos: Breaking with Precedent. For more information see http:/ / www.ncte.org or telephone 800-369-6283.

RETHINKING BASICWRITING CCCC '98 All-Day Workshop. On April 1, the Conference on Basic Writing will host an all-day workshop focusing on issues critical to the field of Basic Writing, with the intention of giving Basic Writing professionals a setting in which to discuss emerging areas of interest. The workshop will feature presentations and break-out sessions on a wide range of topics. Presenters include: William Jones, Rutgers; Kathleen Yancey, UNC-Charlotte; Gary Tate, TCU; and Kate Mangelsdorf, UT-El Paso. 
1998 Kellogg Institute for the training and certification of developmental educators. June 26-July 24, 1998. The Institute will train faculty, counselors, and administrators from developmental and learning assistance programs in the most current techniques for promoting learning improvement. The Institute will be held on the campus of Appalachian State University at Boone, NC. Fees are $\$ 795$ plus $\$ 610$ for room and board. For more information contact Elaine Bingham, Director of the Kellogg Institute, National Center for Developmental Education, Appalachian State University, Boone, NC 28608; (704)2623057. Application deadline is April 1, 1998.

Reflections: Practice, Theory, Reflection, and Action: Transforming Classrooms, Schools, and English Studies. June 18-20, 1998, Seattle, Washington. Keynote Speakers: Sondra Perl and Dan Kirby. For more information call NCTE's Professional Development Services at 217-328-3870 x203 or email pds@ncte.org.

The Summer Seminar in Rhetoric and Composition, Millikin University, June 7-12, 1998. The purpose of the seminar is to introduce college teachers to composition theories, pedagogies, and practices in ways that allow participants to apply these ideas at their home institutions. Keynote Speaker: Ira Shor. Workshops with: Peter Elbow, Patricia Bizzell, Tony Silva, Randy M. Brooks, Nancy DeJoy, and Krista Ratcliffe. For more information contact Nancy DeJoy, Director, Summer Seminar in Rhetoric and Composition, Millikin University, 1184 W. Main St. Decatur, IL, 62522-2084. Registration fees are $\$ 625$ (before April 10) or $\$ 675$ (after April 10). 


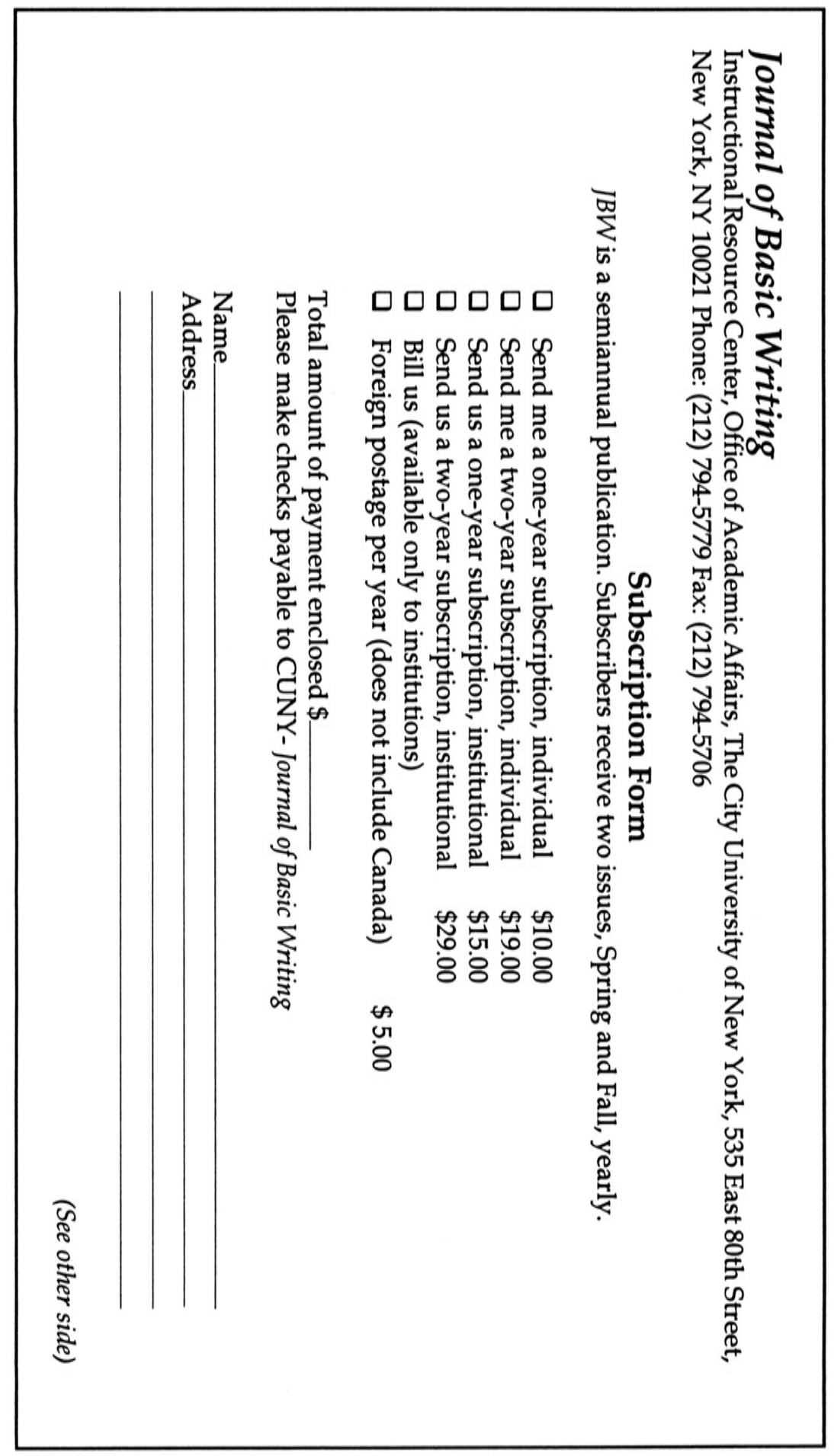




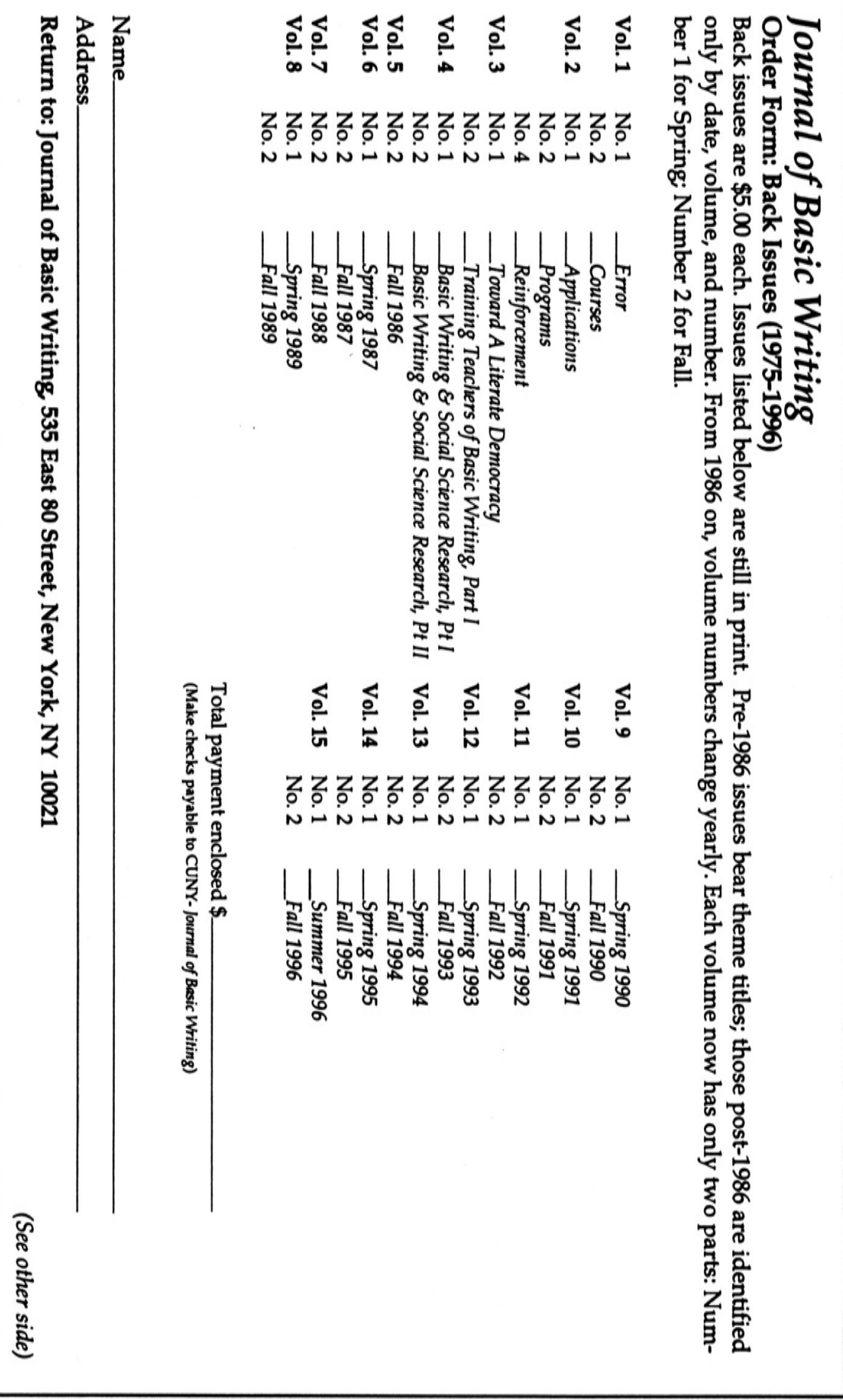





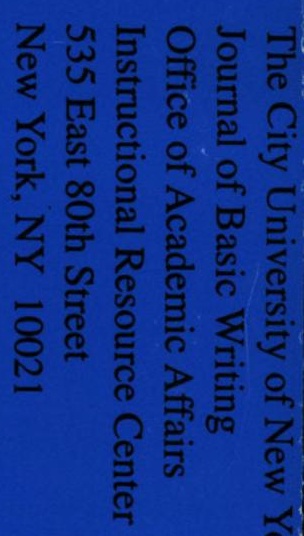

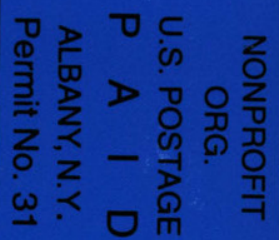

